MARCOS FELIPE BETTINI PEREIRA DE ARAUJO

ESTIMATIVA DO FATOR DE FORMA E DA RESISTÊNCIA AO AVANÇO DE EMBARCAÇÕES ATRAVÉS DA DINÂMICA DOS FLUIDOS COMPUTACIONAL

São Paulo 
MARCOS FELIPE BETTINI PEREIRA DE ARAUJO

ESTIMATIVA DO FATOR DE FORMA E DA RESISTÊNCIA AO AVANÇO DE EMBARCAÇÕES ATRAVÉS DA DINÂMICA DOS

FLUIDOS COMPUTACIONAL

Dissertação apresentada à Escola Politécnica da Universidade de São Paulo para obtenção do título de Mestre em engenharia.

São Paulo 


\title{
ESTIMATIVA DO FATOR DE FORMA E DA RESISTÊNCIA AO AVANÇO DE EMBARCAÇÕES ATRAVÉS DA DINÂMICA DOS FLUIDOS COMPUTACIONAL
}

\author{
Dissertação apresentada à Escola \\ Politécnica da Universidade de São Paulo \\ para obtenção do título de Mestre em \\ engenharia. \\ Área de concentração: \\ Engenharia Naval e Oceânica \\ Orientador: \\ Prof. Dr. Kazuo Nishimoto
}

São Paulo 
Este exemplar foi revisado e corrigido em relação à versão original, sob responsabilidade única do autor e com a anuência de seu orientador.

São Paulo, 28 de fevereiro de 2014.

Assinatura do autor

Assinatura do orientador

FICHA CATALOGRÁFICA

Araujo, Marcos Felipe Bettini Pereira de

Estimativa do fator de forma e da resistência ao avanço de embarcações através da dinâmica dos fluidos computacional / M.F.B.P. de Araujo. -- versão corr. -- São Paulo, 2014.

p.

Dissertação (Mestrado) - Escola Politécnica da Universidade de São Paulo. Departamento de Engenharia Naval e Oceânica.

1.Resistência ao avanço 2.Embarcações 3.Dinâmica dos fluidos computacional I.Universidade de São Paulo. Escola Politécnica. Departamento de Engenharia Naval e Oceânica II.t. 
Dedico este trabalho ao meu pai (in memoriam), à minha esposa e família. 


\section{AGRADECIMENTOS}

O autor expressa seu agradecimento ao Tanque de Provas Numérico da Universidade de São Paulo (TPN) por disponibilizar o software de CFD utilizado nas simulações e pelo apoio durante a elaboração do presente trabalho.

Também agradece o Centro de Engenharia Naval do IPT, pelo apoio durante o tempo em que esteve presente no laboratório e pelo fornecimento dos dados dos testes realizados. 


\section{RESUMO}

Este trabalho discute o efeito da escala na obtenção do fator de forma de embarcações e avalia a estimativa de resistência ao avanço e o padrão de ondas gerado pelo movimento relativo entre o fluido e o casco, através de análises computacionais. A estimativa adequada do fator de forma é importante para a determinação da resistência do casco na escala real, possibilitando o dimensionamento do sistema propulsivo, isto é, motor e hélice. Tradicionalmente o valor do fator de forma é obtido experimentalmente através de ensaios de reboque de modelos em escala reduzida. Observa-se na maioria dos laboratórios, que durante os testes o valor do fator de forma é adotado como constante, independentemente de Froude e Reynolds, conforme proposto de ITTC.

É apresentada uma alternativa computacional para a determinação do fator de forma. Para tal, utiliza-se a metodologia double-model nas simulações relativas ao casco adotado, em que se obtém os coeficientes de resistência viscosa, enquanto que as linhas de correlação da ITTC'57, Grigson e Schoenherr, além das simulações de arrasto de placas planas, calculam os coeficientes de resistência friccional. $\mathrm{Da}$ relação entre os coeficientes viscosos e friccionais encontra-se a tendência do fator de forma em função do número de Reynolds, considerando Froude constante.

Os valores de resistência ao avanço obtidos nas simulações são comparados com os dados experimentais disponibilizados, assim como o padrão de ondas gerado, exemplificando como as ferramentas computacionais podem ser aplicadas de maneira vantajosa, uma vez que os resultados numéricos trazem boas correspondências com aqueles obtidos em tanques de provas e são obtidos mais rapidamente com menor custo. Também são apresentadas, brevemente, algumas descrições matemáticas que são utilizadas no método dos volumes finitos.

Palavras-chave: Resistência ao avanço. Fator de forma. Froude. Padrão de ondas. Linhas de correlação. CFD. Double-model. 


\begin{abstract}
This work discusses the effect of scale in obtaining the form factor of ships and evaluates the estimated resistance and wave pattern generated by the relative motion between the fluid and the hull, through computational analyzes. A suitable estimate of the form factor is important for determining the resistance of the hull in full scale, enabling the sizing of the propulsion system, ie, engine and propeller. Traditionally the value of the form factor is obtained experimentally by towing tests of reduced scale models. It is observed in most laboratories that during testing the value of the form factor is assumed to be constant, regardless of Froude and Reynolds, as proposed by the ITTC.

An alternative computation for determining the form factor is presented. For this purpose, the double-model method is used to simulate resistance tests of the adopted hull, in which the coefficients of viscous resistance are obtained. Meanwhile the coefficients of frictional resistance are calculated by the ITTC'57, Grigson and Schoenherr correlation lines, and by the simulation of flat plates. The relationship between the viscous and frictional coefficients show the trend of the form factor as a function of Reynolds number, considering Froude constant.

The resistance values obtained in the simulations are compared to experimental data available, as well as the pattern of waves, illustrating how computational tools can be applied advantageously, that is, provides similar results to those obtained in the laboratory, but quickly and at lower cost.

Briefly are also presented some mathematical descriptions that are used in the finite volume method.
\end{abstract}

Keywords: Resistance. Form factor. Froude. Wave pattern. Correlation lines. CFD. Double-model. 


\section{LISTA DE FIGURAS}

Figura 1 - Utilização de CFD na área naval e offshore. Fonte: ITTC (2011a) adaptado. 2

Figura 2 - Interesses em ensaios de reboque. Fonte: ITTC (2011a) - adaptado.........2 Figura 3 - Softwares de CFD mais utilizados na área naval e offshore. Fonte: ITTC (2011a) - adaptado.

Figura 4 - Zonas no Shipflow. Fonte: Flowtech International. 6

Figura 5 - a) Casco Wigley; b) Representação em CFD. Fonte: Dávila, Mendonza e Villagómez (2011).

Figura 6 - Comparação entre resultados numéricos e experimentais para três malhas com graus de refino distintos: a) $C_{T} \times F r$; b)Afundamento $x$ Fr; c) Trim $x$ Fr. Fonte: Peric et al. (2011).

Figura 7 - a) Série de cascos analisados; b) Casco original; e c) Casco otimizado. Fonte: Feng et al. (2011).

Figura 8 - Resultados numéricos e experimentais dos coeficientes de pressão, friccional e resistência total. Fonte: Ahmed (2011).

Figura 9 - a) Curvas de coeficiente total por Froude Série 60; b) Curva de resistência total por Froude modelo trimarã. Fonte: Ni et al. (2011).

Figura 10 - Cascos utilizados nas análises e gráficos de fator de forma por Froude para diferentes números de Reynolds/escala para os modelos de porta contêiner. Fonte: Keh-Sik e Seon-Hyung (2009).

Figura 11 - Linha de regressão para a obtenção do fator de forma. Fonte: Keh-Sik e Seon-Hyung (2009). 14

Figura 12 - Efeito da escala sobre o fator de forma. Fonte: Gomez (2000). 15

Figura 13 - Avaliação das linhas de correlação. Fonte: Gomez (2000). 15

Figura 14 - Comparação entre o coeficiente friccional dos cascos analisados e as linhas de correlação comumente encontradas na literatura. Fonte: Eça e Hoekstra (2005).

Figura 15 - a) Coeficiente friccional de placa plana; b) Coeficiente de resistência total dos modelos; c) Coeficiente friccional dos modelos; d) Coeficiente de pressão dos modelos. Fonte: Jen-Shiang , Yen-Jenn e Shiu-Wu (2009).

Figura 16 - Variação de k em função de Reynolds: Análise numérica. Fonte: JenShiang, Yen-Jen e Shiu-Wu (2009). 
Figura 17 - a) Tanque de provas do laboratório TPN; b) Canal de água circulante. Fonte: Marinet.

Figura 18 - Tanque de provas do IPT: a) Vista do carro dinamométrico; b) Vista de um ensaio de resistência ao avanço.

Figura 19 - Montagem do ensaio de resistência ao avanço. Fonte: Bertram (2000) Adaptado.

Figura 20 - a) Modelo 3D do casco DTMB5415; b) Modelo físico que foi ensaiado no tanque de provas do IPT.

Figura 21 - Comparação entre os coeficientes de resistência total. Fonte: ITTC (2011b).

Figura 22 - Incerteza total do coeficiente de resistência. Fonte: ITTC (2011b)

Figura 23 - Média e flutuação de uma grandeza física: a) regime permanente; b) transitório. 33

Figura 24 - Função de parede.

Figura 25 - a) Malha 2D estruturada e não-uniforme; b) Malha 2D não-estruturada e não-uniforme. Fonte: Ferziger et al. (2002).

Figura 26 - Comparação de convergência entre malha poliédrica e tetraédrica.

Fonte: Peric (2004)

Figura 27 - a) Estêncil da aproximação explícita, b) Estêncil do atraso na propagação das condições iniciais e c) Estêncil da aproximação implícita. Fonte: Fortuna (2000)

Figura 28 - Estêncil das equações desacopladas. Fonte: Fortuna (2000)....................53

Figura 29 - Campo de pressão oscilatório......................................................................

Figura 30 - Malha deslocada. Fonte: Saltara (2011) ..................................................54

Figura 31 - Escolha da localização da fronteira de saída. Fonte: Fortuna (2000)......56

Figura 32 - llustração do método SOR.

Figura 33 - Sistema de coordenadas adotado: a) Casco DTMB5415 e b) Placa plana

Figura 34 - Dimensões do domínio computacional nas simulações de casco: análise double-model.

Figura 35 - Dimensões do domínio computacional nas simulações com placa plana.

Figura 36 - Tipos de malhas utilizadas nas: a) Simulações do modelo DTMB5415: double-model; b) Simulações de placa plana. 
Figura 37 - Exemplo de malha utilizada nas simulações com superfície livre.

Figura 38 - Pontos da análise de convergência numérica para o caso do modelo DTMB5415 de 3,05 $\mathrm{m}$ de $L p p$ e velocidade de avanço de 0,55 m/s.

Figura 39 - Distribuição de pressão e velocidade do escoamento à montante: a)

Placa plana; b) Casco DTMB5415.

Figura 40 - Vetores velocidade nas regiões de jusante: a) Placa plana e b) Casco

DTMB5415. Ambos para o comprimento de $5.72 \mathrm{~m}$. .70

Figura 41 - Valor de $y+$ para o caso de velocidade de 2,24 m/s.

Figura 42 - Escoamento ao redor do casco do modelo DTMB5415 para a condição de double-model, $L p p=5,72$ e 0,75 m/s.

Figura 43 - Monitoramento da convergência da resistência da simulação de placa plana de $5,72 \mathrm{~m}$ de $L p p$ e $0,75 \mathrm{~m} / \mathrm{s}$.

Figura 44 - Gráfico de $C_{F}$ por Reynolds, obtido numericamente e pela linha de correlação da ITTC'57, Grigson e Schoenherr.

Figura 45 - Comparação entre valores de $C_{F}$ em relação à linha de correlação da ITTC'57, em função de Reynolds.

Figura 46 - Comparação entre o coeficiente de resistência total das diferentes escalas do DTMB5415 (double-model) e os coeficientes friccionais obtidos pela ITTC'57 e pelas simulações de placas planas.

Figura 47 - Fator de forma do modelo DTMB5415 para escalas distintas, calculado numericamente utilizando a formulação da ITTC'57 e os resultados das simulações de placas planas.

Figura 48 - Fator de forma do modelo DTMB5415 para a escala ensaiada no IPT, calculado numericamente utilizando a formulação da ITTC'57.

Figura 49 - Posição relativa ao casco dos dispositivos de medição de afundamento.

Figura 50 - Comparação entre resistência total e viscosa: Estimativa para a resistência de ondas.

Figura 51 - Padrão de ondas gerado pelo casco DTMB5415. Simulação do modelo de $L p p=3,05 \mathrm{~m}$ e velocidade de avanço de 1,53 m/s; Froude 0,28.

Figura 52 - Padrão de ondas gerado pelo casco DTMB5415. Simulação do modelo de $L p p=3,05 \mathrm{~m}$ e velocidade de avanço de 2,24 m/s; Froude 0,41.

Figura 53 - Contornos das ondas para Froude 0,28, obtidos através do método: a) viscoso; b) potencial. Fonte: Ahmed (2011) - Adaptado. 
Figura 54 - Contornos das ondas para Froude 0,41, obtidos através do método: a) viscoso; b) potencial. Fonte: Ahmed (2011) - Adaptado.

Figura 55 - Comparação entre os padrões de ondas obtidos pela solução potencial e viscosa...... 88

Figura 56 - Perfis de ondas obtidos na superfície do casco, sem considerar o afundamento e trim.

Figura 57 - Perfis de ondas obtidos na superfície do casco, considerando o afundamento e trim. 89 


\section{LISTA DE TABELAS}

Tabela 1 - Características principais do Tanque de Provas do IPT. ............................22

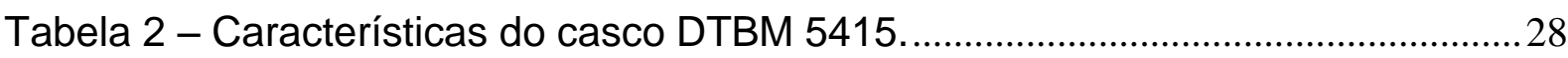

Tabela 3 - Quantidade de resultados enviados para a ITTC...........................................29

Tabela 4 - Resultados dos ensaios do modelo DTMB5415 de $L_{P P}=3,05$ m...............30

Tabela 5 - Dimensões de domínios computacionais em função do $L p p$ da embarcação, encontrados na literatura.

Tabela 6 - Quantidade de elementos e tempo para a solução no caso das

simulações com superfície livre - análises com simetria.

Tabela 7 - Dados do fluido e aceleração da gravidade utilizados nas simulações. ...71

Tabela 8 - Valores de resistência numérica (double-model) do modelo DTMB5415 para diferentes escalas e Froude constante $(F r=0,1)$.

Tabela 9 - Valores de resistência ao avanço obtidos através de ensaios em tanque de provas e via StarCCM+.

Tabela 10 - Afundamento e trim para os ensaios realizados no tanque de provas do IPT.

Tabela 11 - Valores de resistência ao avanço obtidos através de ensaios em tanque de provas e via StarCCM+, considerando o afundamento e trim. 


\section{SIGLAS}

CFD

DFC

DFE

DNS

DTMB

EDP

EFD

ELT

FPSO

IPT

ITTC

LCB

LES

PIV

PMM

PVC

PVI

RANSE

SIMPLE

SOR

TPN

USP

VIM

VIV

VOF
Computational Fluid Dynamics

Dinâmica dos Fluidos Computacional

Dinâmica dos Fluidos Experimental

Direct Numerical Simulation

David Taylor Model Basin

Equações Diferenciais Parciais

Experimental Fluid Dynamics

Erro Local de Truncamento

Floating Production Storage and Offloading

Instituto de Pesquisas Tecnológicas

International Towing Tank Conference

Longitudinal Center of Buoyancy

Large Eddy Simulation

Particle Image Velocimetry

Planar Motion Mechanism

Problema do Valor de Contorno

Problema do Valor Inicial

Reynolds Average Navier-Stokes Equations

Semi Implicit Method for Pressure Linked Equations

Successive Over-Relaxation

Tanque de Provas Numérico

Universidade de São Paulo

Vortex Induced Motion

Vortex Induced Vibration

Volume of Fluid 


\section{LISTA DE SÍMBOLOS}

\begin{tabular}{|c|c|}
\hline $\begin{array}{l}\mathrm{B}_{\mathrm{CT}} \\
\mathrm{Bwl}\end{array}$ & $\begin{array}{l}\text { Erro sistemático do coeficiente de resistência total } \\
\text { Boca na linha da áqua }\end{array}$ \\
\hline$C_{F}$ & Coeficiente friccional \\
\hline $\mathrm{C}_{\mathrm{T}}$ & Coeficiente de resistência total \\
\hline$C_{R}$ & Coeficiente residual \\
\hline $\mathrm{C}_{\mathrm{FM}}$ & Coeficiente friccional do modelo \\
\hline $\mathrm{C}_{\text {TM }}$ & Coeficiente de resistência total do modelo \\
\hline $\mathrm{C}_{\mathrm{RM}}$ & Coeficiente residual do modelo \\
\hline $\mathrm{C}_{\mathrm{FS}}$ ou $\mathrm{C}_{\mathrm{FP}}$ & Coeficiente friccional do protótipo \\
\hline $\mathrm{C}_{T S}$ ou $\mathrm{C}_{\mathrm{TP}}$ & Coeficiente de resistência total do protótipo \\
\hline $\mathrm{C}_{\mathrm{RS}}$ ou $\mathrm{C}_{\mathrm{RP}}$ & Coeficiente residual do protótipo \\
\hline & Coeficiente de ondas \\
\hline $\mathrm{C}_{W M}$ & Coeficiente de ondas do modelo \\
\hline $\mathrm{C}_{W S}$ ou $\mathrm{C}_{W P}$ & Coeficiente de ondas do protótipo \\
\hline & Coeficiente de resistência do ar \\
\hline $\mathrm{C}_{\mathrm{AP}}$ & Coeficiente de resistência de apêndices \\
\hline Co & Número de Courant \\
\hline Fn ou $F_{R}$ & Número de Froude \\
\hline $\mathrm{g}$ & Aceleração gravitacional \\
\hline $\mathrm{k}$ & Energia cinética turbulenta \\
\hline Lpp & Comprimento entre perpendiculares \\
\hline Lwl & Comprimento na linha da água \\
\hline $\mathrm{P}_{\mathrm{CT}}$ & Erro de precisão do coeficiente de resistência total \\
\hline $\mathrm{p}$ & Pressão \\
\hline $\mathrm{R}_{\mathrm{T}}$ & Resistência total \\
\hline Rn ou $\operatorname{Re}$ & Número de Reynolds \\
\hline $\mathrm{R}$ & Constante universal dos gases \\
\hline $\mathrm{S}$ & Área molhada \\
\hline Temp & Temperatura \\
\hline $\mathrm{T}$ & Calado \\
\hline $\mathrm{t}$ & Coeficiente de redução do empuxo \\
\hline$U_{C T}$ & Incerteza total do coeficiente de resistência total \\
\hline $\mathrm{U}$ & Velocidade paralela à parede \\
\hline u & Componente da velocidade na direção $\mathrm{x}$ \\
\hline V & Velocidade \\
\hline $\mathrm{v}$ & Componente da velocidade na direção y \\
\hline w & Componente da velocidade na direção $z$ \\
\hline & Distância da célula até a parede \\
\hline$(1+k)$ & Fator de forma \\
\hline$\varepsilon$ & Dissipação da energia cinética turbulenta \\
\hline$\omega$ & Dissipação especifica \\
\hline$\rho$ & Densidade \\
\hline$\mu$ & Viscosidade \\
\hline$\vartheta$ & Viscosidade cinemática \\
\hline$\phi$ & Grandeza física qualquer \\
\hline$\phi^{\prime}$ & Variação da grandeza física qualquer \\
\hline $\bar{\phi}$ & Média da grandeza física qualquer \\
\hline
\end{tabular}



$\mathrm{u}^{+} \quad$ Velocidade adimensional
$\mathrm{y}^{+} \quad$ Distância adimensional
$u_{T} \quad$ Velocidade tensão friccional
$\tau_{W} \quad$ Tensão friccional na parede
$\delta \quad$ Espessura da camada limite
$\theta \quad$ Constante de Von Karman
$€ \quad$ Diferença entre valor numérico e experimental
$\sigma_{\varepsilon}, \mathrm{C}_{1}, \mathrm{C}_{2}, \sigma_{\mathrm{k}}, \mathrm{C}_{\mu} \quad$ Constantes do modelo de turbulência $k-\varepsilon$
$\sigma, \alpha, \beta, \sigma^{*}, \beta^{*} \quad$ Constantes do modelo de turbulência $k-\omega$ 


\section{SUMÁRIO}

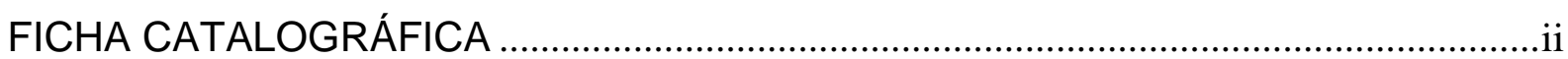

RESUMO

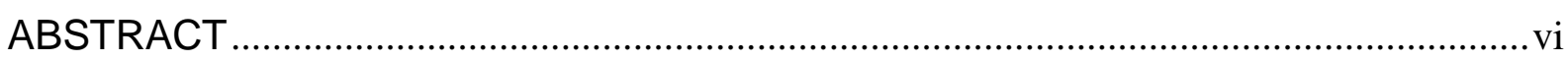

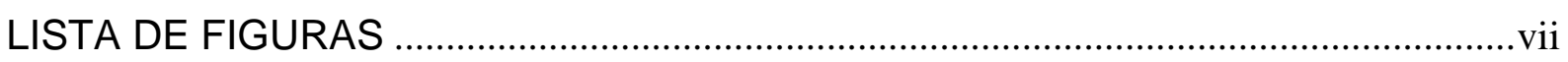

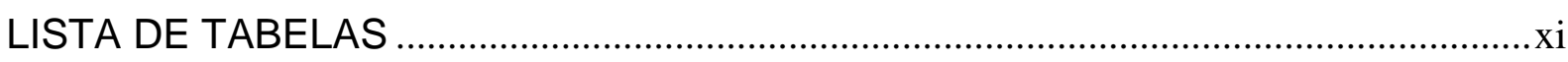

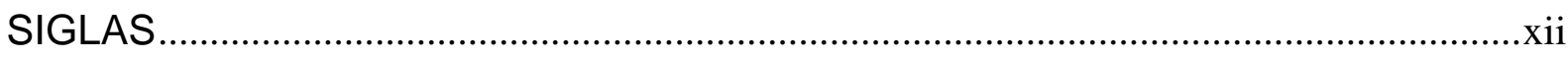

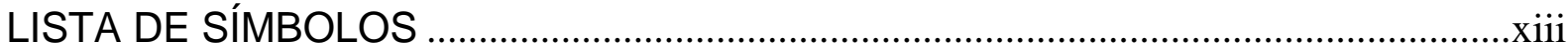

1. INTRODUÇÃO

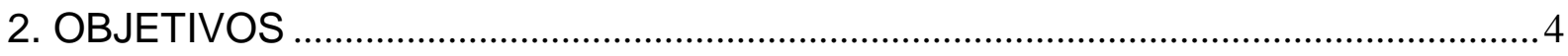

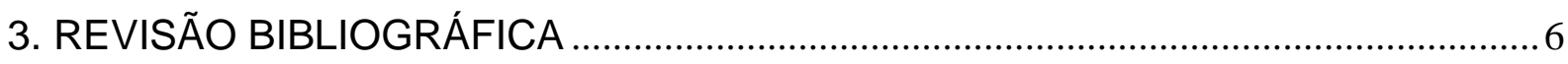

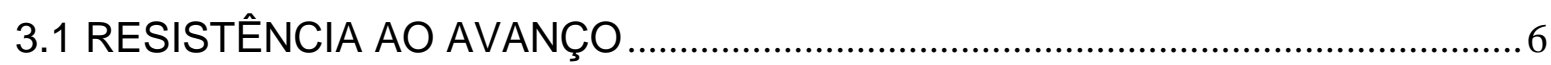

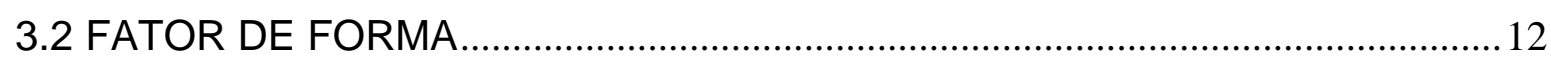

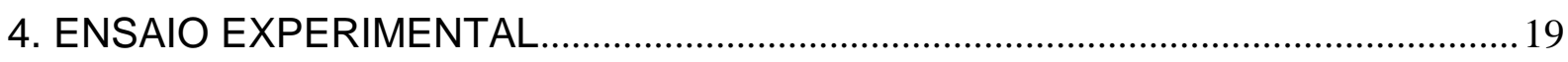

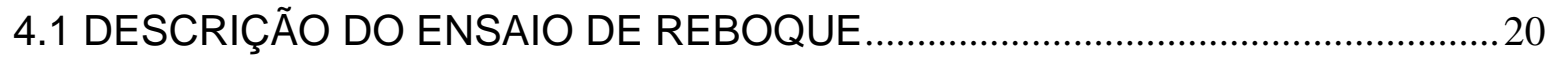

4.2 SIMILARIDADE E EXTRAPOLAÇÃO_.............................................................22

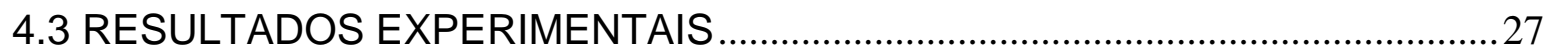

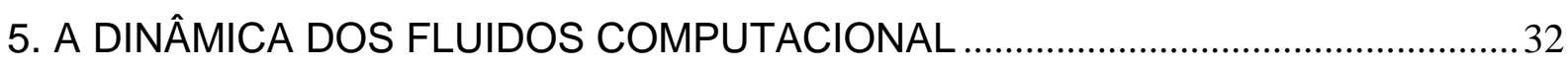

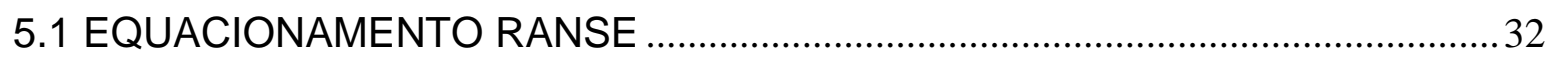

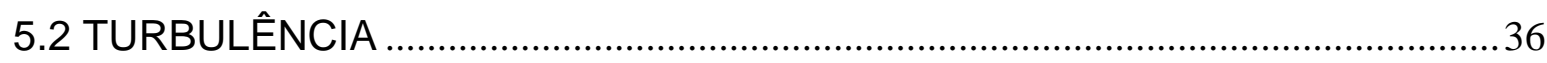

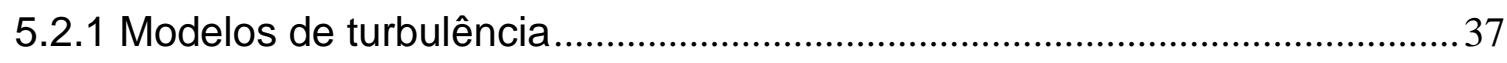

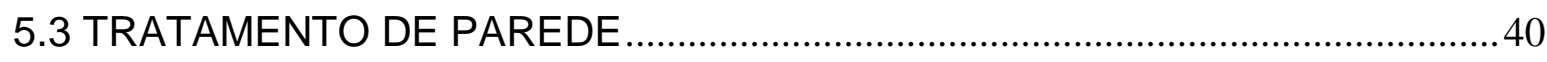

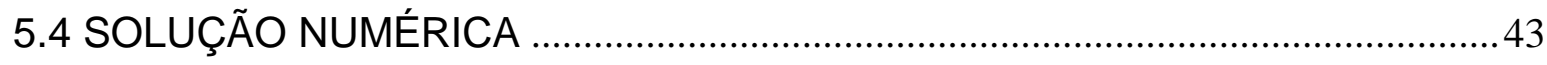

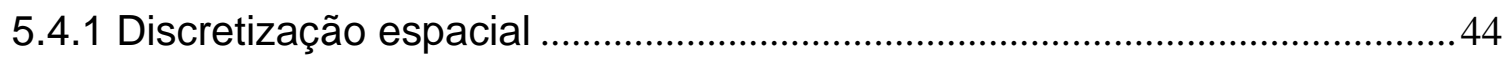

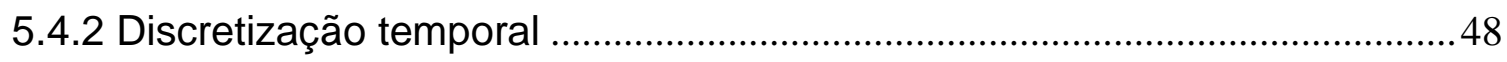

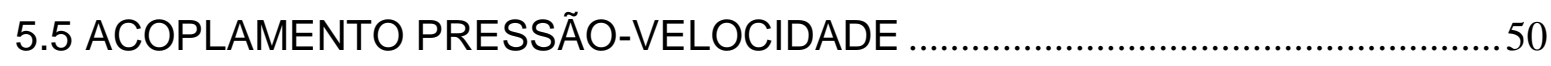

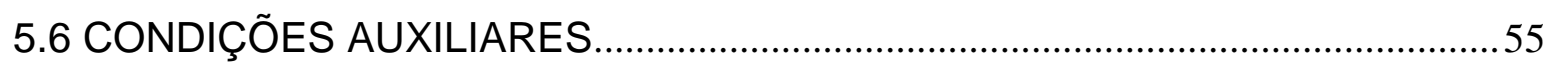

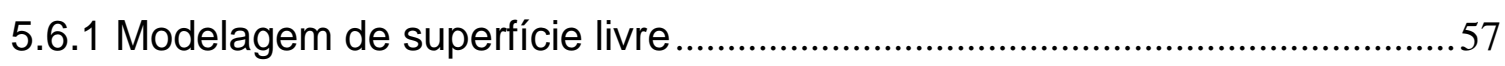

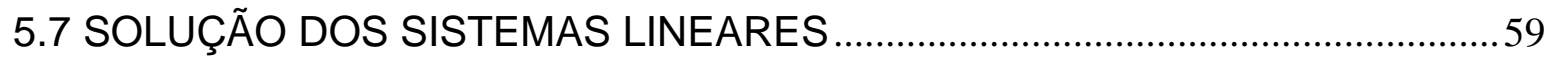

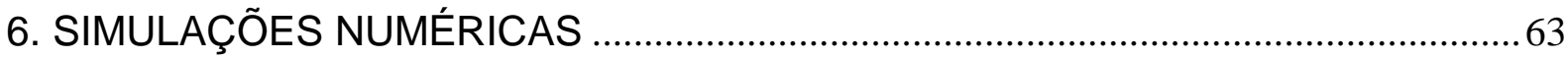

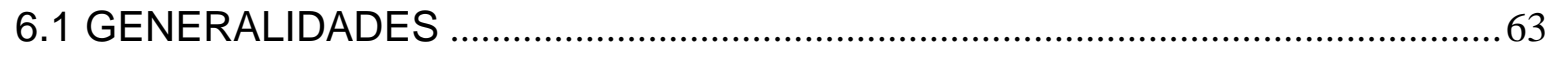

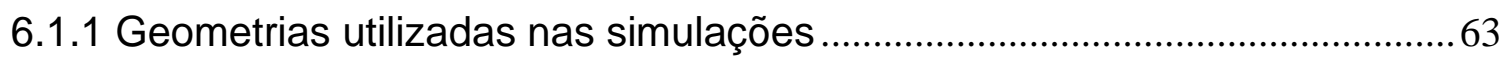

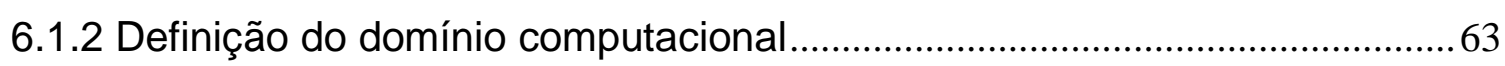

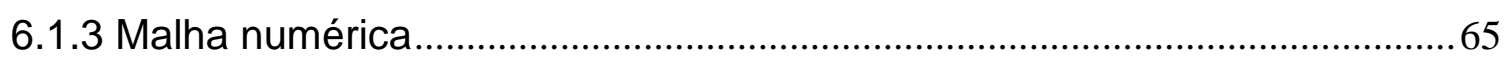

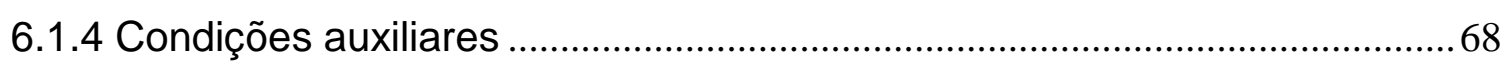

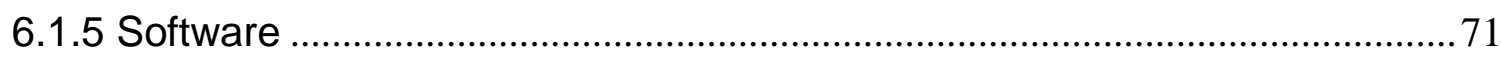


6.2 RESULTADOS

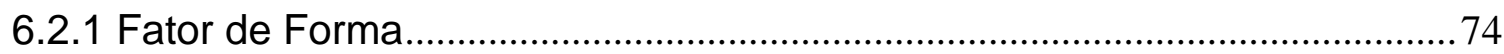

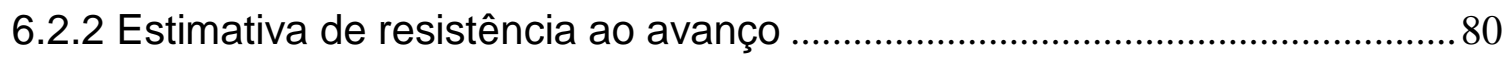

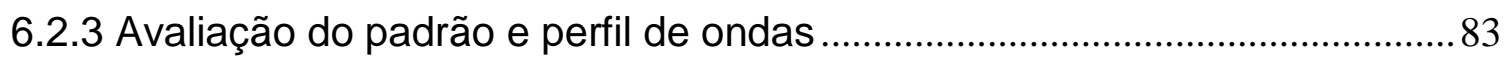

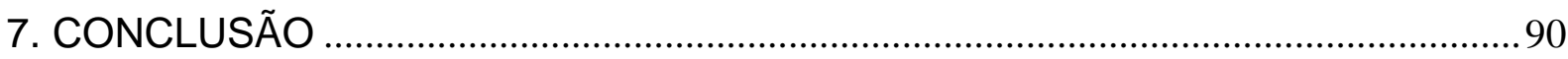

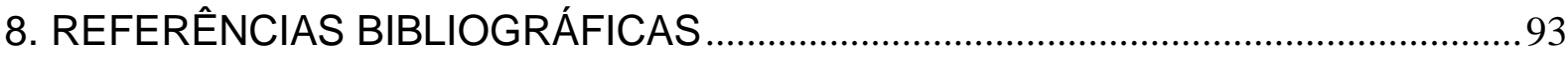




\section{INTRODUÇÃO}

Em grande parte dos métodos tradicionais de projeto há a necessidade de se realizar ensaios com modelos em escala reduzida, que demandam uma quantidade de tempo considerável além de custos elevados. Para minimizar os dois fatores mencionados, a engenharia focou em desenvolver ferramentas numéricas que auxiliassem em seus projetos. Desde os anos 60 a dinâmica dos fluidos computacional $^{1}$ (DFC) está em progressos, graças à crescente demanda industrial e aos avanços tecnológicos e computacionais.

$\mathrm{Na}$ última década houve um desenvolvimento dos softwares de CFD especificamente na área naval e offshore, através da implementação de modelos eficientes para as análises com superfície livre, tornando possível, por exemplo, a predição e análise de desempenho de embarcações. Apesar dos avanços da dinâmica dos fluidos experimental ${ }^{2}$ (DFE), as informações detalhadas do escoamento na região próxima ao casco, associada com o movimento da embarcação, estão além do que a tecnologia experimental pode oferecer. Por outro lado, a aplicação de CFD fornece informações claras do escoamento em regiões características, permitindo que o projetista de uma unidade naval realize alterações em seu projeto de forma a aperfeiçoá-lo.

Observa-se que os programas de CFD têm se mostrado cada vez mais presentes em pesquisas na área naval e embora haja muitas áreas de aplicações, a sua principal utilização, atualmente, tem sido para a estimativa de resistência ao avanço, visando a redução do valor da resistência da embarcação, que acarretará em redução de custo operacional, visto a quantidade de combustível consumida ao longo de sua vida útil. Dessa forma, a indústria naval tem investido cada vez mais em ferramentas numéricas e tem procurado realizar otimizações geométricas, de forma a obter um ganho na redução da resistência ao avanço. A Figura 1 ilustra as áreas de demanda em que mais são utilizados CFD, segundo pesquisa realizada pela International Towing Tank Confererance, ITTC (2011a).

\footnotetext{
${ }^{1}$ Mais conhecido como Computational Fluid Dynamics (CFD)

${ }^{2}$ Mais conhecido como Experimental Fluid Dynamics (EFD)
} 


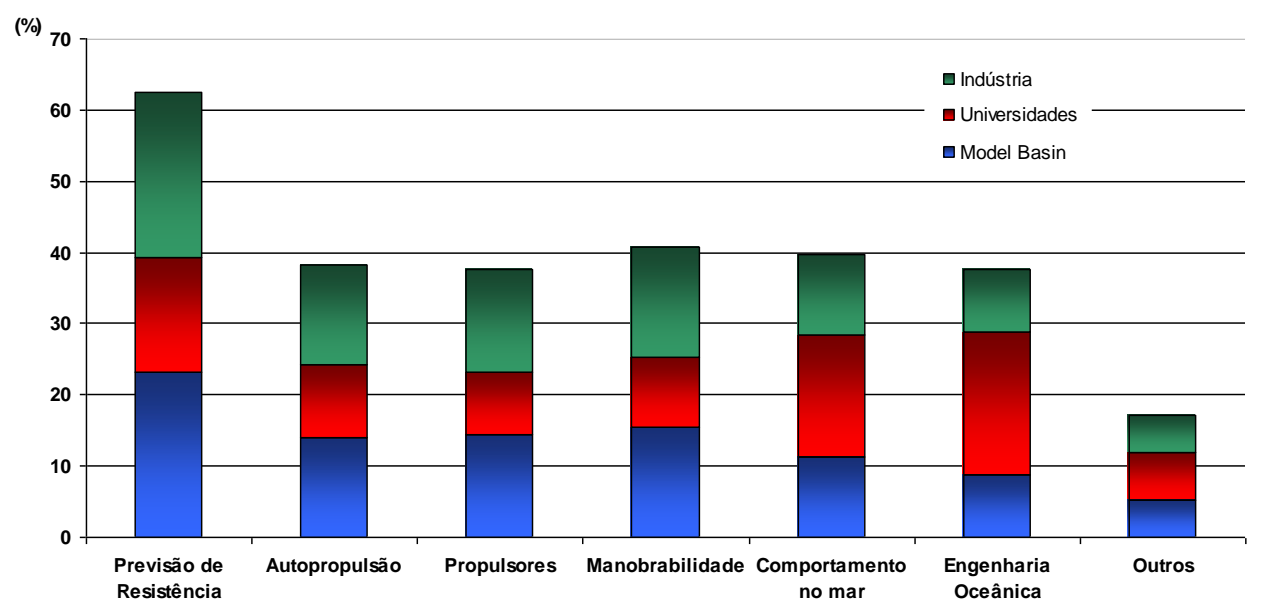

Figura 1 - Utilização de CFD na área naval e offshore. Fonte: ITTC (2011a) - adaptado.

Em relação à previsão de resistência verificou-se que o maior interesse é na obtenção do fator de forma, (1+k), coeficiente de resistência total e avaliação do escoamento ao redor da embarcação, conforme apresentado na Figura 2.

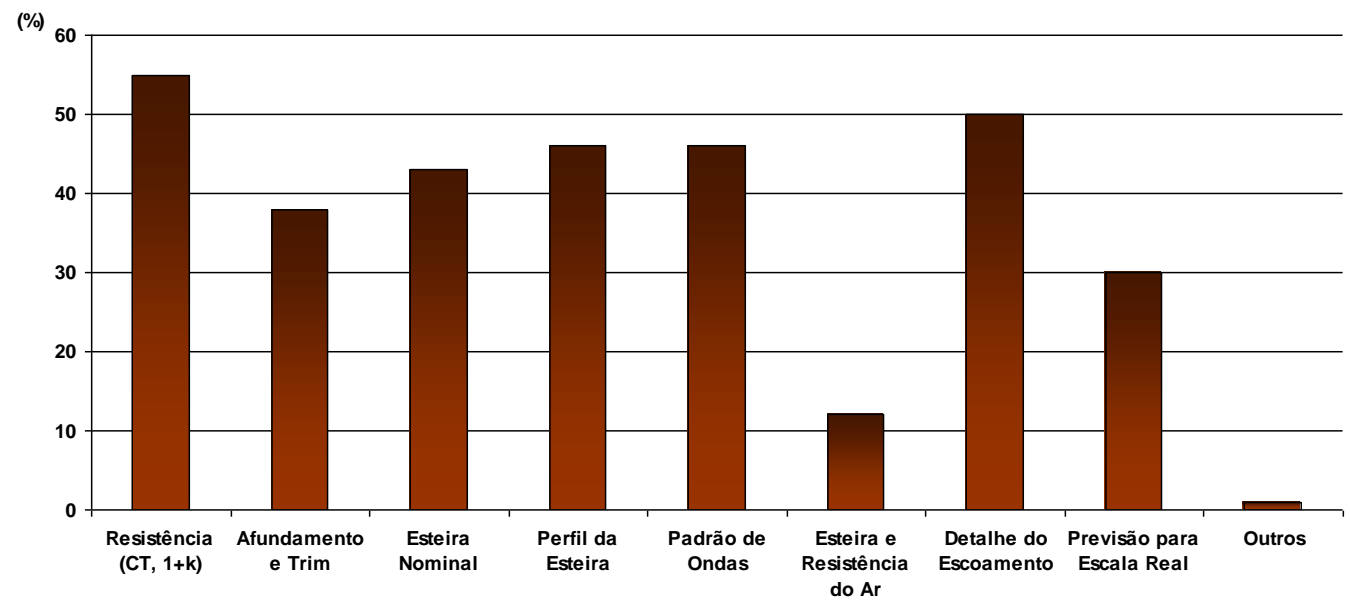

Figura 2 - Interesses em ensaios de reboque. Fonte: ITTC (2011a) - adaptado.

Apesar da estimativa de resistência ser preponderante em relação às demais análises, elas também apresentam grande importância no desempenho hidrodinâmico de embarcações. O estudo da esteira gerada pelo casco na região do propulsor, por exemplo, é necessário para que se determine a melhor configuração do hélice. A cavitação do propulsor é algo que deve ser evitado, pois traz prejuízos ao desempenho do hélice a tal ponto que possa exigir a docagem da embarcação para a substituição do mesmo. A avaliação do comportamento em ondas de um navio é fundamental tanto para garantir a integridade da embarcação como para assegurar as condições de conforto e segurança da tripulação e carga e, portanto, impacta diretamente no projeto do navio. Nesse caso, destacam-se também 
situações em que a embarcação esteja em processo de offloading em alto mar, como por exemplo, um navio do tipo aliviador conectado à plataforma de petróleo. $\mathrm{O}$ fenômeno de sloshing constitui um problema dinâmico em que o líquido em movimento interage com as paredes do tanque, de forma a alterar a dinâmica do sistema significativamente. O problema de green water geralmente ocorre em grandes tempestades em que as ondas e movimentos da embarcação adquirem elevadas amplitudes tais que a água ultrapassa a borda livre da embarcação "lavando" o seu convés. Usualmente essa análise é importante para a segurança e operacionalidade de navios mercantes.

A utilização de CFD também tem se mostrado presente na indústria offshore em análises hidrodinâmicas de plataformas. Alguns dos fenômenos estudados são o de vibração induzida por vórtices (vortex induced vibration - VIV) e movimento induzido por vórtices (vortex induced motion - VIM), decorrentes da correnteza local, sendo o primeiro observado em linhas de ancoragem, risers e umbilicais e o segundo observado nas plataformas, mais acentuados em cascos de estrutura monocolunas. Esses fenômenos solicitam as linhas de amarração, risers e umbilicais de forma cíclica podendo causar falhas estruturais em um tempo relativamente curto. Nesse caso, seria necessária a interrupção da produção para a troca e manutenção das instalações, causando prejuízo na exploração de petróleo. Embora sejam análises complexas, a utilização de programas de CFD pode auxiliar na predição e mapeamento desses fenômenos. Outra análise comumente empregada em unidades offshore é a de comportamento no mar, por conta dos mesmos motivos apresentados anteriormente para o caso de navios.

Mesmo com todo o progresso ao longo dos últimos anos, os resultados obtidos através dos softwares de CFD são uma aproximação da realidade e, portanto, margens para erros devem ser levadas em consideração. É por esse motivo que ensaios experimentais e simulações numéricas devem ser utilizados de forma complementar e que a completa substituição de ensaios experimentais por simulações numéricas não é aconselhável. 


\section{OBJETIVOS}

O objetivo deste trabalho foi avaliar numericamente a variação do fator de forma em função de Reynolds, mantendo-se Froude constante, e estimar o valor da resistência ao avanço de um casco padrão, cujos resultados experimentais fossem conhecidos, avaliando-se também o padrão de ondas gerado devido ao movimento da embarcação.

Para avaliar se o fator de forma é constante, assim como proposto pela ITTC (1978), diferentes escalas do casco adotado foram simuladas através da metodologia double-model, em que a superfície livre foi desconsiderada, isto é, os coeficientes de resistência viscosa e total foram considerados equivalentes. Além disso, também foram simulados ensaios de reboque de placas planas, cujas áreas molhadas e comprimentos eram os mesmos que aos dos cascos analisados, com o intuito de se obter o coeficiente friccional, que foram comparados às linhas de correlação da ITTC'57, Schoenherr e Grigson. Assim, foi possível obter o valor do fator de forma para cada escala utilizada, através da relação entre os coeficientes viscosos e friccionais mencionados.

No caso da estimativa da resistência ao avanço, foi realizada a simulação numérica para três valores de Froude num mesmo valor de escala, em que se consideraram as partes emersas do casco. Neste caso, a resistência é composta pela parcela viscosa e de ondas, em que foi utilizado o volume of fluid (VOF) para o tratamento da superfície livre. O padrão de ondas obtido foi comparado aos resultados encontrados em publicações, visto a dificuldade de se adquirir dados experimentais, conforme descrito em ITTC (2011a).

Durante o decorrer do trabalho serão apresentadas breves descrições matemáticas, que geralmente são encontradas na programação de softwares que utilizam volumes finitos, de forma a subsidiar justificativas de parâmetros adotados nas simulações realizadas. Nas descrições apresentadas foram utilizadas duas dimensões, por questões de facilidade, porém, a extrapolação para três dimensões pode ser realizada de maneira análoga.

O modelo de casco escolhido para as análises foi o David Taylor Model Basin (DTMB) 5415, que foi ensaiado em laboratórios de diversos países através do programa da ITTC e cujos valores do coeficiente de resistência total, afundamento e 
trim foram apresentados para 2 escalas distintas e para uma determinada faixa de Froude, conforme pode ser observado em ITTC (2011b). O modelo que esteve no Brasil em 2010 foi submetido aos ensaios propostos pela ITTC, os quais foram realizados no Tanque de Provas do Instituto de Pesquisas Tecnológicas (IPT) em São Paulo. Os resultados desses ensaios também foram disponibilizados e utilizados nas análises do presente trabalho.

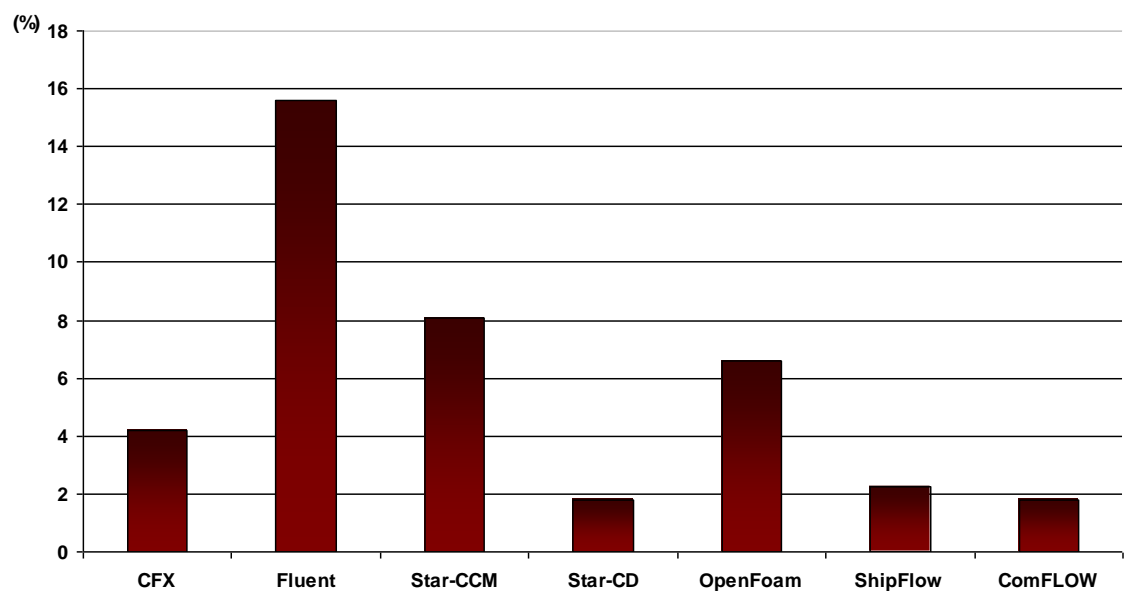

Figura 3 - Softwares de CFD mais utilizados na área naval e offshore. Fonte: ITTC (2011a) adaptado.

Para realizar as análises propostas, utilizou-se o software StarCCM+ da empresa CD-Adapco, que é um dos códigos comerciais mais utilizados na indústria naval, Figura 3, e está disponível no laboratório Tanque de Provas Numérico (TPN) da Universidade de São Paulo (USP). 


\section{REVISÃO BIBLIOGRÁFICA}

Neste capítulo são apresentados trabalhos realizados na área de hidrodinâmica computacional e experimental de embarcações, com foco na estimativa de resistência ao avanço, afundamento e trim, e determinação do fator de forma.

\subsection{RESISTÊNCIA AO AVANÇO}

Uma das fases mais importantes do projeto de uma embarcação é a determinação da resistência ao avanço do casco e o consequente dimensionamento do sistema propulsivo. Tradicionalmente, tais tarefas são realizadas através de ensaios experimentais de reboque e autopropulsão, respectivamente, utilizando modelos em escala reduzida. Apesar de amplamente consolidados, a realização de ensaios com modelos representa, em muitos casos, uma alternativa custosa. Atualmente, a disponibilidade de recursos computacionais de alto desempenho a um custo acessível, aliada aos avanços alcançados no campo da dinâmica dos fluidos computacional, têm incentivado a utilização de códigos proprietários e comerciais em aplicações relacionadas à estimativa da resistência de cascos.

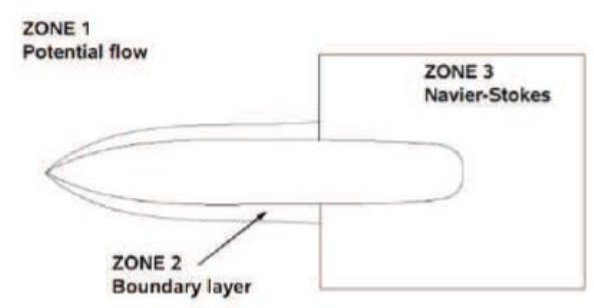

Figura 4 - Zonas no Shipflow. Fonte: Flowtech International.

O trabalho de Lamas et al. (2010) ilustra um caso de avaliação numérica de resistência ao avanço, em que realizaram um estudo comparativo entre os valores de resistência total, parcela de ondas e fator de forma obtidos experimental e numericamente para dois modelos do tipo Suezmax. O software utilizado foi o Shipflow da Flowtech, que divide o domínio computacional em regiões em que se aplicam as equações que regem o escoamento potencial e o viscoso, separadamente, Figura 4. A máxima diferença encontrada nos valores de resistência chegou a $8,0 \%$, o que foi considerado um valor razoável pelos autores. 
A vantagem desse método é o ganho em tempo computacional em relação aos softwares que utilizam apenas as equações de Navier-Stokes e tratamento de parede. Entretanto, pode-se verificar em diversos trabalhos que utilizaram apenas condições viscosas, que o valor do erro é consideravelmente inferior à 8,0\%. Cabe ao projetista ponderar tempo e precisão na obtenção dos resultados. Além disso, Lamas et al. (2010) encontraram para o valor de coeficiente de forma uma diferença de $28 \%$, o que é considerado um valor elevado. A justificativa fornecida foi de que os modelos físicos utilizados apresentavam leme o que não foi considerado na modelagem numérica.

Alho e Paiva (2010) analisaram a incidência de correnteza sobre o casco de uma unidade offshore do tipo Floating Production Storage and Offloading (FPSO), obtendo-se os valores do coeficiente de arrasto para diversos ângulos de aproamento em relação à correnteza. Observou-se que houve discrepâncias nos valores dos coeficientes para os ângulos em torno de $90^{\circ}$, condição essa menos frequente na região de operação da plataforma, segundo os autores. Já para as condições de aproamento mais frequentes, isto é, de $160^{\circ}$ à $180^{\circ}$, os valores obtidos via Ansys CFX e tanque de provas foram comparativamente satisfatórios.

A relevância de se determinar de forma adequada a resistência ao avanço em projetos de embarcações foi exemplificado no trabalho de Alho e Costa (2010). Os autores utilizaram em seu estudo um casco de deslocamento para realizar, numericamente, uma avaliação do arrasto, seguido pela simulação de ensaio de autopropulsão. Embora os coeficientes de empuxo e avanço e o valor do empuxo propriamente dito mostraram boa correspondência com os valores experimentais, o coeficiente de redução de empuxo, $t=\frac{T-R_{T}}{T}$, que foi calculada com base no valor de resistência obtido, apresentou uma diferença de 22,19\%. Segundo os autores, a mencionada discrepância foi ocasionada pela restrição do modelo numérico quanto aos graus de liberdade de pitch e heave da embarcação.

Objetivando-se avaliar o grau de correspondência entre a modelagem numérica e ensaios experimentais, Dávila, Mendonza e Villagómez (2011) realizaram um estudo comparativo para ensaios de resistência ao avanço e geração de ondas, em que adotaram o casco Wigley em suas simulações, Figura 5, cujos resultados de resistência ao avanço são mundialmente conhecidos. Os autores obtiveram boa correspondência entre os dados numéricos e experimentais, 
encontrando uma diferença quanto à força de reboque de 3,9 \%, e ressaltaram que embora os métodos numéricos sejam uma alternativa de alta viabilidade para a finalidade em questão, os mesmos não devem ser vistos como substitutos de ensaios experimentais, mas sim como ferramentas complementares.

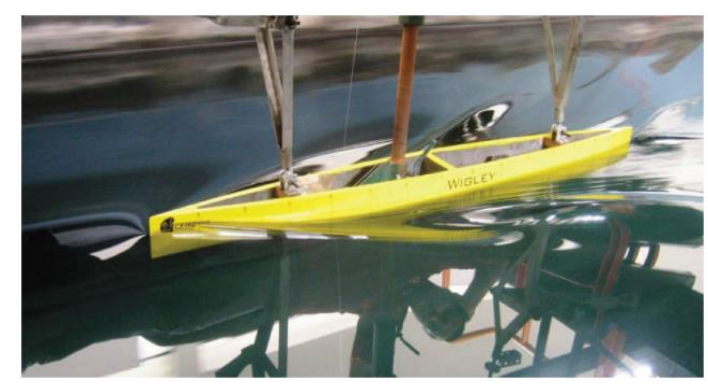

(a)

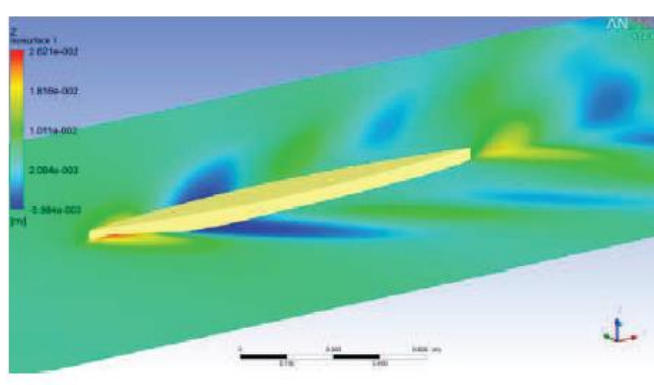

(b)

Figura 5 - a) Casco Wigley; b) Representação em CFD. Fonte: Dávila, Mendonza e Villagómez (2011).

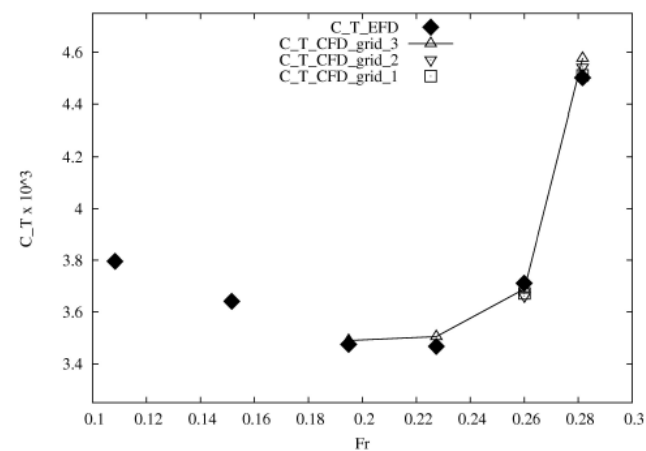

(a)

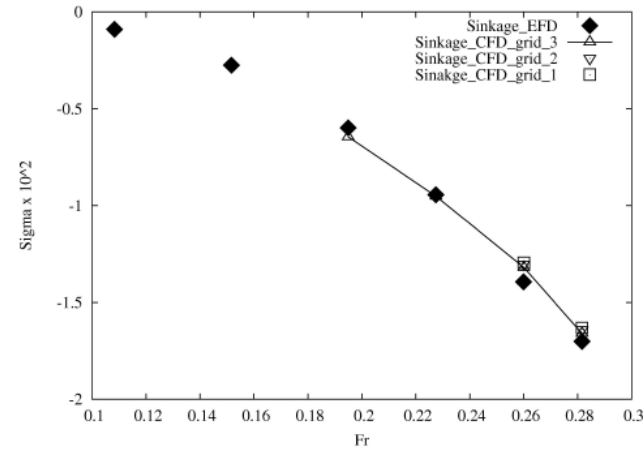

(b)

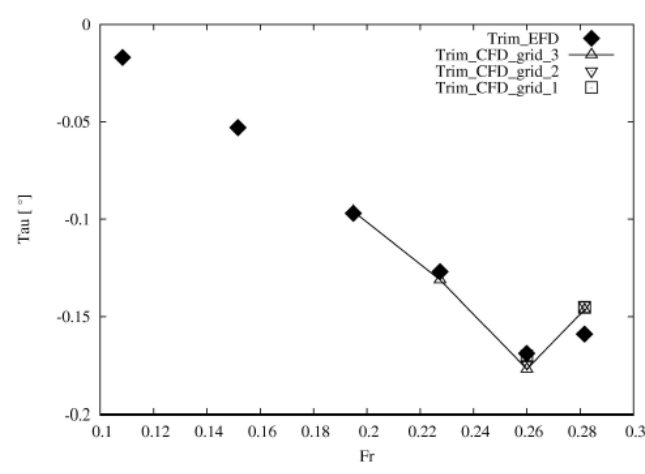

(c)

Figura 6 - Comparação entre resultados numéricos e experimentais para três malhas com graus de refino distintos: a) $C_{T} \times F r$; b)Afundamento x Fr; c) Trim x Fr. Fonte: Peric et al. (2011).

Péric et. al (2011) realizaram um estudo visando obter numericamente o valor de resistência ao avanço de um navio porta contêineres (KRISO), além do 
afundamento e trim para diferentes números de Froude. Para tal, foi utilizado o software Star-CCM+ da CD-Adapco que usa o método dos volumes finitos.

Os resultados numéricos e experimentais foram confrontados, conforme mostra os gráficos da Figura 6. Nota-se que os autores também realizaram uma análise de refino da malha, em que a diferença entre os resultados experimentais (EFD) e numéricos diminuíram com o aumento do refino da malha. No caso do coeficiente de resistência total os valores obtidos se assemelharam com os valores experimentais, porém, para o afundamento e trim os valores numéricos se distanciaram, principalmente para os maiores valores de Froude.

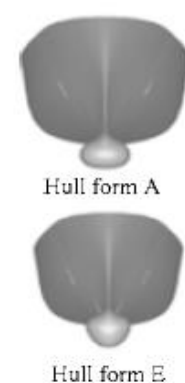

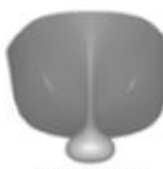

Hull form B

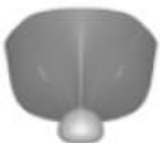

Hull form $\mathrm{F}$

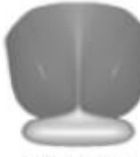

Hull form C

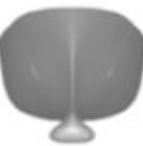

Hull form $\mathrm{G}$

(a)

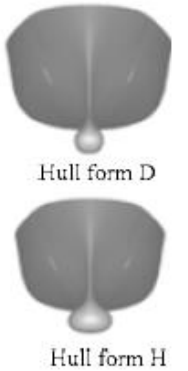

Hull form $\mathrm{H}$

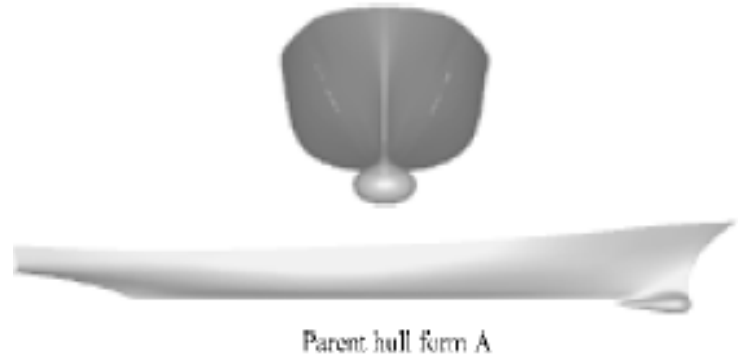

(b)

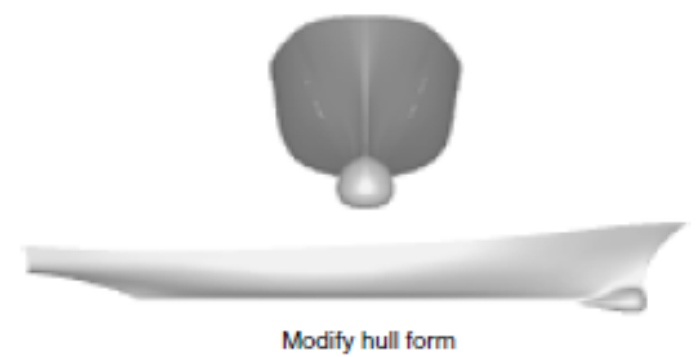

(c)

Figura 7 - a) Série de cascos analisados; b) Casco original; e c) Casco otimizado. Fonte: Feng et al. (2011).

Feng et al. (2011) aplicaram o CFD para avaliar/otimizar o bulbo do modelo DTMB 5415 de forma a melhorar o desempenho do navio. Os autores desenvolveram um programa de otimização multidisciplinar, que gerou variações nas dimensões do bulbo da embarcação, Figura 7, de forma que os coeficientes, dimensões principais e posição do centro de flutuação não sofressem alterações significativas.

Para todos os casos apresentados na Figura 7 foi utilizado apenas um valor de Froude $(0,28)$. Os resultados apresentados foram obtidos numericamente, inclusive o do navio em sua forma original, Figura 7 (b). O software utilizado foi o Shipflow que, como apresentado anteriormente, divide o domínio fluido em regiões 
que utilizam diferentes métodos de solução. Feng et al. (2011) optaram por avaliar apenas a parcela de resistência relativa à geração de ondas e portanto utilizaram apenas a parcela potencial em suas análises.

Os resultados mostraram um decréscimo significativo de $10,8 \%$ no valor de resistência de ondas para o casco ótimo encontrado, porém, é interessante avaliar as demais parcelas da resistência que juntamente com a parcela de ondas deve fornecer um menor valor de resistência total, em relação ao modelo original. A Figura 7 (c) apresenta o casco ótimo obtido pelos autores. Nota-se que não houve mudanças que descaracterizasse o casco original.

O escoamento incompressível e turbulento ao redor do modelo DTMB5415 também foi analisado no trabalho de Ahmed (2011), em que o padrão de ondas gerado foi obtido através do método VOF, além dos valores de coeficientes de pressão e fricção para dois valores distintos de velocidade. O software adotado foi o CFX da Ansys que utiliza o código RANSE de solução. Os padrões de ondas obtidos foram comparados com os dados experimentais, assim como os valores dos coeficientes mencionados anteriormente. Para o caso de menor Froude, o padrão de ondas não apresentou boa correspondência, diferentemente do caso de maior velocidade de avanço, que forneceu melhores resultados. No caso dos coeficientes, o autor considerou que os valores obtidos demonstraram a potencialidade do software utilizado para estimar os coeficientes de resistência em ambas as velocidades. A Figura 8 apresenta os resultados encontrados.

\begin{tabular}{llll}
\hline Froude no. & Coefficient & Experimental results & CFX \\
\hline $\mathrm{F}_{\mathrm{n}}=0.28$ & $\mathrm{C}_{\mathrm{F}}$ & $2.880 \times 10^{-3}$ & $2.995 \times 10^{-3}$ \\
& $\mathrm{C}_{\mathrm{P}}$ & $1.350 \times 10^{-3}$ & $1.513 \times 10^{-3}$ \\
& $\mathrm{C}_{\mathrm{T}}$ & $4.230 \times 10^{-3}$ & $4.384 \times 10^{-3}$ \\
$\mathrm{~F}_{\mathrm{n}}=0.41$ & $\mathrm{C}_{\mathrm{F}}$ & $2.806 \times 10^{-3}$ & \\
& $\mathrm{C}_{\mathrm{P}}$ & $3.094 \times 10^{-3}$ & $2.738 \times 10^{-3}$ \\
& $\mathrm{C}_{\mathrm{T}}$ & $5.900 \times 10^{-3}$ & $2.919 \times 10^{-3}$ \\
& & $6.075 \times 10^{-3}$ \\
\hline
\end{tabular}

Figura 8 - Resultados numéricos e experimentais dos coeficientes de pressão, friccional e resistência total. Fonte: Ahmed (2011).

$\mathrm{Ni}$ et al. (2011) realizaram um estudo utilizando dois modelos distintos em escala reduzida, sendo um deles da série 60 e outro do tipo trimarã. Ambos os modelos foram ensaiados em tanque de reboque e analisados através do software Fluent. No caso da $\mathrm{S} 60$ os autores realizaram comparações entre os resultados físicos e numéricos para afundamento, trim e coeficiente de arrasto, sendo que para o último também foi considerada diferentes condições de graus de liberdade, isto é, 
modelo com e sem restrições de pitch e heave. Observou-se que o afundamento obtido via CFD permaneceu acima dos valores experimentais para toda a faixa de Froude adotada, enquanto que os valores de trim foram consistentes com os dados experimentais.

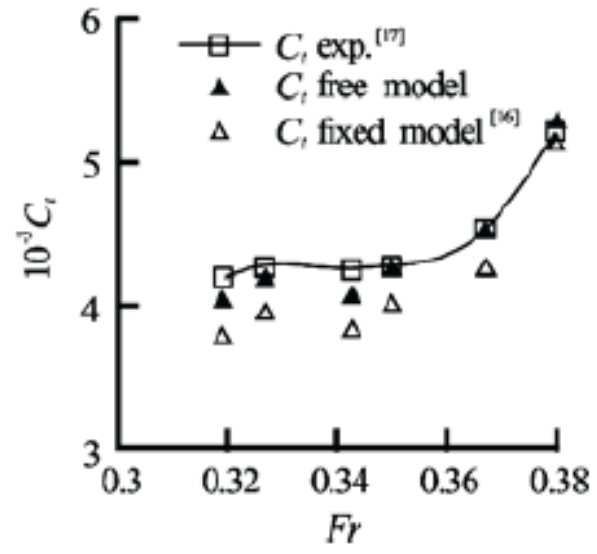

(a)

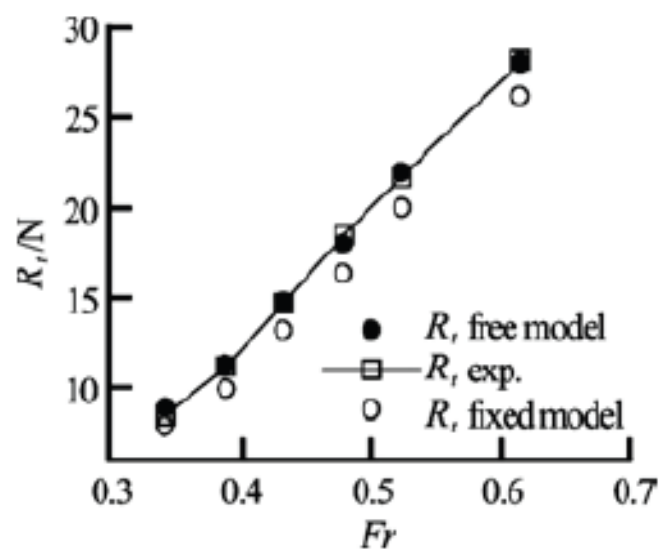

(b)

Figura 9 - a) Curvas de coeficiente total por Froude Série 60; b) Curva de resistência total por Froude modelo trimarã. Fonte: Ni et al. (2011).

Com relação à resistência ao avanço verificou-se que para heave e pitch livres os resultados numéricos foram satisfatórios, porém, para o caso com restrição de movimentos os valores de resistência foram inferiores ao experimental, fato este também observado no modelo trimarã, Figura 9. Segundo os autores, por conta do modelo estar com heave e pitch livres o mesmo adquiriu maior calado, devido à mudança na distribuição de pressão ao redor do casco durante o avanço, fazendo com que houvesse o aumento no arrasto. Os autores também ressaltaram que a elevação da superfície livre para os casos com e sem restrição são distintos devido ao afundamento dos cascos.

Aiguo et al. (2012) avaliaram numericamente a resistência ao avanço de uma embarcação da marinha Norte Americana (INSEAN 2340), considerando o afundamento e trim do casco. Os resultados obtidos foram comparados com dados experimentais, apresentando boa correlação para os sete números de Froude utilizados. Os valores de afundamento encontrados apresentaram um pequeno offset, enquanto que para o trim e padrão de ondas as curvas praticamente se sobrepuseram. A maior diferença encontrada na comparação de resistência foi de $3,56 \%$, valor este observado na maioria dos softwares que utiliza as equações de Navier-Stokes para solução do escoamento ao redor de embarcações. 


\subsection{FATOR DE FORMA}

O conceito de fator de forma foi introduzido para considerar a parcela de resistência decorrente da forma do casco. O conceito da ITTC admite que o fator de forma esteja relacionado principalmente com a viscosidade do fluido.

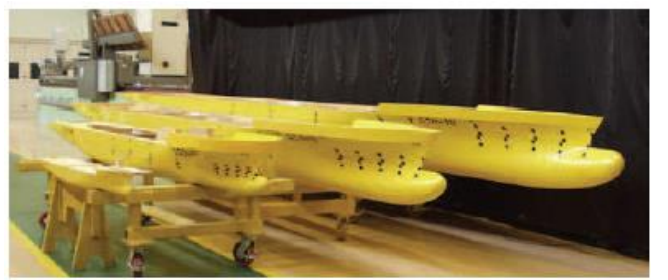

Porta contêiner 8600 TEU

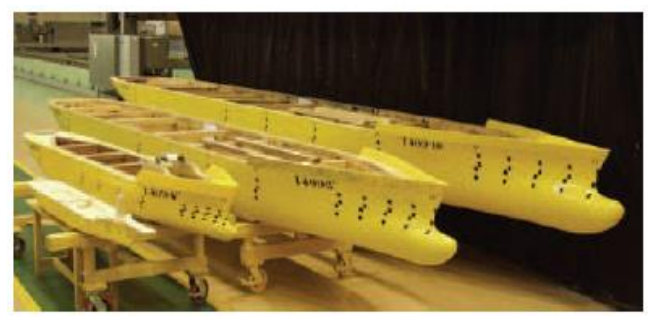

GNL $155000 \mathrm{~m}^{3}$

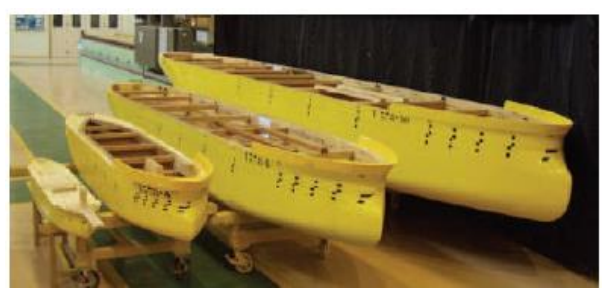

VLCC 317000 TDW
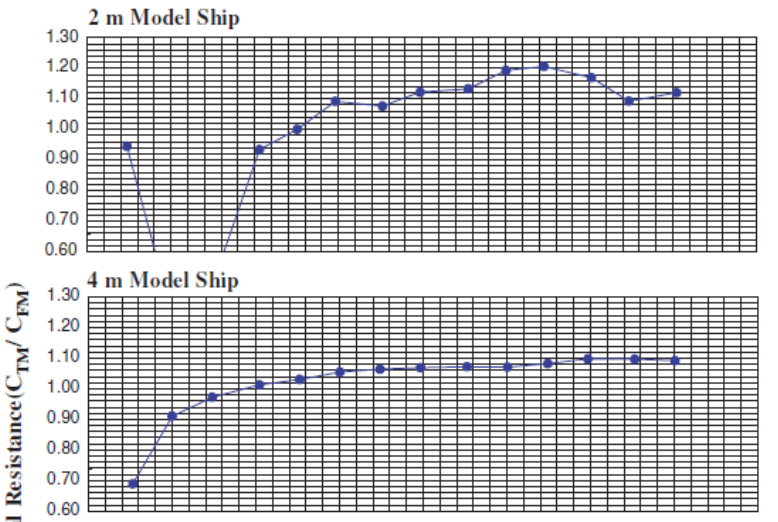

$7.584 \mathrm{~m}$ Model Ship

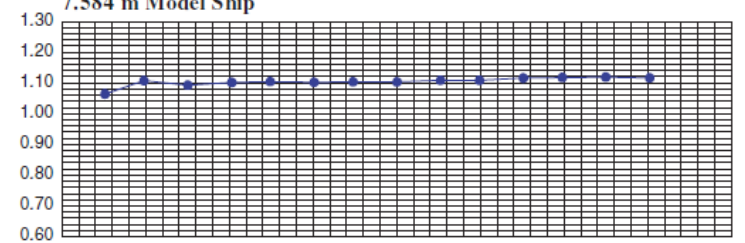

$10 \mathrm{~m}$ Model Ship

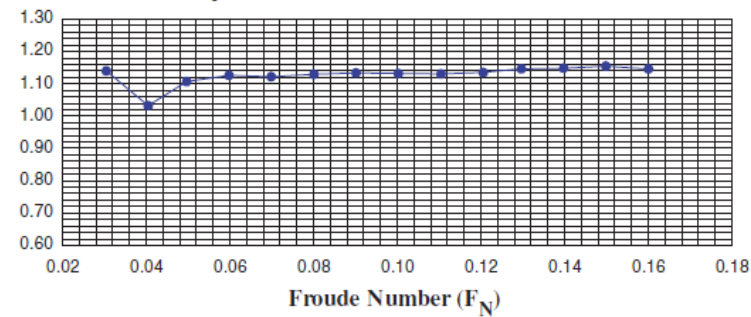

Figura 10 - Cascos utilizados nas análises e gráficos de fator de forma por Froude para diferentes números de Reynolds/escala para os modelos de porta contêiner. Fonte: Keh-Sik e Seon-Hyung (2009).

Embora os desenvolvimentos tecnológicos corroborassem para o avanço dos métodos aplicados em ensaios experimentais, ainda não foi possível medir a resistência de ondas diretamente, assim, a obtenção do fator de forma ainda é realizada através de ensaios de reboque em baixas velocidades, em que a resistência de ondas pode ser desconsiderada. Tal dificuldade pôde ser contornada com a utilização de ferramentas numéricas, visto que atualmente os softwares de CFD são capazes de dividir a resistência em suas componentes, possibilitando se estimar o valor do fator de forma dos cascos quase que de maneira direta.

Apesar do método padrão da ITTC para a estimativa de resistência ao avanço ser utilizado em larga escala, os resultados das extrapolações para a escala real 
variam consideravelmente entre laboratórios. Grande parte dessas diferenças está na determinação do fator de forma, por conta da dificuldade de medição de resistência em baixas velocidades, e possivelmente na adoção das hipóteses propostas pela ITTC.

Dado o exposto, Keh-Sik e Seon-Hyung (2009) realizaram um estudo baseado em ensaios com doze tipos de cascos, sendo alguns deles em mais de uma escala, contabilizando um total de trinta e dois ensaios, de forma a desenvolver um método que determinasse o fator de forma não só para velocidades baixas, mas para qualquer velocidade de avanço. A Figura 10 ilustra alguns dos cascos utilizados e as respectivas variações de escala.

Os gráficos da Figura 10 apresentam a tendência do fator de forma para cada escala adotada e embora sejam do modelo porta contêiner, características semelhantes podem ser observadas para os demais casos. Observa-se que as maiores variações nos valores da relação entre os coeficientes de resistência total e friccional, $C_{T M} / C_{F M}$, foram obtidas para modelos de menores dimensões enquanto que no caso das escalas mais elevadas os valores encontrados estão mais próximos da constância, embora apresentem menores flutuações.

Dados os resultados obtidos, os autores constataram que os valores do fator de forma crescem com o aumento do comprimento do casco, ou seja, com o aumento do número de Reynolds. Assim, concluíram que o fator de forma para a escala real é diferente dos modelos em escala e sugeriram que a hipótese da ITTC'78 fosse corrigida.

Através dos resultados experimentais, Keh-Sik e Seon-Hyung (2009) realizaram uma regressão utilizando a relação entre o fator de forma obtido para cada Froude e o fator de forma para o caso de escoamento plenamente desenvolvido, isto é, para o escoamento a partir do valor de Reynolds de 1,0E+09, conforme admitido pelos autores. As doze categorias de embarcações utilizadas foram divididas em quatro grupos, conforme pode ser observado na Figura 11, em que foi apresentada a linha de regressão obtida, denominada como linha de correção do fator de forma. Os autores propuseram o uso da metodologia desenvolvida por eles como alternativa para a obtenção do fator de forma para a escala real, no entanto, testes que validem o modelo desenvolvido ainda devem ser realizados. 


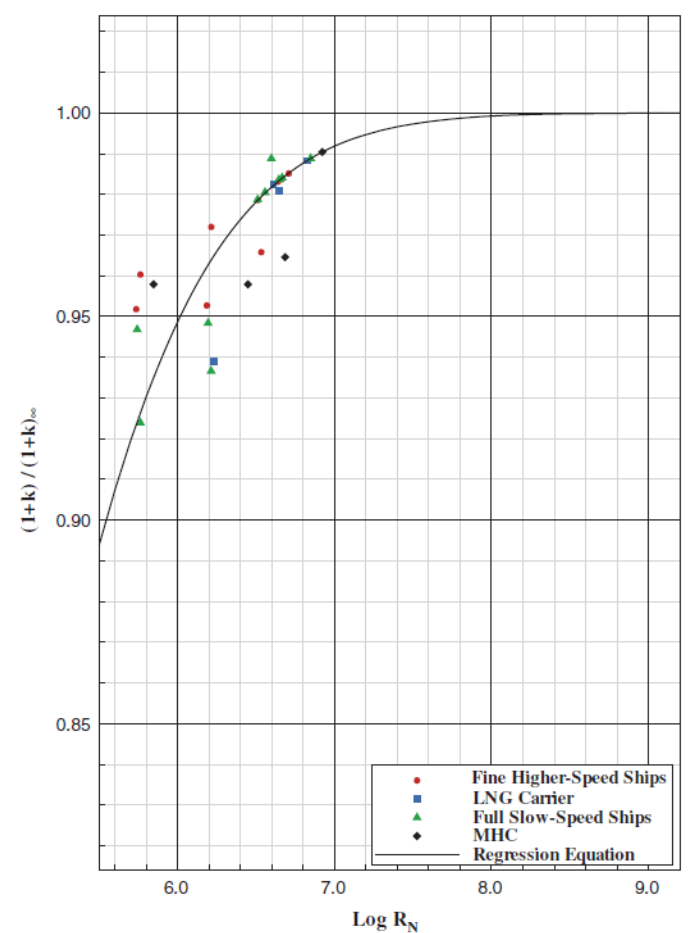

Figura 11 - Linha de regressão para a obtenção do fator de forma. Fonte: Keh-Sik e SeonHyung (2009).

Gómez (2000) propôs em seu estudo uma equação que pudesse ser utilizada para estimar o efeito da escala no fator de forma. A fórmula foi obtida através da regressão dos dados dos ensaios realizados com modelos em escala reduzida, para quatro tipos de navios, sendo cada um deles testado em diferentes escalas, mantendo-se o valor de Froude constante, ou seja, avaliou-se a variação do fator de forma em função do número de Reynolds. Para a obtenção dos valores de $(1+k)$ durante o ensaio de resistência ao avanço, Gómez. (2000) utilizou a metodologia proposta por Prohaska, ITTC (1975), e a linha de correlação da ITTC'57. Utilizando o método dos mínimos quadrados para os dados encontrados, o autor chegou à regressão apresentada na Figura 12.

Assumindo-se que o valor do coeficiente viscoso de um casco seja constante, tem-se que 0 valor do fator de forma variará de acordo com a correlação adotada $\left(C_{V}=C_{F}(1+k)\right)$, assim, o autor também fez uma breve comparação entre as linhas de correlação de Grigson e Schoenherr com a da ITTC'57. O gráfico da Figura 13 (a) apresenta as relações dos coeficientes friccionais obtidos por Grigson e Schoenherr em relação ao da ITTC, em que se pode observar que para valores de Reynolds na escala do modelo o coeficiente obtido por Schoenherr é menor que o da ITTC, mas para Reynolds na escala real as linhas podem ser consideradas semelhantes. De 
acordo com Gomez (2000), adotando-se Schoenherr em ensaios de resistência ao avanço, o efeito da escala sobre o fator de forma será menor, conforme mostra a Figura 13 (b).

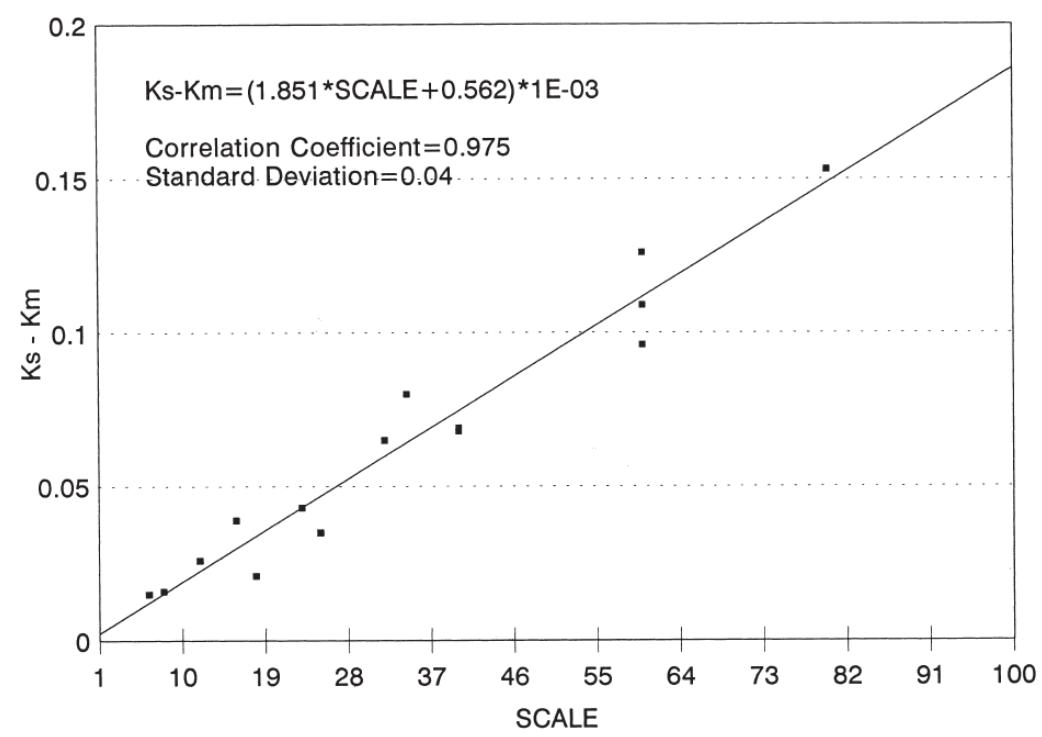

Figura 12 - Efeito da escala sobre o fator de forma. Fonte: Gomez (2000).

Vale ressaltar que a dependência ou independência do fator de forma em função do número de Reynolds deve ser associada á uma linha de correlação, a qual cada laboratório tem a liberdade de trabalhar com a que melhor lhe convém, porém, atualmente, a linha da ITTC é utilizada como padrão.

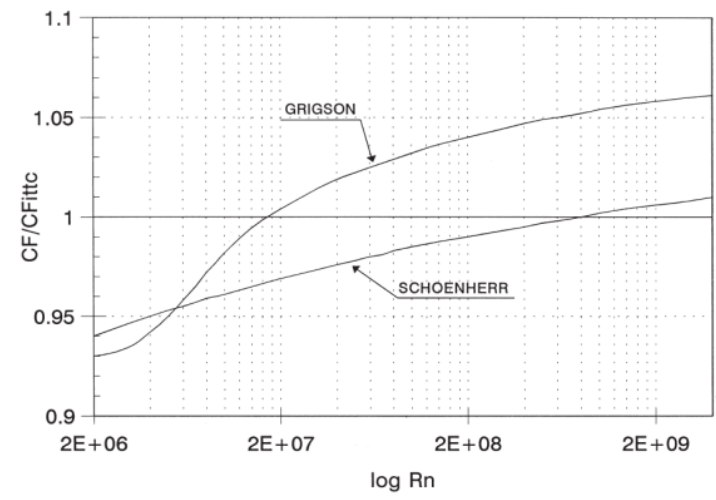

(a) Comparação entre linhas de correlação

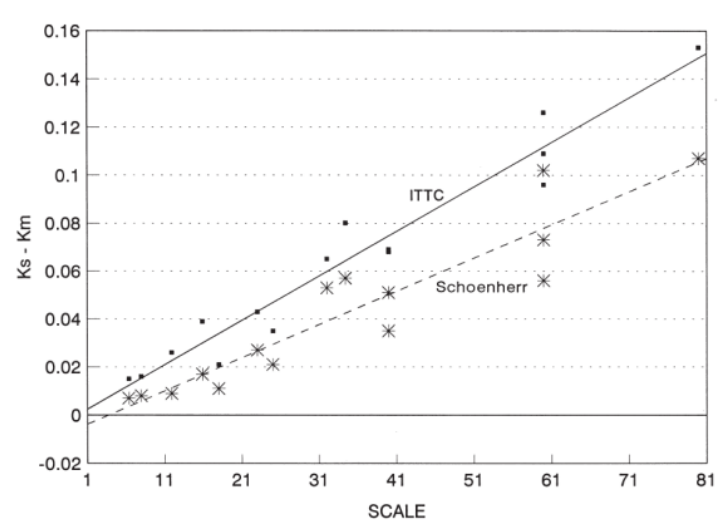

(b) Comparação entre fator de forma

Figura 13 - Avaliação das linhas de correlação. Fonte: Gomez (2000).

Eça e Hoekstra (2005) realizaram em seu estudo análises numéricas de avanço de cascos e placas planas, cujas áreas molhadas eram equivalentes aos dos cascos adotados. Os autores compararam os valores dos coeficientes friccionais obtidos numericamente com o padrão da ITTC'57, linhas de Grigson e de Schoenherr. No caso das placas planas os resultados numéricos coincidiram com o valor médio das curvas de correlação, enquanto que para os cascos houve 
diferenças ocasionadas pelo efeito da forma, ou seja, pela variação de velocidade e pressão ao longo do comprimento das embarcações em estudo. Pode-se verificar na Figura 14, que a maior e a menor diferença encontradas entre os coeficientes dos cascos e as linhas de correlação, para a faixa de Reynolds do navio, foi em relação à curva da ITTC e à de Grigson, respectivamente.

$\mathrm{Na}$ análise numérica a superfície livre foi desconsiderada, ou seja, utilizou-se a metodologia de double-model. Assim, a resistência total e a resistência viscosa encontradas foram consideradas equivalentes $\left(C_{T}=C_{V}\right)$ e, portanto, foi possível obter o fator de forma para os diferentes Reynolds, dado Froude constante. Os resultados apresentaram que conforme o Reynolds aumenta há também o aumento do fator de forma, conforme visto em Keh-Sik e Seon-Hyung (2009).

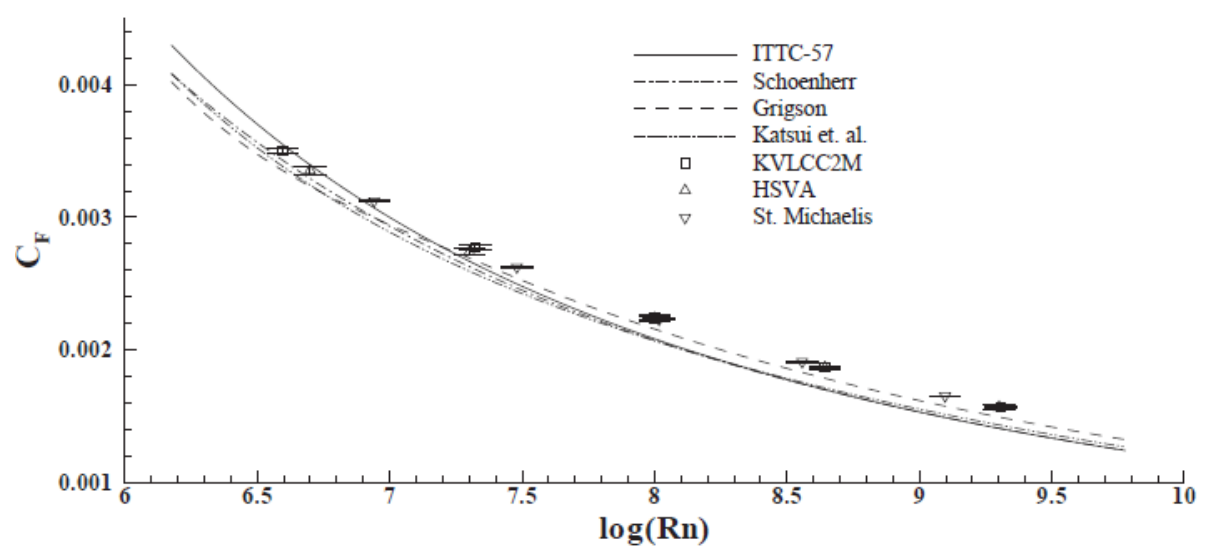

Figura 14 - Comparação entre o coeficiente friccional dos cascos analisados e as linhas de correlação comumente encontradas na literatura. Fonte: Eça e Hoekstra (2005).

A importância de se avaliar o efeito da escala no valor do fator de forma, além da utilização de uma linha de correlação adequada, também foi ressaltada no trabalho de Jen-Shiang, Yen-Jen e Shiu-Wu (2009). Os autores questionaram a utilização da linha de correlação da ITTC'57 e a compararam com as linhas da ATTC, Grigson e com os valores de $C_{F}$ de uma placa plana, obtidos numericamente. Observou-se que os resultados numéricos estavam mais próximos à linha de Grigson, a partir de Reynolds 1,0E+07, Figura 15 (a). De acordo com o exposto, talvez fosse cabível a utilização de outra correlação ao invés da tipicamente utilizada em ensaios em tanques de provas. A adoção inadequada possibilitaria que a resistência ao avanço de uma embarcação, quando extrapolada para a escala real, fosse subestimada. 


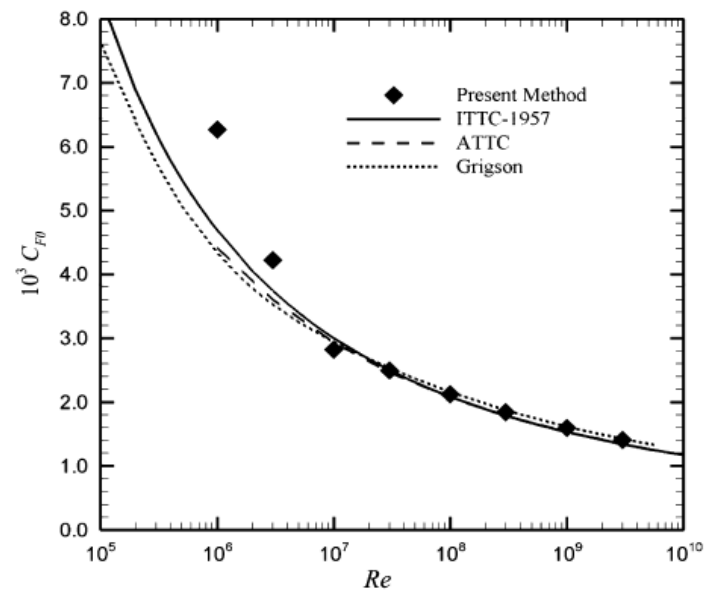

(a)

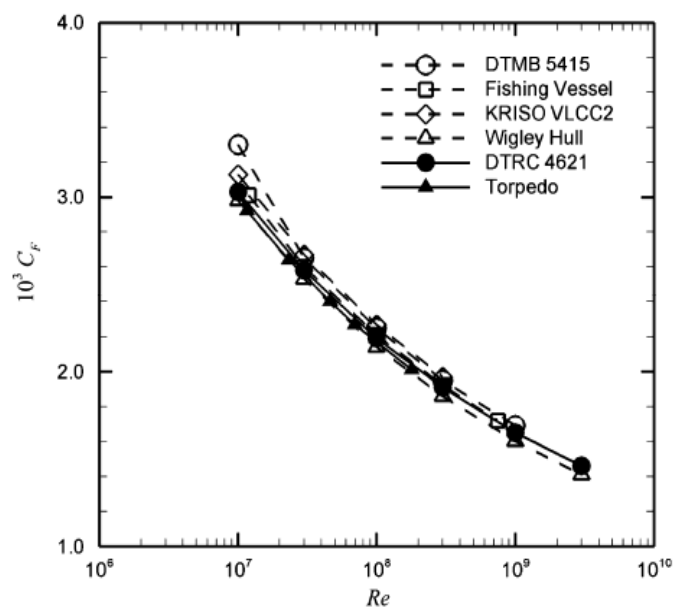

(c)

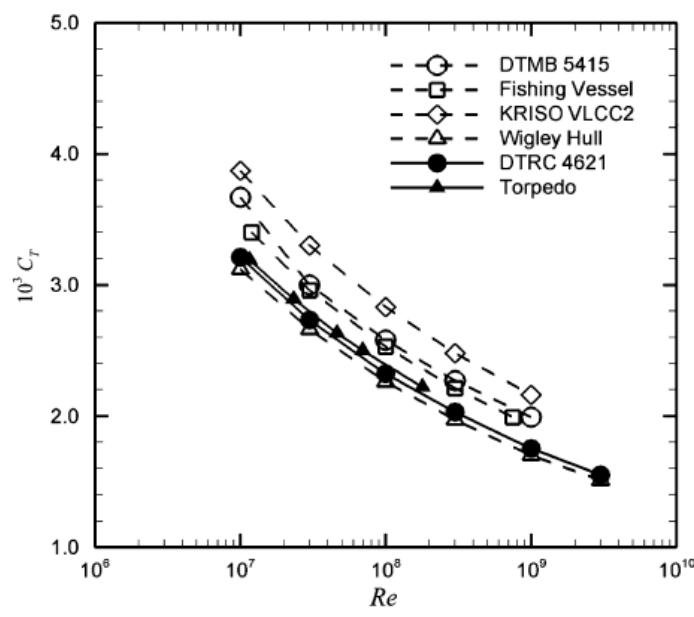

(b)

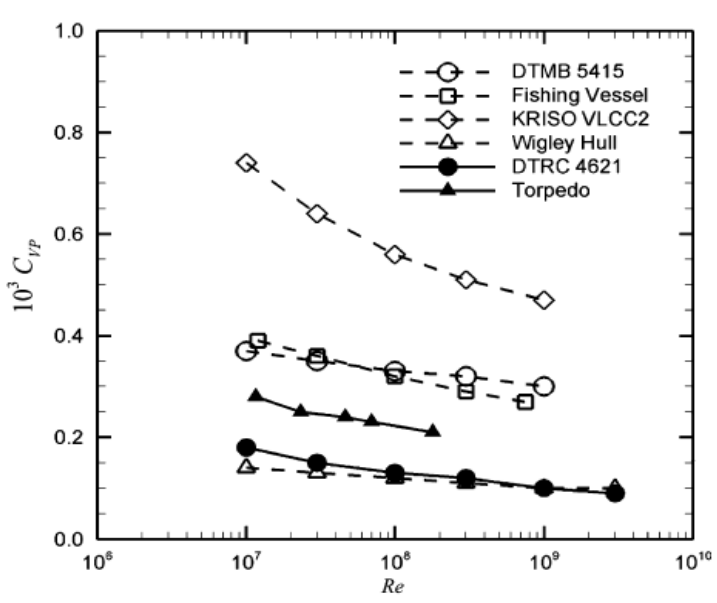

(d)

Figura 15 - a) Coeficiente friccional de placa plana; b) Coeficiente de resistência total dos modelos; c) Coeficiente friccional dos modelos; d) Coeficiente de pressão dos modelos. Fonte: Jen-Shiang , Yen-Jenn e Shiu-Wu (2009).

Para o estudo do efeito de escala os autores realizaram, através de CFD, análises com quatro cascos e dois corpos axi-simétricos (torpedos), obtendo os coeficientes friccionais e de pressão de cada caso, os quais compõem o coeficiente de resistência total. A superfície livre foi desconsiderada nas análises, portanto, 0 coeficiente de pressão levou em conta apenas a parcela oriunda da viscosidade/forma, negligenciando a parcela de ondas. Os resultados demonstraram que embora houvesse diferenças entre os coeficientes de resistência total dos cascos, a parcela friccional não apresentou variações assim como ocorreu com a parcela relativa à pressão, podendo se concluir que a parcela de pressão é mais sensível às mudanças de forma do casco, Figura 15 (b), (c) e (d). 
Os autores encontraram, através de CFD e pelo proposto pela ITTC'57, os valores de fator de forma dos seis corpos estudado, e verificaram que houve variação entre os resultados em função do número de Reynolds. Em ambos os métodos o valor do fator de forma cresce com o número de Reynolds, entretanto, a variação observada no caso numérico é menor e, segundo os autores, poderia ser o mais indicado para refletir a dependência do fator de forma por Reynolds.

O gráfico da Figura 16 apresenta a variação do fator de forma em função de Reynolds, em que as distintas inclinações das curvas apontam a suscetibilidade do valor de $k$ à variação de Reynolds para cada casco analisado. Os primeiros pontos, equivalentes à Reynolds de 1,0E+07, devem ser desconsiderado, pois a malha numérica utilizada nas análises foi otimizada para o escoamento com Reynolds na ordem de $1,0 \mathrm{E}+08$, tal que a primeira célula ${ }^{1}$ estivesse com valor de $y^{+}$inserido na região logarítmica. Assim, observa-se que as curvas são praticamente lineares e que algumas quase não apresentam variação significativa com o aumento de Reynolds, porém, é interessante notar que, embora o casco VLCC2 seja o mais rombudo dentre os cascos, aquele que mais depende de Reynolds é o DTMB5415.

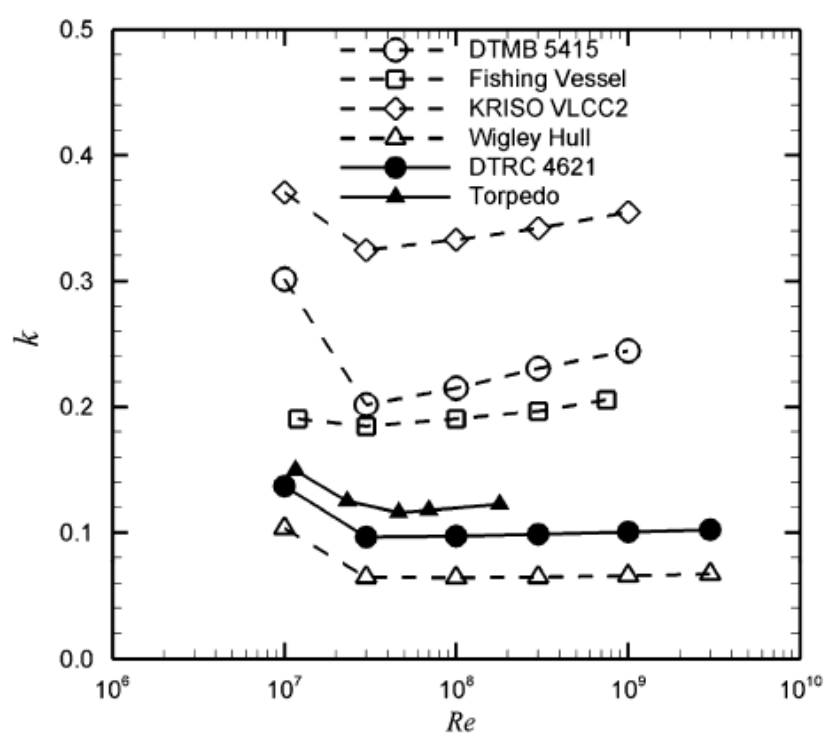

Figura 16 - Variação de $k$ em função de Reynolds: Análise numérica. Fonte: Jen-Shiang, YenJen e Shiu-Wu (2009).

Os autores ainda ressaltam a importância de se averiguar a influência da superfície livre, ou seja, da parcela de resistência oriunda da geração de ondas, no fator de forma. 


\section{ENSAIO EXPERIMENTAL}

Os ensaios experimentais no âmbito naval e offshore são normalmente realizados em laboratórios, através de modelos em escala reduzida, por questões de praticidade e custo, pois em muitos casos há a impossibilidade física de se monitorar uma variável de interesse na escala real e, quando possível, dependerá de fatores climáticos, ambientais e da disponibilidade operacional do navio ou plataforma em questão. Assim, como uma alternativa para se avaliar o fenômeno desejado, surgiram os tanques de provas, em que o ambiente é controlável e a física do problema é simplificadamente representada em escala, porém sem deixar de apresentar resultados adequados. Os tanques possuem características distintas dependendo da área de estudo, porém, dentro de cada setor os tanques de provas apresentam padrões semelhantes decorrentes da sua finalidade.

Podem-se mencionar alguns tipos de tanques como, por exemplo, os tanques para ensaio de comportamento no mar (Sea Keeping), que possuem geometrias e profundidades variadas e que apresentam como característica principal a presença de batedores em seu perímetro, assim como observado no TPN, Figura 17 (a), em que é possível avaliar o comportamento em ondas por tempo "indeterminado". Alguns desses tanques também possuem água circulante e ventiladores para simular a correnteza e o vento respectivamente, permitindo a realização de ensaios com condições climáticas mais próximas às reais.

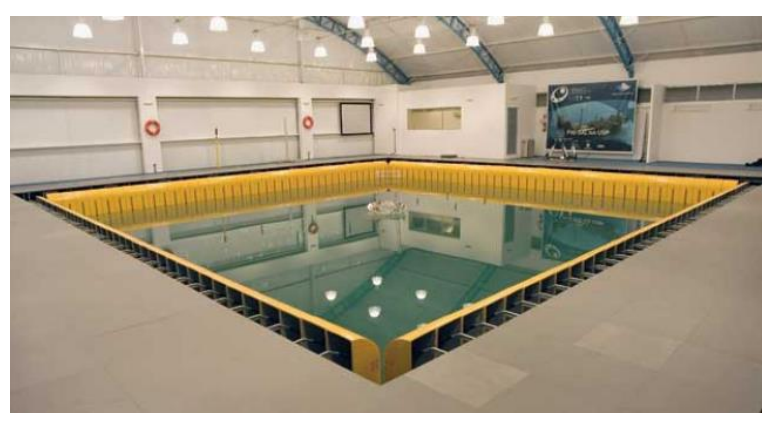

(a)

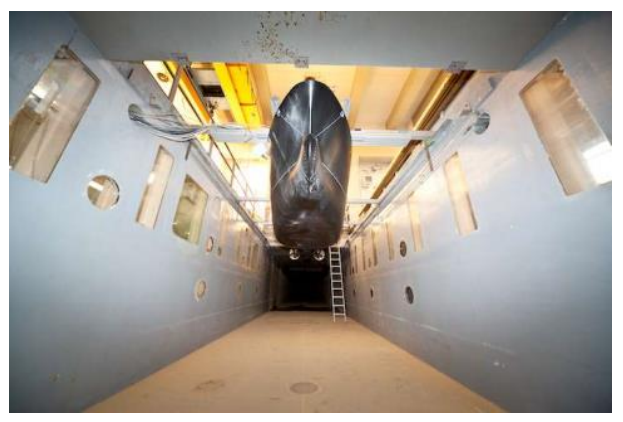

(b)

Figura 17 - a) Tanque de provas do laboratório TPN; b) Canal de água circulante. Fonte: Marinet.

Tanques ou canais de água circulante, Figura 17 (b), consistem em um circuito fechado e geralmente apresentam pequenas dimensões para as escalas dos modelos comumente utilizados no âmbito naval. Embora de maneira geral o 
desenvolvimento tecnológico tenha possibilitado a realização de ensaios com modelos de dimensões reduzidas, ainda não foi o suficiente para que os canais de água circulante se tornassem o método principal de estudos em laboratórios navais e offshore. Durante os ensaios algumas correções por conta de efeito de camada limite e blocagem devem ser realizadas, porém, a visualização do escoamento em torno do casco é facilitada pelo modelo se encontrar com velocidade nula em relação ao solo.

Os tanques mais utilizados em projetos navais são os tanques de reboque, que geralmente são retangulares e apresentam batedores em seus extremos como é o caso do tanque de provas do IPT. Entretanto, diferentemente do tanque do TPN em que é possível gerar diversas condições de mar, no tanque de reboque são geradas apenas ondas unidirecionais, que permitem a execução de ensaios menos complexos de comportamento em ondas e ensaios de resistência adicional ao avanço decorrentes da incidência de ondas. Embora seja menos eficiente em ensaios de sea keeping, o tanque de reboque é o único capaz de estimar o valor de resistência ao avanço do modelo com precisão adequada. Outros ensaios possíveis de serem realizados em tanque de reboque são ensaio de manobrabilidade utilizando-se o PMM (Planar Motion Mechanism), autopropulsão, ensaios de VIM e VIV, analisando-se também a emissão de vórtices através de tecnologias tais como o PIV (Particle Image Velocimetry), que embora seja adequado para certas análises, nem sempre é acessível por conta do custo e dificuldade de operação elevados. Além disso, muitas vezes esses equipamentos não são aplicáveis em determinadas situações em que se verifica a importância de uma ferramenta numérica que possa auxiliar nas análises hidrodinâmicas do projeto.

\subsection{DESCRIÇÃO DO ENSAIO DE REBOQUE}

Ensaios de reboque são utilizados para se estimar, através da extrapolação de dados obtidos com modelos em escala reduzida, a resistência total da embarcação em escala real, visando o dimensionamento do propulsor e motor. Muitos ensaios realizados em tanques de provas também objetivam a otimização hidrodinâmica do casco de forma a reduzir a resistência e consequentemente o consumo de combustível a longo prazo, dada uma vida útil estimada em 25 anos. 
Para a realização do ensaio de resistência é aconselhável que os procedimentos da ITTC (2002) sejam adotados e que o modelo utilizado possua a maior escala possível, levando em consideração as dimensões do tanque, além da velocidade máxima do carro dinamométrico, devido aos efeitos de blocagem. Os modelos podem ser ensaiados com ou sem a presença de apêndices, porém, para o presente estudo os apêndices foram desconsiderados.

Durante os ensaios de resistência ao avanço, o modelo é rebocado mediante um sistema de deslocamento ao longo do comprimento do tanque de provas. No caso do tanque de provas do IPT, onde também foram realizados ensaios do casco DTMB5415, o modelo é conectado ao carro dinamométrico, Figura 18 (a), que se movimenta sobre trilhos.

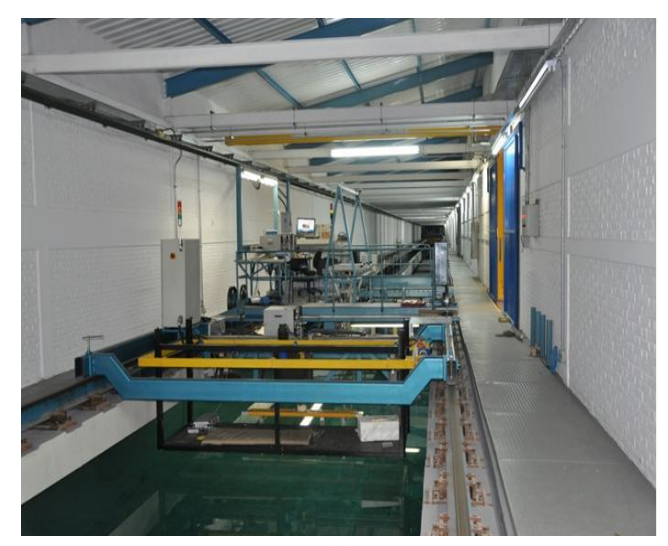

(a)

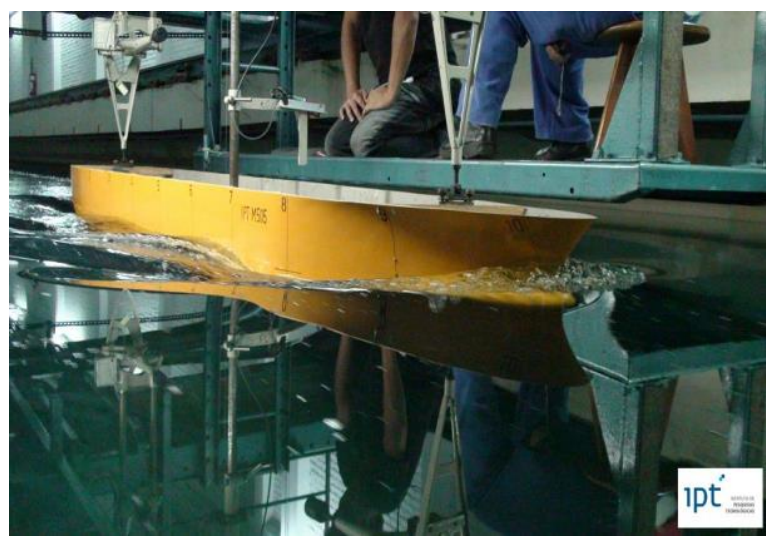

(b)

Figura 18 - Tanque de provas do IPT: a) Vista do carro dinamométrico; b) Vista de um ensaio de resistência ao avanço.

O acoplamento ao carro é realizado por um dispositivo que permite apenas os movimentos de heave e pitch, enquanto que o movimento de surge é restrito por um cabo, em que uma das pontas está conectada ao modelo e a outra à uma célula de carga dimensionada e previamente calibrada para o ensaio e fixa à estrutura do carro. O cabo, quando possível, deve coincidir com a linha de eixo do propulsor e estar preso na mesma posição do LCB do casco, para evitar efeito de trim artificial.

Após o carro e o modelo atingirem a velocidade de interesse e se estabilizarem, obtêm-se como resultado forças longitudinais denominadas como resistências ao avanço, que são as forças que se opõem ao movimento. A Figura 19 ilustra um esboço do aparato comumente utilizado em ensaios de resistência ao avanço e a Tabela 1 apresenta as dimensões do tanque de provas do IPT. 


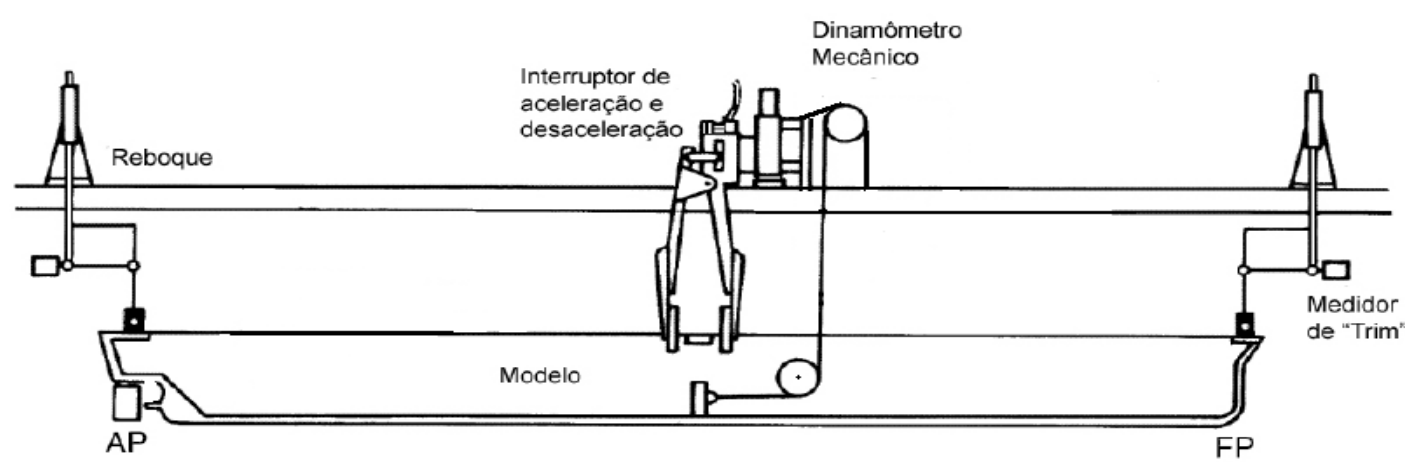

Figura 19 - Montagem do ensaio de resistência ao avanço. Fonte: Bertram (2000) - Adaptado.

Durante os ensaios experimentais procura-se representar as condições de contorno reais do protótipo ${ }^{1}$ da melhor maneira possível como, por exemplo, instalar estimuladores de turbulência nos cascos dos modelos para evitar o escoamento laminar. Assim como na modelagem numérica os ensaios experimentais também são aproximações da realidade e estão suscetíveis à erros.

Tabela 1 - Características principais do Tanque de Provas do IPT.

\begin{tabular}{c|c}
\hline Comprimento total & $280,00 \mathrm{~m}$ \\
\hline Largura total & $6,60 \mathrm{~m}$ \\
\hline Profundidade & $4,50 \mathrm{~m}$ \\
\hline $\begin{array}{c}\text { Velocidade máxima de } \\
\text { ensaio }\end{array}$ & $3,50 \mathrm{~m} / \mathrm{s}$ \\
\end{tabular}

É importante conhecer a prática corrente de ensaios com modelos, para estabelecer em que condições as simulações computacionais podem completar ou substituir parte dos ensaios, e quais podem ser as dificuldades em se relacionar resultados experimentais a valores do projeto ou compará-los com resultados numéricos.

\subsection{SIMILARIDADE E EXTRAPOLAÇÃO}

Para que a análise em escala reduzida produza resultados com boa precisão, as características do escoamento ao redor do casco do modelo devem ser similares às do casco em escala real, ou seja, deve haver similaridade dinâmica. No caso de ensaio de resistência ao avanço, para que a similaridade total fosse satisfeita seria

\footnotetext{
${ }^{1}$ No presente trabalho a designação modelo será utilizada quando se fizer referência ao casco em escala reduzida e protótipo para a escala real.
} 
necessário que os adimensionais Reynolds e Froude fossem os mesmos simultaneamente, porém, a simultaneidade dos adimensionais é praticamente impossível a não ser com uma grande alteração da gravidade ou da viscosidade do fluido:

$$
\begin{aligned}
& \frac{L_{1} V_{1} \rho}{\mu}=\frac{L_{2} V_{2} \rho}{\mu} \\
& \frac{V_{1}}{\sqrt{g L_{1}}}=\frac{V_{2}}{\sqrt{g L_{2}}}
\end{aligned}
$$

Da igualdade de Reynolds, eq. (1), verifica-se que a velocidade do modelo deveria apresentar velocidade de avanço elevada, na mesma proporção da razão entre protótipo/modelo, o que na prática é inviável. Por exemplo, um modelo 49 vezes menor que o protótipo teria que desenvolver uma velocidade 49 vezes maior em tanque de reboque.

Desde o surgimento da necessidade de se estimar a resistência de embarcações, diversos estudos foram realizados para que houvesse simplificações coerentes de forma a permitir a similaridade dinâmica durante a execução de ensaios experimentais. No ano de 1867, William Froude apresentou seu trabalho, em que decompôs a resistência em parcelas friccionais e residuais:

$$
C_{T}=C_{R}+C_{F}
$$

Além disso, propôs que os ensaios de resistência fossem conduzidos para um mesmo adimensional, conhecido até hoje por número de Froude, considerando as devidas correções para o efeito de diferentes números de Reynolds. Assim, da similaridade de Froude, um modelo 49 vezes menor deverá apresentar velocidade de avanço menor, na ordem da raiz quadrada da escala, que para o exemplo utilizado seria de 7, o que é aceitável em termos práticos.

William Froude notou, através de ensaios com modelos de diferentes escalas, que navios semelhantes produzem ondas semelhantes, ou seja, navios semelhantes, porém, com escalas distintas, apresentarão semelhança nos fenômenos referentes à forma. Portanto, os coeficientes residuais do modelo e do navio em escala real serão os mesmos. Tal fato não pôde ser observado para a parcela de resistência friccional, que era obtida através de ensaios de reboque de uma placa plana, cuja área molhada e comprimento eram equivalentes à do modelo 
ensaiado. Através dos dados experimentais, foi possível obter regressões para a estimativa do coeficiente de resistência friccional.

Em 1957 a ITTC propôs uma linha de correlação para a estimativa de $C_{F}$ em função de Reynolds:

$$
C_{F}=\frac{0,075}{(\log R e-2)^{2}}
$$

Atualmente a correlação da eq.(4) tem sido utilizada como padrão, porém, existem outras linhas de correlação tais como a de Schoenherr e Grigson que serão apresentadas no decorrer do trabalho.

Assim, para se estimar a resistência do casco do protótipo, primeiramente, os valores do coeficiente total do modelo são definidos através de ensaio e o coeficiente friccional através das linhas de correlação, obtendo-se o coeficiente residual do modelo que é o mesmo do protótipo, eq.(5) e eq.(6), possibilitando se estimar o valor do coeficiente total da embarcação, eq.(7) e consequentemente a sua resistência ao avanço para a condição de prova de mar, eq.(8):

$$
\begin{gathered}
C_{R M}=C_{T M}-C_{F M} \\
C_{R M}=C_{R S} \\
C_{T S}=C_{R M}+C_{F S} \\
R_{T}=\frac{1}{2} \rho \mathrm{V}^{2} S C_{\mathrm{T}}
\end{gathered}
$$

A metodologia apresentada por Froude é utilizada até os dias de hoje, porém, em 1978, com o intuito de se melhorar o método tradicional de estimativa de resistência ao avanço, a ITTC introduziu o conceito de fator de forma para navios:

$$
C_{T S}=C_{T M}+(1+k)\left(C_{F S}-C_{F M}\right)+\Delta C_{F}+C_{A A}
$$

O termo $(1+k)$, definido como fator de forma, associa a resistência de forma, decorrente da distribuição de pressão sobre o casco, à resistência viscosa e foi definido pela ITTC considerando-se duas suposições:

$1^{\circ} \mathrm{O}$ fator de forma do modelo é o mesmo que o fator de forma do navio na escala real;

$2^{\circ} \mathrm{O}$ fator de forma é independente da velocidade de avanço;

Conforme observado na eq.(9), a ITTC (1978) realizou a decomposição do coeficiente de resistência total em duas parcelas diferentes da observada anteriormente. A parcela residual foi decomposta em parcelas de pressões normais e tangenciais ao casco, relacionadas à geração de ondas e à pressão de origem 
viscosa, respectivamente, sendo que o termo de distribuição de pressão tangencial foi associado ao coeficiente friccional, definindo a parcela viscosa:

$$
\begin{gathered}
C_{T}(R e, F r)=C_{F}(R e)+C_{R}(R e, F r) \\
C_{T M}=(1+k) C_{F M}+C_{W} \\
C_{V M}=C_{F M}(1+k) \\
C_{W M}=C_{W S}=C_{W}
\end{gathered}
$$

O método que apresentaria maior precisão para se determinar o valor de $(1+k)$ seria através da utilização direta da eq.(11), em que as parcelas de resistência de ondas e total seriam obtidas simultaneamente em ensaios experimentais. Porém, devido às grandes imprecisões e dificuldades na obtenção da parcela de ondas, a medição simultânea deve ser descartada.

A sugestão proposta pela ITTC é que o fator de forma seja encontrado através de dois ou mais ensaios com Froudes baixos $(0,12<F n<0,2)$ e distintos. Para a obtenção do fator de forma são utilizados dois métodos:

\section{Método direto}

Primeiramente uma série de ensaios deve ser realizada para baixos números de Froude, obtendo-se valores de $C_{T M} / C_{F M}$. Por questões de conveniência serão adotados as seguintes igualdades:

$$
x=F r, \quad y=\frac{C_{T M}}{C_{F M}}
$$

Os dados são interpolados por equações polinomiais através do método dos mínimos quadrados, por equações de segunda ou terceira ordens:

$$
\begin{gathered}
y=a x^{2}+b x+c \\
y=a x^{3}+b x^{2}+c x+d
\end{gathered}
$$

O fator de forma torna-se o termo independente das eqs.(15) e (16), conforme observado no caso de Froude tendendo à zero:

$$
1+k=\lim _{F r \rightarrow 0} \frac{C_{T M}}{C_{F M}}=\lim _{x \rightarrow 0} y
$$

Dessa forma, o valor de $(1+k)$ será determinado no cruzamento da curva de interpolação com o eixo das ordenadas.

\section{Método indireto}


O método indireto é baseado na seguinte aproximação, em que o coeficiente de resistência de ondas foi introduzindo considerando-se que o fator de forma fosse constante e os ensaios em baixas velocidades:

$$
C_{T M}=(1+k) C_{F M}+a F r^{n}
$$

Onde $C_{W}=a F_{n}^{n}$ e $n=4,5$ ou 6 .

$\mathrm{Na}$ eq.(18) o termo a é uma constante relacionada ao coeficiente de resistência de ondas. No método proposto por Prohaska, ITTC (1975), o expoente $n$ na eq.(18) representa o quanto o coeficiente de resistência de ondas é invariável. $\mathrm{Na}$ teoria linear de ondas, a expansão assintótica da expressão da resistência de ondas para baixos números de Froude mostra que a resistência de ondas varia com a $6^{\circ}$ potência de número de Froude. Do ponto de vista físico, o expoente geralmente varia entre 4 e 6 , dependendo da forma do navio.

Neste método, o gráfico de $F_{n}{ }^{n} / C_{F M}$ versus $C_{T M} / C_{F M}$ é elaborado através de resultados obtidos para ensaios em baixa velocidade. Por questões de conveniência as relações anteriores são consideradas como:

$$
x=\frac{F r^{n}}{C_{F M}}, \quad y=\frac{C_{T M}}{C_{F M}}
$$

Os dados são interpolados por equações polinomiais de segunda ou terceira ordens através do método dos mínimos quadrados, onde o fator de forma é o termo independente, sendo obtido de forma análoga ao método direto.

Após definir o fator de forma, obtêm-se os valores de $C_{W}$ do modelo para as escalas adotadas, eq.(20), que são utilizados para estimar o coeficiente de resistência total do navio na escala real, eq.(21).

$$
\begin{gathered}
C_{W}=C_{T M}-(1+k)_{M} C_{F M} \\
C_{T S}=(1+k)_{S} C_{F S}+C_{W}
\end{gathered}
$$

Pode-se utilizar ainda de correções propostas pela ITTC (1978), que considera $(1+k)$ constante, chegando-se à expressão:

$$
C_{T P}=C_{T M}+(1+k)\left(C_{F P}-C_{F M}\right)+\Delta C_{F}+C_{A A}+C_{A P}
$$

Sendo $\Delta C_{F}$ uma correção de rugosidade do casco, $C_{A A}$ é a correção de resistência do ar e $C_{A P}$ é a resistência de apêndices. A expressão adotada para $\Delta C_{F}$ pela ITTC foi proposta por Townsin:

$$
10^{3} \Delta C_{F}=44\left[\left(\frac{h}{L_{W L}}\right)^{\frac{1}{3}}-10(R e)^{-\frac{1}{3}}\right]+0,125
$$


Onde $h$ é a altura média da rugosidade. Deve-se notar que a forma dos elementos que determinam a altura da rugosidade pode causar muitas diferenças no $\Delta C_{F}$, embora não sejam contabilizadas na equação.

É importante mencionar que a determinação do fator de forma pode variar de acordo com o tamanho do modelo utilizado, pois a resistência de forma é influenciada pela viscosidade, ou seja, pelo tamanho da camada limite. Modelos com dimensões diferentes ensaiados para um mesmo Froude apresentam espessuras de camadas limites distintas e provavelmente não apresentarão valores iguais de $(1+k)$, indicando que talvez as duas suposições da ITTC estejam incorretas.

Embora haja um procedimento padrão proposto pela ITTC e que o mesmo é aplicado em diversos tanques de provas do mundo, os resultados obtidos durante os ensaios e consequentemente o valor da extrapolação variam consideravelmente entre os laboratórios, devido à dificuldade de se medir a resistência em baixas velocidades, afetando diretamente a determinação do fator de forma. Atualmente, ferramentas numéricas têm sido uma aliada na determinação do fator de forma, demonstrando que algumas correções devem ser realizadas nos procedimentos de extrapolações, evitando que a resistência total do casco em escala real seja subestimada.

\subsection{RESULTADOS EXPERIMENTAIS}

Para o presente estudo foi escolhido o modelo DTMB5415, que foi concebido como um projeto preliminar de um navio de combate da marinha. A geometria do casco apresenta sonar na região de proa e popa transom. A propulsão é fornecida por dois hélices cujos eixos são suportados por pés de galinha, porém, no caso do presente trabalho, foi utilizado casco nu, desconsiderando também a presença do leme. A Figura 20 ilustra o modelo do casco em 3D e o modelo físico que foi ensaiado no IPT.

O $24^{\circ}$ comitê de resistência da ITTC convidou todos os seus membros para participarem de uma série de testes comparativos, de âmbito mundial, em que foram identificadas variações de resultados e incertezas dos ensaios realizados nas respectivas instalações. Adotaram-se para a execução dos ensaios duas geometrias semelhantes do modelo DTMB5415 com comprimentos entre perpendiculares de 5,72 m e 3,05 m. A Tabela 2 apresenta as características principais da embarcação 
para as dimensões mencionadas e para a escala real, entretanto, por se tratar de um projeto preliminar, o casco em escala 1:1 não foi construído e consequentemente não há medições ou testes disponíveis nesta escala.

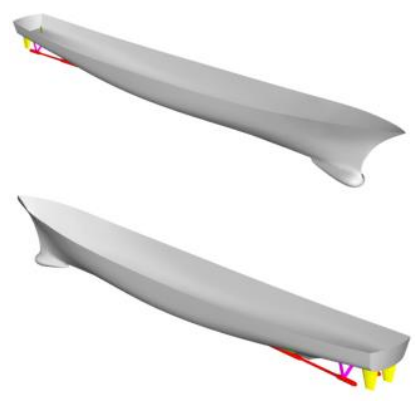

(a)

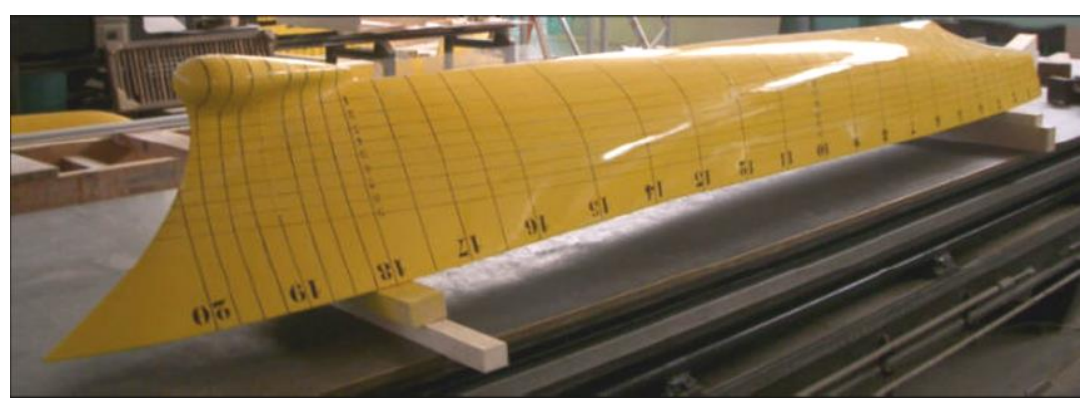

(b)

Figura 20 - a) Modelo 3D do casco DTMB5415; b) Modelo físico que foi ensaiado no tanque de provas do IPT.

Tabela 2 - Características do casco DTBM 5415.

\begin{tabular}{c|c|c|c}
\hline Escala & $1: 1$ & $1: 24,83$ & $1: 46,59$ \\
\hline $\mathrm{Lpp}[\mathrm{m}]$ & 142,00 & 5,719 & 3,048 \\
\hline $\mathrm{Lwl}[\mathrm{m}]$ & 142,18 & 5,726 & 3,052 \\
\hline $\mathrm{Bwl}[\mathrm{m}]$ & 19,06 & 0,768 & 0,409 \\
\hline $\mathrm{T}[\mathrm{m}]$ & 6,15 & 0,248 & 0,132 \\
\hline Deslocamento $\left[\mathrm{m}^{3}\right]$ & 8424,40 & 0,554 & 0,083 \\
\hline $\begin{array}{c}\text { Velocidade de projeto } \\
{[\mathrm{m} / \mathrm{s}]}\end{array}$ & 18,00 & 3,61 & 2,64 \\
\hline $\begin{array}{c}\text { Froude de projeto } \\
\text { Froud }\end{array}$ & 0,48 & 0,48 & 0,48
\end{tabular}

O levantamento das diferenças dos resultados entre laboratórios foi realizado para a estimativa de resistência ao avanço, afundamento e trim, conforme podem ser observados em ITTC (2011b).
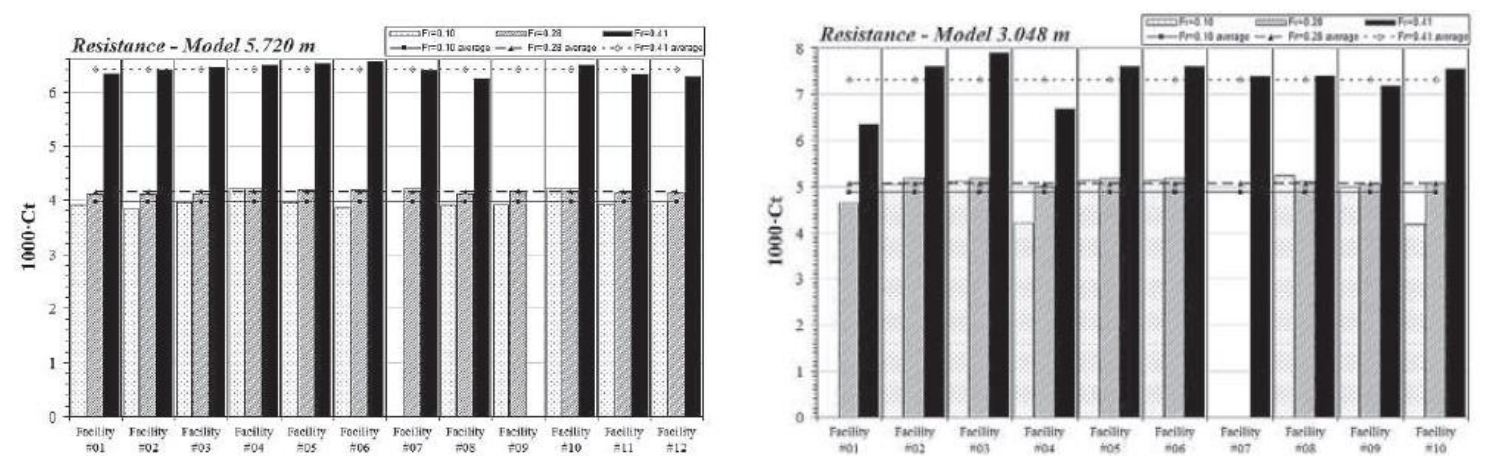

Figura 21 - Comparação entre os coeficientes de resistência total. Fonte: ITTC (2011b).

Cada instituição realizou uma bateria de testes em quatro datas distintas, contribuindo com as análises de incertezas, isto é, avaliaram-se as diferenças entre repetições de ensaios de cada laboratório. Durante cada dia de ensaio foram 
realizadas dez corridas para três números de Froude, em que as instituições utilizaram a sua técnica padrão de testes e corrigiram seus resultados levando em consideração efeitos de blocagem, onde necessário. A quantidade de dados submetidos para a ITTC está indicada na Tabela 3.

Tabela 3 - Quantidade de resultados enviados para a ITTC.

\begin{tabular}{c|c|c|c}
\hline $\begin{array}{c}\text { Modelo }- \\
L p p\end{array}$ & $\begin{array}{c}\mathrm{N}^{\circ} \text { laboratórios que } \\
\text { testaram o modelo }\end{array}$ & $\begin{array}{c}\mathrm{N}^{\circ} \text { laboratórios que } \\
\text { enviaram os resultados }\end{array}$ & $\begin{array}{c}\mathrm{N}^{\circ} \text { de resultados } \\
\text { válidos }\end{array}$ \\
\hline $5,72 \mathrm{~m}$ & 21 & 14 & 12 \\
\hline $3,05 \mathrm{~m}$ & 15 & 10 & 10
\end{tabular}

Os resultados válidos enviados pelos laboratórios foram compilados em gráficos para fins comparativos, conforme verificado na Figura 21. Como alguns gráficos não oferecem boa resolução vale esclarecer que as colunas pontilhadas representam os resultados para $F r=0,10$, as colunas hachuradas para $F r=0,28$ e as colunas sólidas $F r=0,41$, enquanto que as médias de cada item estudado são representadas pela linha contínua com quadrados para $F r=0,10$, linha tracejada com triângulos para $\mathrm{Fr}=0,28$ e linha pontilhada com diamantes para $\mathrm{Fr}=0,41$. Pode-se observar que nem todos os laboratórios realizaram os testes para os três números de Froude e que as variações do coeficiente de resistência total em torno da média são mais acentuadas para o modelo de 3,05 m de comprimento, sendo que as variações entre os resultados de alguns laboratórios são bastante significativas.
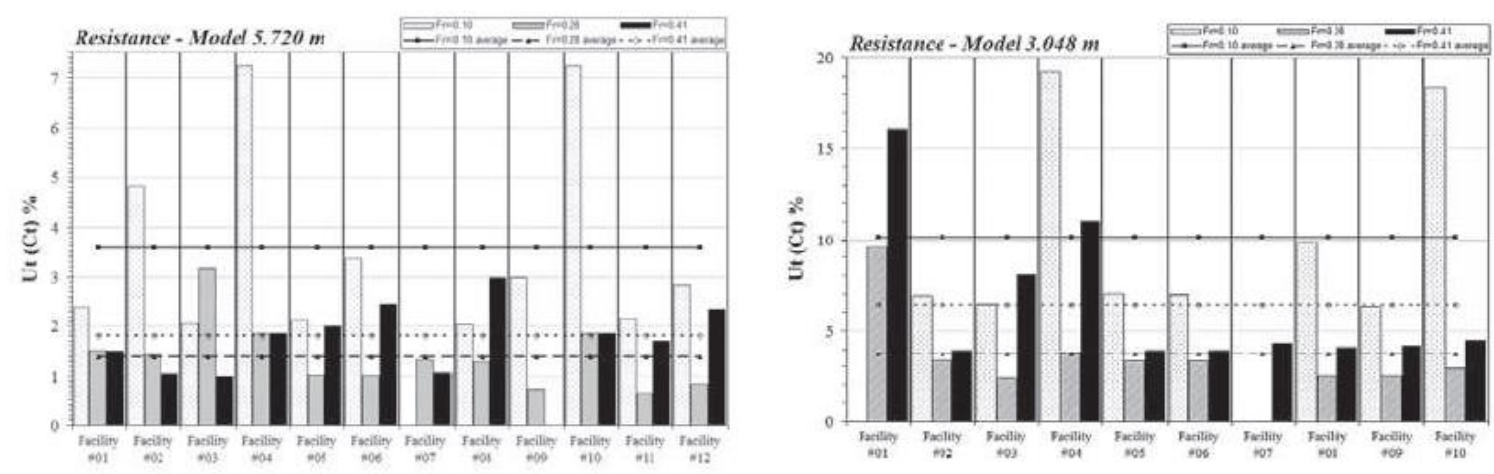

Figura 22 - Incerteza total do coeficiente de resistência. Fonte: ITTC (2011b).

Segundo a ITTC (2011b), as incertezas durante o ensaio de resistência ao avanço são geradas pelos erros sistemáticos $\left(B_{C T}\right)$ e os erros de precisão $\left(P_{C T}\right)$, sendo os primeiros decorrentes de certas características tais como a geometria do modelo, isto é, comprimento, forma, área molhada, a calibração dos pesos utilizados para lastrear o modelo, a medição de velocidade através de encoder, que está 
localizado no carro dinamométrico, a calibração da célula de carga e do sistema de aquisição de sinais, a medição de temperatura e consequentemente a definição da densidade e viscosidade da água do tanque de provas. Os erros de precisão estão relacionados com o desvio padrão das corridas realizadas, considerando as montagens e desmontagens do aparato experimental e as possíveis variações como, por exemplo, o alinhamento do casco em relação a seu avanço, o afundamento e o trim, para diferentes dias de ensaios.

Os valores das incertezas totais dos coeficientes de resistência total $\left(U_{C T}\right)$, expressos em porcentagem de $C_{T}$, estão apresentados na Figura 22, onde:

$$
\left(U_{C T}\right)^{2}=\left(B_{C T}\right)^{2}+\left(P_{C T}\right)^{2}
$$

Observa-se que as incertezas são maiores para os menores números de Froude, indicando a dificuldade de se realizar medições de resistência em baixas velocidades. As maiores médias das incertezas encontradas foram de 3,6\% e 10,1\% para o modelo de maior e menor escala, respectivamente, porém, há valores isolados que chegam a aproximadamente $19,0 \%$, no caso do modelo de menor comprimento.

Tabela 4 - Resultados dos ensaios do modelo DTMB5415 de $L_{P P}=3,05 \mathrm{~m}$.

\begin{tabular}{c|c|c}
\hline \multirow{2}{*}{ Ensaio } & Froude & $\begin{array}{c}\text { Resistência [N] } \\
\text { Valor médio }\end{array}$ \\
\hline \multirow{3}{*}{ Dia1 } & 0,1 & 0,99 \\
\cline { 2 - 3 } & 0,28 & 8,27 \\
\cline { 2 - 3 } & 0,41 & 25,62 \\
\hline \multirow{3}{*}{ Dia2 } & 0,1 & 1,03 \\
\cline { 2 - 3 } & 0,28 & 8,31 \\
\cline { 2 - 3 } Dia3 & 0,41 & 25,71 \\
\cline { 2 - 3 } & 0,1 & 1,01 \\
\cline { 2 - 3 } & 0,28 & 8,33 \\
\hline \multirow{3}{*}{ Dia4 } & 0,41 & 25,68 \\
\cline { 2 - 3 } & 0,1 & 1,02 \\
\cline { 2 - 3 } & 0,28 & 8,16 \\
\hline
\end{tabular}

De acordo com o apresentado, verifica-se que muitos dos laboratórios deveriam questionar se os resultados obtidos realmente estão dentro dos níveis considerados aceitáveis pelos mesmos. Maiores detalhes podem ser verificados em ITTC (2011b). 
Para fins comparativos entre resultados numéricos e experimentais serão utilizados os dados obtidos através dos ensaios realizados no tanque de provas do IPT, em que foi utilizada a escala de menor dimensão. A Tabela 4 apresenta os valores de resistência para cada valor de Froude, para os diferentes dias de ensaio. Os valores dos erros não constam na tabela, pois não foram divulgados. 


\section{A DINÂMICA DOS FLUIDOS COMPUTACIONAL}

A utilização de CFD na área naval e offshore geralmente está focada em problemas hidrodinâmicos. Na maioria dos problemas a serem resolvidos deseja-se calcular as componentes de pressões e velocidade globais do fluido ao redor do casco ou plataforma. Dessa forma, é possível determinar as forças e momentos que agem nesses corpos, sendo o regime permanente ou transiente.

Geralmente em simulações na área naval, adotam-se hipóteses usuais para o escoamento ao redor de embarcações, isto é, que o fluido seja incompressível, homogêneo e isotérmico. Também é possível adotar outras hipóteses considerando o comportamento do fluido, dependendo da natureza do problema e os efeitos de interesse. No caso do presente trabalho o interesse está no regime permanente e a única força de campo adotada será a gravitacional.

\subsection{EQUACIONAMENTO RANSE}

Através da análise numérica resolve-se uma ou mais equações diferenciais, substituindo as derivadas existentes por expressões algébricas que envolvem a função incógnita, isto é, quando não é possível aplicar a solução analítica opta-se por fazer uma aproximação numérica da equação diferencial, obtendo-se uma solução para um número discreto de pontos, com um determinado erro, esperando que quanto maior for este número de pontos mais perto da solução exata será a aproximação. Os principais métodos de discretização são de volumes finitos, elementos finitos e diferenças finitas.

O software adotado na pesquisa utiliza volumes finitos em que o domínio fluido é dividido em um número finito de volumes contíguos, nos quais as leis de conservação serão aplicadas. Uma das equações de conservação é a eq.(25) conhecida como equação da continuidade.

$$
\frac{d \rho}{d t}+\nabla \cdot(\rho \overrightarrow{\mathrm{u}})=0
$$

Para fluidos incompressíveis, como o caso em questão, e assumindo-se que o fluido é Newtoniano e que a densidade seja constante ao longo do escoamento, a equação da continuidade é apresentada por:

$$
\nabla \cdot \vec{u}=0
$$


A outra equação de conservação é a do momento linear:

$$
\rho \frac{\partial \vec{u}}{\partial t}+\rho(\vec{u} \cdot \nabla) \vec{u}=\mu \nabla^{2} \vec{u}+[\rho \vec{g}-\nabla \cdot p]
$$

Onde o vetor $\vec{u}$ é composto por $u_{x}, u_{y}$ e $u_{z}$.

A eq.(27) apresenta quatro termos gerais: derivada temporal, termo convectivo, termo difusivo e termo fonte. A derivada temporal leva em conta a parcela transiente do escoamento, o termo convectivo se refere ao transporte de propriedades através do campo de velocidade, o termo difusivo de refere aos movimentos inerentes aos fluidos em geral, já o termo fonte é a forçante do sistema.

As equações anteriores são suficientes para a descrição de escoamento incompressível e laminar. Sendo também uma descrição do continuo, elas são nãolineares e estão sujeitas às instabilidades. Isso faz com que as equações não possam ser resolvidas analiticamente exigindo métodos numéricos para resolver o escoamento.

Assume-se que as componentes do fluxo de velocidade e pressão consistem em um valor médio com flutuações sobrepostas. Essas flutuações são limitadas a permanecer dentro de um espectro de valores em termo de frequência e amplitude. Tal espectro de energia cinética de turbulência pode ser analisado utilizando ferramentas estatísticas, pelas quais uma variedade de formulações para a conservação da massa e momento pode ser obtida.
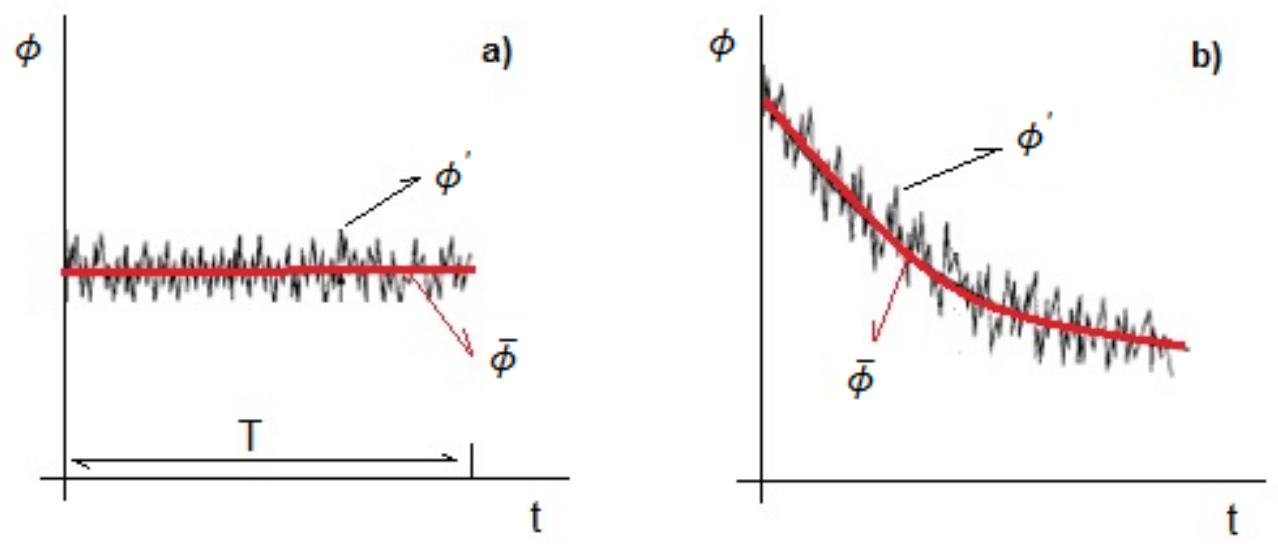

Figura 23 - Média e flutuação de uma grandeza física: a) regime permanente; b) transitório.

Dentre as análises realizadas no referido espectro a mais conhecida, e que será utilizada na presente pesquisa, é a média de Reynolds e forma a base para o RANSE (Reynolds-averaged Navier Stokes Equation). 
Seja $\phi$ uma grandeza física qualquer tal como velocidade, pressão e etc. Em condições de escoamento turbulento é possível escrever $\phi$ como uma parcela que leva em consideração flutuações e um valor médio da grandeza em análise, Figura 23:

$$
\phi=\bar{\phi}+\phi^{\prime}
$$

Por definição $\bar{\phi}(x)$ é a média temporal da grandeza avaliada, sendo calculada numa escala de tempo característica bastante maior que a das flutuações no escoamento, de forma que seu valor seja independente do tamanho do intervalo de tempo:

$$
\bar{\phi}=\frac{1}{\Delta t} \int_{t_{0}}^{t_{0}+\Delta t} \phi d t
$$

Por analogia tem-se:

$$
\begin{aligned}
& u=\bar{u}+u^{\prime} \\
& p=\bar{p}+p^{\prime}
\end{aligned}
$$

Por facilidade será adotada a notação indicial. Assim, temos que a equação da continuidade é dada por:

$$
\frac{\partial u_{j}}{\partial x_{j}}=0
$$

Substituindo-se a eq.(30) na eq.(32):

$$
\frac{\partial\left(\bar{u}_{j}+u_{j}^{\prime}\right)}{\partial x_{j}}=0
$$

Retirando-se a média temporal de ambos os lados da equação (33):

$$
\frac{1}{\Delta t} \int_{t_{0}}^{t_{0}+\Delta t} \frac{\partial\left(\bar{u}_{j}+u_{j}^{\prime}\right)}{\partial x_{j}} d t=\frac{1}{\Delta t} \int_{t_{0}}^{t_{0}+\Delta t} 0 d t
$$

Ou seja:

$$
\frac{\partial \overline{\left.\overline{u_{j}}+u_{j}^{\prime}\right)}}{\partial x_{j}}=0 \Rightarrow \frac{\partial \overline{\overline{u_{j}}}}{\partial x_{j}}+\frac{\partial \overline{u_{j}^{\prime}}}{\partial x_{j}}=0
$$

Porém, sabe-se que a média das médias é a própria média e que a média de uma oscilação é nula:

$$
\begin{aligned}
& \overline{\overline{u_{J}}}=\overline{u_{J}} \\
& \overline{u_{\jmath}^{\prime}}=0
\end{aligned}
$$

E dessa forma a equação da continuidade pode ser descrita: 


$$
\frac{\partial \overline{u_{j}}}{\partial x_{j}}=0
$$

A substituição da eq.(38) na eq.(33) resulta em:

$$
\frac{\partial u_{j}^{\prime}}{\partial x_{j}}=0
$$

Utilizando-se também notação indicial para a equação de Navier-Stokes, tem-se:

$$
\frac{\partial u_{i}}{\partial t}+u_{j} \frac{\partial u_{i}}{\partial x_{j}}=-\frac{1}{\rho} \frac{\partial p}{\partial x_{i}}+\vartheta \frac{\partial^{2} u_{i}}{\partial x_{j} \partial x_{j}}
$$

Através de manipulação matemática, acrescenta-se um termo à parcela convectiva:

$$
\begin{aligned}
\frac{\partial u_{i}}{\partial t}+u_{j} \frac{\partial u_{i}}{\partial x_{j}} & +u_{i} \frac{\partial u_{j}}{\partial x_{j}}=-\frac{1}{\rho} \frac{\partial p}{\partial x_{i}}+\vartheta \frac{\partial^{2} u_{i}}{\partial x_{j} \partial x_{j}} \Rightarrow \frac{\partial u_{i}}{\partial t}+\frac{\partial\left(u_{j} u_{i}\right)}{\partial x_{j}} \\
& =-\frac{1}{\rho} \frac{\partial p}{\partial x_{i}}+\vartheta \frac{\partial^{2} u_{i}}{\partial x_{j} \partial x_{j}}
\end{aligned}
$$

Substituindo-se $u_{i}=\bar{u}_{\imath}+u_{i}^{\prime}$ e $p=\bar{p}+p^{\prime}$ :

$$
\frac{\left.\partial \overline{\left(u_{l}\right.}+u_{i}^{\prime}\right)}{\partial t}+\frac{\left.\left.\partial\left[\overline{\left(u_{j}\right.}+u_{j}^{\prime}\right) \overline{\left(u_{l}\right.}+u_{i}^{\prime}\right)\right]}{\partial x_{j}}=-\frac{1}{\rho} \frac{\partial\left(\bar{p}+p^{\prime}\right)}{\partial x_{i}}+\vartheta \frac{\left.\partial^{2} \overline{\left(u_{l}\right.}+u_{i}^{\prime}\right)}{\partial x_{j} \partial x_{j}}
$$

E aplicando-se a média em ambos os lados da equação anterior:

$$
\frac{\partial \overline{\left.\overline{\left(u_{\imath}\right.}+u_{\imath}^{\prime}\right)}}{\partial t}+\frac{\partial\left[\overline{\left.\left.\overline{\left(u_{j}\right.}+u_{j}^{\prime}\right) \overline{\left(u_{\imath}\right.}+u_{\imath}^{\prime}\right)}\right]}{\partial x_{j}}=-\frac{1}{\rho} \frac{\partial \overline{\left(\bar{p}+p^{\prime}\right)}}{\partial x_{i}}+\vartheta \frac{\partial^{2} \overline{\left.\overline{\left(u_{\imath}\right.}+u_{\imath}^{\prime}\right)}}{\partial x_{j} \partial x_{j}}
$$

Analisando-se apenas o numerador do termo convectivo:

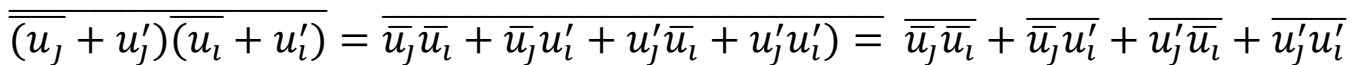

$$
\begin{aligned}
& =\bar{u}_{\jmath} \bar{u}_{\imath}+\bar{u}_{\jmath} \bar{u}_{l}^{\prime}+\bar{u}_{\jmath}^{\prime} \bar{u}_{\imath}+\bar{u}_{\jmath}^{\prime} \bar{u}_{l}^{\prime}
\end{aligned}
$$

Onde: $\overline{u_{l}^{\prime}}=\overline{u_{\jmath}^{\prime}}=0$ e $\overline{u_{\jmath}} \overline{u_{l}}=\overline{u_{\jmath} u_{l}}$.

Assim, a equação (43) pode ser dada por:

$$
\frac{\partial \overline{u_{l}}}{\partial t}+\frac{\partial\left(\overline{u_{j}} \bar{u}_{\imath}\right)}{\partial x_{j}}+\frac{\partial\left(\overline{u_{j}^{\prime}} \overline{u_{l}^{\prime}}\right)}{\partial x_{j}}=-\frac{1}{\rho} \frac{\partial \bar{p}}{\partial x_{i}}+\vartheta \frac{\partial^{2} \bar{u}_{\imath}}{\partial x_{j} \partial x_{j}}
$$

Que pode ser rearranjada na seguinte forma:

$$
\frac{\partial \bar{u}_{l}}{\partial t}+\frac{\partial\left(\bar{u}_{\jmath} \bar{u}_{\imath}\right)}{\partial x_{j}}=-\frac{1}{\rho} \frac{\partial \bar{p}}{\partial x_{i}}+\frac{\partial}{\partial x_{j}}\left(\vartheta \frac{\partial \bar{u}_{l}}{\partial x_{j}}-\left(\overline{u_{j}^{\prime} u_{\jmath}^{\prime}}\right)\right)
$$

Ou ainda:

$$
\frac{\partial \bar{u}_{l}}{\partial t}+\bar{u}_{\jmath} \frac{\partial\left(\bar{u}_{\imath}\right)}{\partial x_{j}}=-\frac{1}{\rho} \frac{\partial \bar{p}}{\partial x_{i}}+\frac{\partial}{\partial x_{j}}\left(\vartheta \frac{\partial \overline{u_{l}}}{\partial x_{j}}-\left(\overline{u_{\jmath}^{\prime} u_{\jmath}^{\prime}}\right)\right)
$$


As eqs.(46) e (47) são as equações de RANSE sendo a primeira na sua forma conservativa. O termo $\vartheta \frac{\partial \overline{u_{l}}}{\partial x_{j}}$ é a tensão viscosa enquanto que $\overline{u_{j}^{\prime} u_{j}^{\prime}}$ é chamado de tensor de Reynolds ou tensão turbulenta.

\subsection{TURBULÊNCIA}

A turbulência do escoamento é uma parte crucial na determinação de muitos parâmetros relevantes para a engenharia como, por exemplo, o arrasto, a separação da camada limite e a transição de regime laminar para turbulento. Após anos de estudos intensivos, teóricos e experimentais, chegou-se a conclusão de que não há um modelo universal para a turbulência. Nas últimas décadas surgiram uma grande variedade de modelos e a decisão de qual se utilizar não é uma escolha trivial. Como disse o professor Peter Bradshaw da Universidade de Huddersfield em seu estudo a respeito de turbulência: "A turbulência foi uma invenção do diabo no sétimo dia, enquanto Deus não estava observando". Dessa forma, deve-se escolher o modelo que seja mais adequado para o caso específico.

A turbulência é produzida por gradientes do escoamento médio. Quando o número de Reynolds do escoamento é alto e os gradientes de velocidade estão presentes, as forças viscosas não conseguem dissipar as perturbações do escoamento e estas se amplificam dando origem ao fenômeno da turbulência.

A turbulência apresenta vorticidades e se caracteriza por diversas escalas de comprimento. As maiores escalas são produzidas pelos gradientes do escoamento médio, isto é, grandes vórtices, que ao se estirarem geram vórtices menores no fenômeno da cascata de energia. Quando os vórtices se tornam suficientemente pequenos sua energia é dissipada pela viscosidade do escoamento.

As flutuações de escalas de comprimento e tempo são o que torna muito complicada a simulação direta do escoamento turbulento. Existem diversas formas de lidar com a turbulência, entre as quais os métodos Direct Numerial Simulaition (DNS), Large Eddy Simulation (LES) e RANSE, que foi apresentado anteriormente. Os primeiros capturam mais facetas do fenômeno a um elevado custo computacional, e o último utiliza modelos matemáticos, sendo o mesmo o mais aplicado em engenharia. 


\subsubsection{Modelos de turbulência}

Verifica-se que as equações resultantes do método RANSE não estão fechadas, isto é, o número de variáveis é superior ao número de equações, por conta dos tensores de Reynolds. O fechamento do problema requer algumas aproximações, o que em geral significa prescrever os valores destes termos. A estas aproximações se dá o nome de modelos de turbulência.

A maioria dos modelos de turbulência é baseada na hipótese de Boussinesq e podem ser divididos de acordo com o número de equações a serem resolvidas para realizar o fechamento da solução do escoamento:

- Modelo zero-equation ou modelo algébrico: expressa a viscosidade turbulenta em termos do fluxo médio e gradientes médios sem levar em consideração equações adicionais. Esse tipo de equação dificilmente é utilizado em analises hidrodinâmicas de navios.

- Modelo one-equation: utiliza uma equação adicional para a viscosidade turbulenta. Regularmente é verificada em análises de embarcações a utilização do modelo Menter e Spalart-Allmaras. Os dois modelos citados são complementados com uma correção para o fluxo dos turbilhões com o intuito de melhorar as estimativas de esteiras.

- Modelo two-equations: utiliza duas equações adicionais para a viscosidade turbulenta, sendo uma para a energia cinética $k$ e outra para a taxa de dissipação, tipicamente $\varepsilon$ ou $\omega$. Esse tipo de modelagem é o mais utilizado e se tem mostrado capaz de fornecer resultados precisos em aplicações navais.

Considerando-se um escoamento incompressível, a tensão viscosa é dada por:

$$
\sigma_{i j}=-p \delta_{i j}+\mu\left(\frac{\partial u_{i}}{\partial x_{j}}+\frac{\partial u_{j}}{\partial x_{i}}\right)
$$

Boussinesq realizou associações entre as tensões viscosas e turbulentas, chegando-se na seguinte expressão para a tensão turbulenta:

$$
-\rho \overline{u_{\jmath}^{\prime} u_{\jmath}^{\prime}}=-\rho \frac{2}{3} k \delta_{i j}+\mu_{t}\left(\frac{\partial \overline{u_{l}}}{\partial x_{j}}+\frac{\partial \overline{u_{j}}}{\partial x_{i}}\right)
$$

Onde: 
- $\mu_{t}$ é a viscosidade turbulenta, que não é uma propriedade do fluido, mas sim do escoamento.

- $k$ é a energia cinética da turbulência. Sendo $\vec{u}=u \overrightarrow{e_{x}}+v \overrightarrow{e_{y}}+w \overrightarrow{e_{z}}, k=\frac{\overline{u^{2}}+\overline{v^{2}}+\overline{w^{\prime 2}}}{2}$.

O modelo de Boussinesq, embora seja muito utilizado, apresenta inconsistências em sua concepção, pois as tensões turbulentas, que estão no nível do contínuo, foram associadas às tensões viscosas, que estão em um nível molecular, ou seja, a associação é uma aproximação e dessa forma os modelos numéricos não apresentarão resultados iguais ao modelo físico. As diferenças encontradas entre o resultado numérico e o experimental são oriundas do termo $-\rho \frac{2}{3} k \delta_{i j}$ da modelagem de Boussinesq.

\section{Modelo k- $\varepsilon$ de turbulência}

Ao multiplicar-se a equação de Navier-Stokes por $u_{i}^{\prime}$ e calcular a sua média é possível obter uma equação de transporte exata para $k$, a qual envolve um balanço entre produção da energia turbilhonar, $P_{k}$, e sua dissipação, $\varepsilon$. Esta equação é bastante complexa e acaba por ter pouca utilidade prática, de forma que foi realizada uma modelagem desta equação:

$$
\frac{\partial(\rho k)}{\partial t}+\frac{\partial\left(\rho U_{j} k\right)}{\partial x_{j}}=\frac{\partial}{\partial x_{j}}\left[\left(\mu+\frac{\mu_{t}}{\sigma_{k}}\right) \frac{\partial k}{\partial x_{j}}\right]+\rho P_{k}-\rho \varepsilon
$$

Onde $\sigma_{\mathrm{k}}$ é uma constante

$\mathrm{Na}$ eq.(50), observa-se que a taxa de variação temporal de $k$ é igual à difusão de $k$ acrescida sua produção e subtraída sua dissipação. As variáveis $P_{k}$ e $\varepsilon$ são definidas conforme as equações:

$$
\begin{gathered}
P_{k}=-\overline{u_{\imath}^{\prime} u_{\jmath}^{\prime}} \frac{\partial U_{j}}{\partial x_{j}} \\
\varepsilon=v \overline{\frac{\partial u_{\imath}^{\prime}}{\partial x_{\jmath}} \frac{\partial u_{l}^{\prime}}{\partial x_{\jmath}}}
\end{gathered}
$$

Como o modelo em questão é do tipo two-equation é necessário que mais uma equação de transporte seja utilizada, ou seja, uma equação para $\varepsilon$. Derivandose a equação de Navier-Stokes com respeito a $x_{k}$, multiplicando por $2 v \frac{\partial u_{i}^{\prime}}{\partial x_{k}} \mathrm{e}$ calculando a sua média é possível obter uma equação de transporte exata para $\varepsilon$, 
mas esta é de complexidade ainda maior que aquela que define o $k$, de forma que também foi definida uma equação modelada:

$$
\frac{\partial(\rho \varepsilon)}{\partial t}+\frac{\partial\left(\rho U_{j} \varepsilon\right)}{\partial x_{j}}=\frac{\partial}{\partial x_{j}}\left[\left(\mu+\frac{\mu_{t}}{\sigma_{\varepsilon}}\right) \frac{\partial \varepsilon}{\partial x_{j}}\right]+\rho C_{1} \frac{\varepsilon}{k} P_{k}-\rho C_{2} \frac{\varepsilon^{2}}{k}
$$

Onde $\sigma_{\varepsilon}, \mathrm{C}_{1}$ e $\mathrm{C}_{2}$ são constantes.

De forma análoga à equação do $k$, a eq.(53), é caracterizada por um termo de difusão, produção e dissipação do $\varepsilon$. A viscosidade turbilhonar é determinada por análise dimensional:

$$
\mu_{t}=\rho C_{\mu} \frac{k^{2}}{\varepsilon}
$$

Onde $\mathrm{C}_{\mu}$ é uma constante.

As duas equações modeladas de $k$ e $\varepsilon$, juntamente com equação da viscosidade turbilhonar definem o modelo de turbulência $k-\varepsilon$ standard. As cinco constantes apresentadas foram definidas experimentalmente para alguns ensaios específicos. Existe uma variação do modelo $k-\varepsilon$ standard, que considera uma equação um pouco diferente para $\varepsilon$ e usa uma equação dependente do escoamento médio para $\mu_{\mathrm{t}}$. Esta variação é o modelo $k-\varepsilon$ realizável, que é considerado mais preciso para a maioria das aplicações.

\section{Modelo k- $\omega$ de turbulência}

Outro modelo de turbulência comumente utilizado é o modelo $k$ - $\omega$ standard, que é definido por uma equação para a energia turbulenta, $k$, e outra para a taxa de dissipação específica, $\omega$, que se relaciona com a taxa de dissipação da seguinte forma:

$$
\omega=\frac{\varepsilon}{C_{\mu}{ }^{*} k}=\frac{\varepsilon}{\beta^{*} k}
$$

A equação modelada para $k$ é definida como:

$$
\frac{\partial(\rho k)}{\partial t}+\frac{\partial\left(\rho U_{j} k\right)}{\partial x_{j}}=\frac{\partial}{\partial x_{j}}\left[\left(\mu+\sigma^{*} \mu_{t}\right) \frac{\partial k}{\partial x_{j}}\right]+\rho P_{k}-\beta^{*} \rho \omega k
$$

Onde $\sigma^{*}$ e $\beta^{*}$ são constantes.

A equação modelada de $\omega$ é definida como:

$$
\frac{\partial(\rho \omega)}{\partial t}+\frac{\partial\left(\rho U_{j} \omega\right)}{\partial x_{j}}=\frac{\partial}{\partial x_{j}}\left[\left(\mu+\sigma \mu_{t}\right) \frac{\partial \omega}{\partial x_{j}}\right]+\rho \alpha \frac{\omega}{k} P_{k}-\beta \rho \omega^{2}
$$

Onde $\sigma$, a e $\beta$ são constantes. 
A produção de energia turbulenta, $P_{k}$, é definida da mesma forma que no modelo $k-\varepsilon$, e a viscosidade turbulenta $\mu_{t}$ pode ser definida por análise dimensional:

$$
\mu_{t}=\rho \frac{k}{\omega}
$$

Da mesma forma que no modelo $k-\varepsilon$, as cinco constantes do modelo $k-\omega$ foram obtidas experimentalmente.

Geralmente o modelo $k-\omega$ produz melhores resultados que $0 k-\varepsilon$ quando aplicados em escoamentos com gradientes de pressão adversos, pois o modelo $k-\omega$ tem um termo de difusão cruzada, que pode ser observado quando se faz a mudança de variável $\omega=\varepsilon /\left(\beta^{*} k\right)$ na equação de $\omega$. Na camada logarítmica, se o gradiente de pressão é nulo os dois modelos são equivalentes, porém se o gradiente é positivo, devido ao termo de difusão cruzada, $k$ varia consideravelmente com a distância da parede, efeito que o modelo $k-\omega$ considera. Em contrapartida, o modelo $k-\omega$ apresenta maior sensibilidade em relação aos valores usados nas condições de contorno na corrente livre do que o modelo $k-\varepsilon$, sendo esta sua principal desvantagem. Então, o modelo $k-\varepsilon$ é menos sensível aos valores em corrente livre, mas geralmente é inadequado em gradientes de pressão adversos.

Tendo em vista os méritos dos dois modelos citados foi desenvolvido o modelo $k$ - $\omega$ SST, no qual a equação de transporte de $\omega$ é reescrita de forma a garantir que a equação de $k-\varepsilon$ seja recuperada longe da parede, resultando em um modelo que tem comportamento de $k-\omega$ perto da parede e de $k-\varepsilon$ ao se afastar da mesma, reunindo as vantagens de ambos os modelos. Entretanto para que os benefícios sejam visíveis há a exigência de que a malha esteja refinada a ponto de discretizar a subcamada viscosa.

\subsection{TRATAMENTO DE PAREDE}

A condição imposta na parede, no caso a superfície do casco, está relacionada com a camada limite. Quanto mais próximo à superfície, maiores são os gradientes das variáveis do escoamento e dessa forma, uma maior concentração de volumes é requerido próximo à parede para resolver os gradientes. Além disso, quanto mais próximo ao casco, menores são as flutuações turbulentas e os efeitos de viscosidade se tornam importantes na região conhecida como sub-camada limite. Essa mudança na estrutura turbulenta mostra que os modelos de turbulência 
padrões não são válidos na parede e dessa forma um tratamento especial na parede é necessário, chamados funções de parede.

O adimensional conhecido como $y^{+}$deve ser utilizado como um guia para definir a configuração da malha e o correspondente modelo de turbulência. Além disso, está associado à escolha do melhor tratamento de parede, isto é, se será utilizada a lei de parede ou então a modelagem de proximidade da parede (near-wall modeling). A Figura 24 ilustra as zonas da região próxima à parede e os respectivos valores de $y^{+}$. De acordo com Salim e Cheah (2009) e Ariff, Salim e Cheah (2009), valores de $y^{+}$superiores a 30 são mais utilizados no caso de funções de parede enquanto que valores próximos de 1 o near-wall modeling é mais usual. Os autores realizaram em seu trabalho análises com e sem perturbações no escoamento, para três níveis de refino de malha, ou seja, para três valores de $y^{+}$, em que obtiveram o perfil de velocidades e o valor do coeficiente friccional para alguns modelos de turbulência, dentre eles o $k-\varepsilon$ e $k-\omega$. Salim e Cheah (2009) afirmaram que o modelo de turbulência $k-\varepsilon$ precisa ser correlacionado à região de parede através de uma função de parede, sendo a região de lei logarítmica a mais adequada, enquanto que o modelo $k-\omega$ não necessita de função de parede e nesse caso é necessário um elevado grau de refino, partindo-se para o tratamento near-wall modeling.

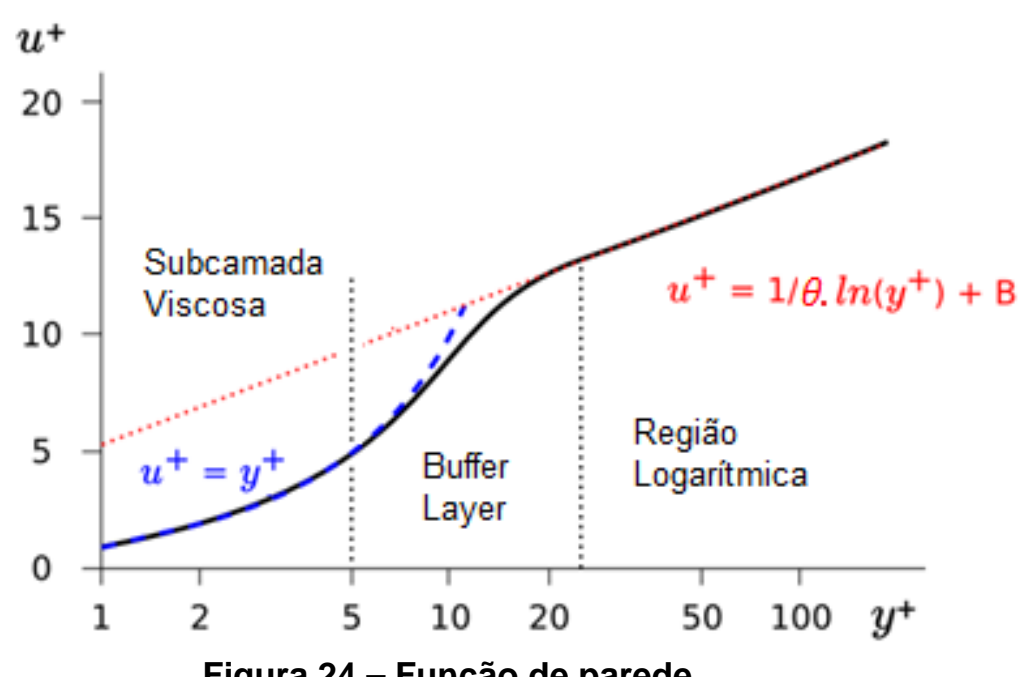

Figura 24 - Função de parede.

Nas avaliações dos perfis de velocidades verificaram que para ambas as condições do escoamento o perfil é praticamente invariável com o valor de $y^{+}$e 0 modelo de turbulência adotado. Porém, ao avaliarem a influência de $y^{+}$e dos modelos de turbulência no valor do coeficiente friccional, para a condição sem perturbação, observaram que a malha menos refinada oferece melhores resultados 
para o modelo de turbulência $k-\varepsilon$ e que o quadro se inverte quando a malha com maior refino é utilizada, isto é, $k-\omega$ foi mais adequado. Já para o caso de 0 escoamento com perturbações, o modelo $k-\varepsilon$ apresentou melhores resultados, independentemente do grau de refino da malha, indicando que é possível obter bons resultados sem apelar para simulações que caiam na região da subcamada limite, evitando-se a utilização de recursos e tempo computacionais desnecessários. Dado o exposto, pode-se dizer que a adoção de $y^{+}$maior que 30 e a utilização do modelo $k-\varepsilon$ nas análises realizadas no presente trabalho foram pertinentes.

A tensão encontrada na parede é a tensão viscosa dada por $\tau_{w}$. A medida que se distancia da superfície começam a surgir as tensões turbulentas, encontradas no RANSE. Adotando-se y como a distância normal à superfície e $U$ como a velocidade média paralela à parede, tem-se que:

$$
\tau_{w}=\left.\mu \frac{\partial U}{\partial y}\right|_{y=0} \text {, onde se assumiu que } \frac{\partial \tau}{\partial y} \cong 0 \text { e } y \ll \delta
$$

A velocidade friccional é definida por:

$$
u_{T}=\left(\frac{\tau_{w}}{\rho}\right)^{\frac{1}{2}} \Rightarrow \tau_{w}=u_{T}{ }^{2} \rho
$$

Igualando as eqs.(59) e (60) e integrando-se em seguida, obtém-se:

$$
u_{T}^{2} y=\vartheta U+C_{1}{ }^{\prime}
$$

Porém, ao aplicar a condição de $y=0, U$ será nulo, definindo-se a constante $C_{1}$, também nula. Dessa forma:

$$
\frac{U}{u_{T}}=\frac{u_{T} y}{\vartheta}
$$

Onde o lado esquerdo da eq.(62) é definido como a velocidade adimensional $u^{+}$e 0 lado direito, a distância adimensional até a parede, $y^{+}$.

No limite da subcamada viscosa $y^{+}$vale 5 , e nesse limite a tensão viscosa se deve tanto pela tensão na parede quanto pelo tensor de Reynolds. Assim, igualando-se as tensões:

$$
\tau_{R e}=\rho \overline{u_{1} u_{2}}=\tau_{w}=u_{T}^{2} \rho
$$

Sendo o tensor de Reynolds dado por:

$$
\tau_{R e}=\rho(\theta y)^{2}\left(\frac{\partial U}{\partial y}\right)^{2}
$$

Onde $\theta$ é a constante de Von Karman. Portanto, reescrevendo a eq.(63): 


$$
u_{T}=\theta y\left(\frac{\partial U}{\partial y}\right)
$$

Integrando-se a eq.(65), obtém-se:

$$
\frac{U}{u_{T}}=\frac{1}{\theta} \ln y+C_{2}{ }^{\prime}=u^{+}
$$

Ou ainda:

$$
u^{+}=\frac{1}{\theta} \ln \left(\frac{u_{T} y}{\vartheta}\right)+B=\frac{1}{\theta} \ln y^{+}+B
$$

Para a demonstração da formulação para a camada logarítmica assumiu-se a hipótese de que não houvesse transição entre a subcamada viscosa e a região logarítmica, ou seja, a buffer-layer, cujo intervalo de $y^{+}$é $5<y^{+}<30$, foi desconsiderada.

Se o escoamento próximo à parede é determinado por condições na parede, então se pode esperar que $u^{+}$seja uma função universal de $y^{+}$. Esse fato é observado na relação linear de $u^{+}$e $y^{+}$na sub-camada viscosa, e na relação logarítmica nas camadas adjacentes à sub-camada. O limite da validade de $y^{+}$ depende de fatores externos tais como o gradiente de pressão e, em algumas circunstancias, a faixa de validade pode ser afetada por influências locais.

\subsection{SOLUÇÃO NUMÉRICA}

Para tratar o modelo computacionalmente, é necessário expressar as equações e a região em que elas são válidas de forma adequada. Como não é possível obter soluções numéricas sobre um domínio continuo, devido aos infinitos pontos que o compõe, a região deve ser discretizada, ou seja, dividida em um número finito de pontos, nos quais as soluções serão obtidas. Para o conjunto de pontos dá-se o nome de malha. A distribuição adequada dos pontos no domínio é fundamental para se obter uma solução numérica representativa do escoamento.

Os termos que aparecem nas equações devem ser escritos em função dos valores das incógnitas em pontos discretos adjacentes, resultando em um conjunto de equações algébricas, que podem ou não estar acopladas. Nessa etapa introduzem-se as condições de contorno do problema, normalmente modificando-se apropriadamente as equações para pontos próximos às fronteiras. As condições de contorno juntamente com as condições iniciais, as propriedades físicas do fluido e os 
parâmetros do escoamento especificam o problema a ser tratado. Por fim, as equações algébricas são resolvidas, fornecendo a solução do problema.

A seguir serão apresentadas resumidamente as etapas de análise computacional, considerando-se uma ou duas dimensões por questões de praticidade. Para o caso de três dimensões o raciocínio é análogo, porém, utiliza-se um maior número de equações.

\subsubsection{Discretização espacial}

O tamanho, formato e distribuição espacial das células que compõe a malha definem a eficiência e precisão da solução do escoamento, sendo que um grande número de células pode ser mais preciso, porém requer maior recurso computacional.

De acordo com as características das malhas, elas assumem diferentes denominações. Caso os pontos que compõe a malha estejam igualmente espaçados, a malha é dita como uniforme, porém, domínios com geometrias complexas necessitam de malhas mais elaboradas e com espaçamento variável entre os pontos, isto é, uma malha não-uniforme.
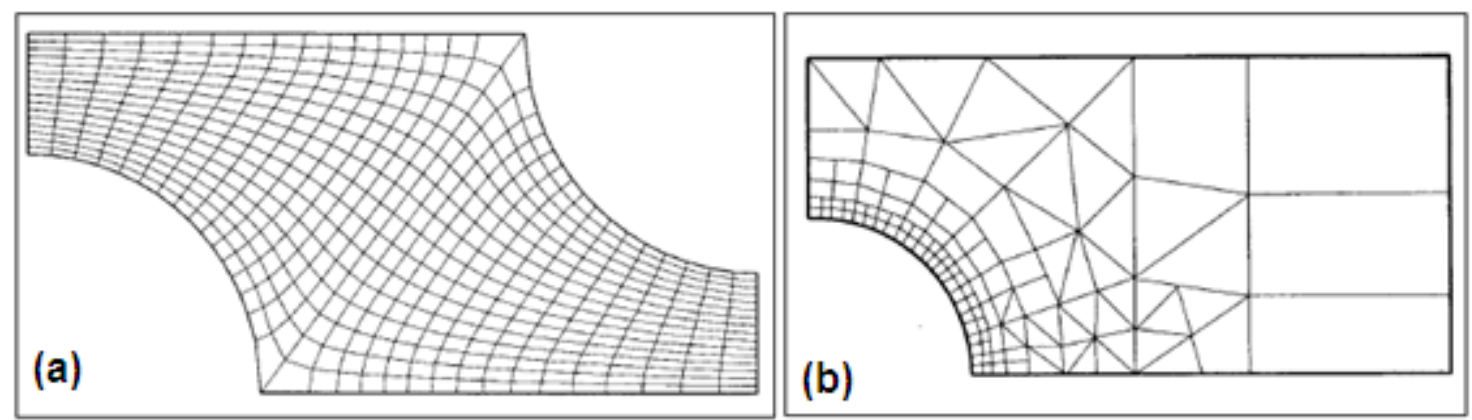

Figura 25 - a) Malha 2D estruturada e não-uniforme; b) Malha 2D não-estruturada e nãouniforme. Fonte: Ferziger et al. (2002).

As malhas ainda podem ser estruturadas, onde apresentam uma regularidade na distribuição espacial dos pontos, ou não-estruturadas em que há ausência dessa regularidade. Geralmente, quando se está interessado em análises de geometrias complexas é preferível a utilização de malha não-estruturada, pois essa classe de malha permite a discretização do domínio de forma mais direta se comparada às malhas estruturadas. Normalmente as malhas não-estruturadas são malhas nãouniformes. A Figura 25 ilustra alguns exemplos de malhas. 
Além da classificação das malhas há também a denominação para os tipos de células que as compõe. Tipicamente as células podem ser classificadas em tetraédricas, hexaédricas e poliédricas.

Existem diversos métodos de geração de malha, podendo-se mencionar o método cartesiano que simplesmente divide a região ao redor do objeto em estudo em células hexaédricas. Embora esse método seja simples e frequentemente utilizado como malha de fundo (background), ele possui muitas limitações na resolução da camada limite, sendo necessária a utilização de inflation layers na região próxima à superfície do corpo, fornecendo um processo mais apropriado e eficiente.

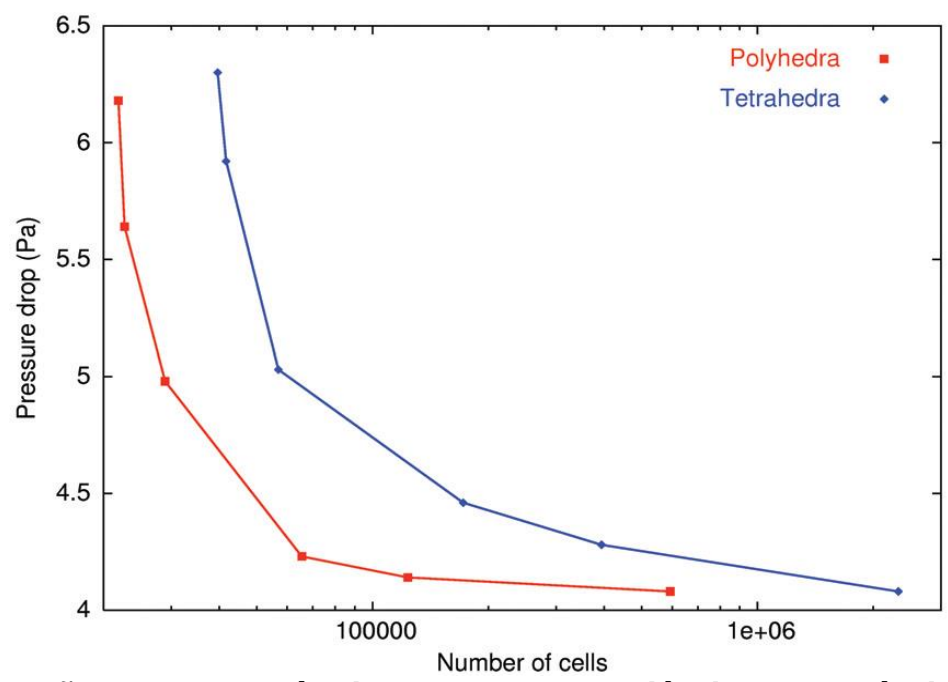

Figura 26 - Comparação de convergência entre malha poliédrica e tetraédrica. Fonte: Peric (2004).

Muitos métodos de malhas não-estruturadas utilizam células tetraédricas com inflation layers para resolver o escoamento na camada limite. Algumas técnicas tais como a subdivisão Octree e ponto de intersecção de Dalaunay são utilizadas para criar células tetraédricas que podem ser combinadas para fornecer células poliédricas que são mais eficientes, como mostra a Figura 26.

Os métodos de geração de malha também podem ser combinados utilizandose técnicas de malha não-conforme em que esquemas especiais, dentro do algoritmo de solução do escoamento, são utilizados para interpolar os parâmetros do escoamento de uma malha para a outra. Isso pode ser feito utilizando técnicas de sobreposição, conhecida como overset ou overlapping. Esses esquemas de interpolação de grande complexidade podem ser aplicados dinamicamente a movimentos transientes e malhas deslizantes para levar em conta movimentos 
relativos como, por exemplo, entre o casco de um navio e seu propulsor em uma simulação de ensaio de auto-propulsão.

Uma boa solução numérica para o escoamento depende de uma malha de pontos de boa qualidade, isto é, que seja refinada em regiões nas quais os gradientes das variáveis de interesse são elevados, por exemplo. Ao contrário do que possa parecer, o problema da geração da malha não é trivial, principalmente para análises em três dimensões, e a sua obtenção de forma adequada pode se tornar um problema mais complexo do que se calcular o escoamento do fluido.

\section{Aproximações por diferenças finitas}

É característico do método dos volumes finitos que os valores das variáveis sejam calculados nos centroides das células, de forma que é necessário realizar aproximações dos valores da grandeza de interesse nas faces das mesmas para então calcular as integrais de superfície, cuja solução é obtida através de equações diferenciais parciais (EDP). Por não serem lineares as EDP's não são capazes de serem resolvidas analiticamente, fazendo-se necessário a utilização de métodos computacionais.

Para que seja possível tratar numericamente as EDP's elas devem ser expressas na forma de operações aritméticas, as quais o computador possa executar. Essencialmente, os diferenciais das equações devem ser representados por expressões algébricas, ou seja, deve-se discretizar a EDP. Antes das equações serem resolvidas de forma numérica é necessário definir, para os termos que nela aparecem, as respectivas expressões em função dos pontos da malha. Tais expressões são denominadas de aproximações por diferenças finitas.

As EDP são aplicáveis de acordo com as características do fenômeno físico analisado, podendo ser divididas em duas categorias. A primeira delas trata do problema de valor de contorno (PVC) que é utilizado para os casos de equilíbrio, isto é, quando as propriedades de interesse não se alteram com 0 tempo. Matematicamente o PVC geralmente é representado por equações parciais elípticas e a solução é obtida especificando-se condições sobre a variável dependente na fronteira da região em que se quer resolver o problema. Já os problemas transientes, ou de propagação, envolvem a variação temporal das grandezas físicas de interesse. A partir dos valores iniciais dessas grandezas calculam-se, pela 
solução da EDP, seus novos valores em sucessivos intervalos de tempo, até que o instante final seja atingido.

Os fenômenos transientes são representados por equações diferenciais parabólicas ou hiperbólicas. Os fenômenos que apresentam mecanismos de dissipação de energia, ditos como dissipativos, são descritos por equações parabólicas, caso contrário, são representados por equações hiperbólicas. Diferentemente dos problemas de equilíbrio, os problemas transientes necessitam de valores para a variável dependente no instante de tempo inicial, além de condições de fronteira. Problemas desse tipo são denominados problemas de valor inicial (PVI).

As aproximações de diferenças finitas são comumente encontradas através da série de Taylor ou interpolação polinomial. Para fins de compreensão optou-se por utilizar apenas a série de Taylor:

$$
f(x)=f\left(x_{0}\right)+\left.(\Delta x) \frac{d f}{d x}\right|_{x_{0}}+\left.\frac{(\Delta x)^{2}}{2 !} \frac{d^{2} f}{d x^{2}}\right|_{x_{0}}+\left.\frac{(\Delta x)^{3}}{3 !} \frac{d^{3} f}{d x^{3}}\right|_{x_{0}}+\cdots+R_{N}
$$

Isolando-se a derivada de primeira ordem e utilizando um ponto genérico $x_{i}$, tem-se:

$$
\left.\frac{\partial f}{\partial x}\right|_{i}=\frac{f\left(x_{i}+\Delta x\right)-f\left(x_{i}\right)}{\Delta x}+\left[-\left.\frac{(\Delta x)}{2 !} \frac{\partial^{2} f}{\partial x^{2}}\right|_{i}-\left.\frac{(\Delta x)^{2}}{3 !} \frac{\partial^{3} f}{\partial x^{3}}\right|_{i}-\cdots\right]
$$

Em que o termo entre colchetes é chamado de erro local de truncamento (ELT), que fornece uma medida da diferença entre o valor exato da derivada e sua aproximação numérica, e está relacionado com a discretização:

$$
E L T=\left[-\left.\frac{(\Delta x)}{2 !} \frac{\partial^{2} f}{\partial x^{2}}\right|_{i}-\left.\frac{(\Delta x)^{2}}{3 !} \frac{\partial^{3} f}{\partial x^{3}}\right|_{i}-\cdots\right]
$$

A ordem do $\mathrm{ELT}, \mathrm{O}(\Delta x)$, é definida através do termo dominante, ou seja, pelo $(\Delta x)^{n}$ de menor expoente $n$, pois $\Delta x \ll 1$. Assim, pode-se dizer que caso $n$ seja unitário, o erro será de primeira ordem, o que significa que para uma redução de $\Delta x$ pela metade, o ELT será reduzido pela metade. Já para o caso de segunda ordem, a mesma redução de $\Delta x$ para $\Delta x / 2$ acarretará em uma redução de 1/4 no ELT. O termo $O(\Delta x)$, que será observado nas próximas equações, indica como o ELT varia com o refinamento da malha e não o valor do erro.

As aproximações das EDP's ainda podem ser divididas em progressiva, atrasada ou centrada. Através da simplificação da eq.(69) e alterando as notações de $f\left(x_{i}\right)$ para $f_{i}$ e $f\left(x_{i}+\Delta x\right)$ para $f_{i+1}$, tem-se que as diferenças progressivas, de ordem 1, podem ser representadas por: 


$$
\left.\frac{\partial f}{\partial x}\right|_{i}=\frac{f_{i+1}-f_{i}}{\Delta x}+O(\Delta x)
$$

Denomina-se a aproximação dada pela eq.(71) como progressiva, pois para a derivada no ponto $x_{i}$ foi utilizado um ponto adiante de $x_{i}$, no caso $x_{i+1}$. Analogamente, se na expansão da série de Taylor for utilizado $f\left(x_{i}-\Delta x\right)$ ao invés de $f\left(x_{i}+\Delta x\right)$, a aproximação por diferenças atrasadas será obtida:

$$
\left.\frac{\partial f}{\partial x}\right|_{i}=\frac{f_{i}-f_{i-1}}{\Delta x}+O(\Delta x)
$$

Manipulando-se convenientemente a série de Taylor para se obter uma aproximação de segunda ordem e utilizando os pontos $x_{i+1}$ e $x_{i-1}$ para o cálculo da primeira derivada da função $f$ no ponto central $x_{i}$, obtém-se a aproximação por diferenças centradas de ordem 2:

$$
\left.\frac{\partial f}{\partial x}\right|_{i}=\frac{f_{i+1}-f_{i-1}}{2 \Delta x}+O(\Delta x)^{2}
$$

Novamente através de manipulações da série de Taylor é possível obter uma aproximação para derivadas de segunda ordem que comumente é encontrada na literatura:

$$
\left.\frac{\partial^{2} f}{\partial x^{2}}\right|_{i}=\frac{f_{i+1}-2 f_{i}+f_{i-1}}{(\Delta x)^{2}}+O(\Delta x)^{2}
$$

\subsubsection{Discretização temporal}

A discretização temporal pode ser classificada em explícita, implícita e semiimplícita, sendo os dois primeiros de primeira ordem e o último de segunda ordem. A primeira calcula a variável de interesse num instante de tempo $n+1$ em função das características da variável no instante $n$. Tomando-se como exemplo a equação da difusão da temperatura:

$$
\left.\frac{\partial T}{\partial t}\right|_{i}=\left.\propto \frac{\partial^{2} T}{\partial x^{2}}\right|_{i}
$$

E aplicando as aproximações progressivas e as centradas de segunda ordem, centradas no instante de tempo $n$, é possível resolver a equação anterior, obtendo uma representação do método de Euler explícito:

$$
\frac{T_{i}^{n+1}+T_{i}^{n}}{\Delta t}=\alpha \frac{T_{i-1}^{n}-2 T_{i}^{n}+T_{i+1}^{n}}{(\Delta x)^{2}}+O\left[(\Delta t),(\Delta x)^{2}\right]
$$


O estêncil da discretização explicita pode ser observado na Figura 27 (a).

Embora as soluções explícitas sejam obtidas de maneira direta, elas são condicionalmente estáveis, ou seja, são instáveis e também sofrem um atraso na propagação das condições de fronteira com o avanço temporal ${ }^{1}$, como pode ser observado no estêncil. Esse é um efeito totalmente numérico e fisicamente incorreto. A marcha de tempo explicita é raramente utilizada na solução RANSE, sendo utilizado em LES e DNS na qual se resolve escalas de tempo de turbilhões que exigem um time-step muito pequeno.

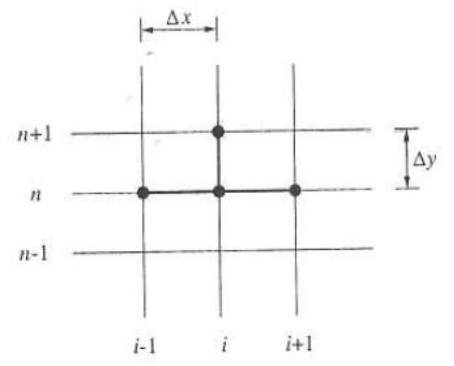

(a)

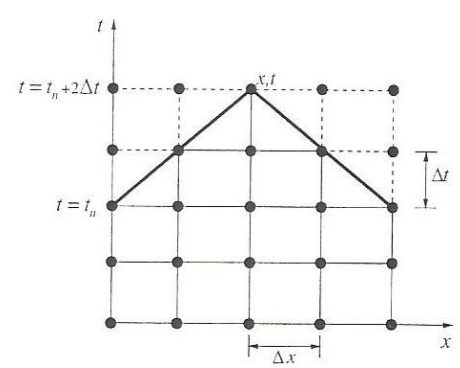

(b)

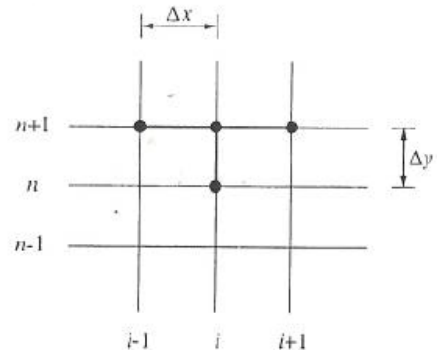

(c)

Figura 27 - a) Estêncil da aproximação explícita, b) Estêncil do atraso na propagação das condições iniciais e c) Estêncil da aproximação implícita. Fonte: Fortuna (2000).

A maioria dos códigos de CFD empregados na análise hidrodinâmica de embarcações utiliza a discretização implícita. Novamente utilizando como exemplo a equação de difusão, eq.(75), e aplicando as aproximações progressivas e centradas, porém agora no instante de tempo $n+1$, tem-se a discretização do método de Euler implícito:

$$
\frac{T_{i}^{n+1}+T_{i}^{n}}{\Delta t}=\alpha \frac{T_{i-1}^{n+1}-2 T_{i}^{n+1}+T_{i+1}^{n+1}}{(\Delta x)^{2}}+O\left[(\Delta t),(\Delta x)^{2}\right]
$$

Verifica-se que as equações geradas estarão acopladas, exigindo a solução de um sistema de equações a cada passo no tempo, mas a solução será incondicionalmente estável, ou seja, a solução será estável. O estêncil, Figura 27 (c), ilustra o mencionado a respeito da eq.(77). Por conta da estabilidade, a discretização implícita possibilita a utilização de um time-step maior em comparação com a discretização explicita, acelerando a solução numérica para escoamentos com grandes time-scale. A marcha de tempo implícita, entretanto, requer soluções de um sistema de equações não lineares que incorre em custo computacional.

Quando o fenômeno de interesse é transiente é aconselhável que se utilize métodos de segunda ordem, pois apresentará melhor precisão temporal. A 
discretização semi-implícita apresenta o método de segunda ordem e proporciona uma estabilidade incondicional e um sistema linear de solução eficiente. O método de Crank-Nicolson, utilizado nos casos de uma dimensão espacial, é um exemplo que apresenta as qualidades da discretização semi-implícita:

$$
\begin{aligned}
\frac{T_{i}^{n+1}-T_{i}^{n}}{\Delta t}= & \frac{\alpha}{2(\Delta x)^{2}}\left[\left(T_{i-1}^{n}-2 T_{i}^{n}+T_{i+1}^{n}\right)+\left(T_{i-1}^{n+1}-2 T_{i}^{n+1}+T_{i+1}^{n+1}\right)\right] \\
& +O\left[(\Delta t)^{2},(\Delta x)^{2}\right]
\end{aligned}
$$

\subsection{ACOPLAMENTO PRESSÃO-VELOCIDADE}

No processo de discretização, o sistema de equações pode ser concebido para ser resolvido de maneira segregada ou acoplada. A solução segregada consiste em resolver os sistemas lineares de cada equação um a um, atualizando seus coeficientes devido às não linearidades e ao acoplamento entre as variáveis. A solução acoplada, por sua vez, cria uma única matriz envolvendo todos os coeficientes e resolvendo todas as incógnitas simultaneamente, necessitando de atualizações da matriz de coeficientes apenas devido às não linearidades do problema.

Observando-se as equações de Navier-Stokes e da continuidade para escoamentos incompressíveis, nota-se que há o mesmo número de equações e incógnitas. A partir de um campo inicial de velocidade e pressão, obtém-se a evolução temporal da velocidade, mas não há um termo que exprima a evolução temporal da pressão. Além disso, como o escoamento é incompressível, a equação de estado, $p=\rho R($ Temp), não pode ser aplicada, visto que $\rho$ é constante, ou seja, a pressão não é uma grandeza termodinâmica.

A falta de uma equação dedicada para a pressão é a principal dificuldade encontrada na resolução das equações de Navier-Stokes aplicadas a escoamentos incompressíveis. Dessa forma, para se determinar o valor da pressão nos sucessivos instantes de tempo, pode-se utilizar a equação de Poisson, eq.(79), ou o método da compressibilidade artificial, porém, no presente trabalho será abordada a equação de Poisson que faz a ligação entre as equações de momento e continuidade.

$$
\frac{\partial^{2} p}{\partial x^{2}}+\frac{\partial^{2} p}{\partial y^{2}}=f(x, y)
$$


Os métodos que utilizam a solução segregada usam a equação de conservação da quantidade de movimento para calcular as componentes do vetor velocidade e transformam a equação de conservação da massa em uma equação que origina uma correção para o campo de pressões utilizado anteriormente. Este novo campo de pressões deve corrigir as velocidades de tal forma que a massa seja conservada. Assim, é necessário que a solução da equação de Poisson a cada passo seja realizada.

Um dos procedimentos pioneiros na utilização da metodologia de solução segregada foi apresentado por Chorin (1967; 1971), em que se obtém um campo de velocidades $V^{*}$ a partir da solução das equações de conservação da quantidade de movimento sem considerar os efeitos da pressão. A relação entre as componentes do vetor velocidade, $u$ e $v$, em uma situação bidimensional, e as componentes de $V^{*}$, $u^{*}$ e $v^{*}$, são dadas por:

$$
\begin{aligned}
& u=u^{*}-\frac{\Delta t}{\rho} \frac{\partial p}{\partial x} \\
& v=v^{*}-\frac{\Delta t}{\rho} \frac{\partial p}{\partial y}
\end{aligned}
$$

Onde a pressão deve ser calculada de forma que a equação de conservação da massa seja satisfeita. Chorin (1967) propôs o seguinte esquema iterativo para avançar a pressão de um nível iterativo i para o nível $i+1$ :

$$
p^{i+1}=p^{i}-\lambda D
$$

Em que $D$ é o erro da aproximação numérica da equação de conservação da massa e $\lambda$ é um coeficiente de relaxação. Assim, quando $D$ for igual a zero, a pressão estará convergida. $O$ procedimento iterativo deste método se resume a alguns passos:

1. Calcular $V^{*}$

2. Corrigir $u$ e $v$ com as equações (80) e (81);

3. Calcular $p$ com a equação (82);

4. Iterar entre os itens 2 e 3 até convergir a pressão e a velocidade;

5. Avançar a solução no tempo;

Patankar (1972), a partir das ideias de Chorin criou o método Semi Implicit Linked Equations (SIMPLE), de enorme repercussão na área de CFD. Neste, equações similares às eqs. (80) e (81), baseadas na conservação da quantidade de movimento, são substituídas na equação de conservação da massa para calcular uma correção para o campo de pressão. O ciclo iterativo contém os mesmos passos 
já descritos por Chorin. O método SIMPLE, por sua vez, originou uma série de outros métodos para o tratamento do acoplamento pressão-velocidade, tais como o SIMPLER e SIMPLEC.

Apesar de os métodos segregados terem demonstrado sua capacidade para resolver escoamentos complexos, em muitos casos obter a convergência é uma tarefa extremamente custosa. O fraco acoplamento entre pressão e velocidade proporcionado por esta classe de métodos exige a utilização de fatores de relaxação, como o da eq.(82), e uma análise criteriosa na escolha do passo de tempo a ser utilizado.

Sabe-se que os valores das incógnitas de velocidade e pressão são armazenados nos pontos da malha. Caso as incógnitas sejam definidas no mesmo ponto, a malha é denominada co-localizada. Para explorar algumas características da discretização da equação de Poisson para a pressão na malha co-localizada, a eq.(79) será discretizada a partir das equações de momento.

$$
\begin{aligned}
& \frac{\partial p}{\partial x}=-\rho\left[\frac{\partial u}{\partial t}+\frac{\partial\left(u^{2}\right)}{\partial x}+\frac{\partial(u v)}{\partial y}\right]+\mu\left(\frac{\partial^{2} u}{\partial x^{2}}+\frac{\partial^{2} u}{\partial y^{2}}\right) \\
& \frac{\partial p}{\partial y}=-\rho\left[\frac{\partial v}{\partial t}+\frac{\partial\left(v^{2}\right)}{\partial y}+\frac{\partial(u v)}{\partial x}\right]+\mu\left(\frac{\partial^{2} v}{\partial x^{2}}+\frac{\partial^{2} v}{\partial y^{2}}\right)
\end{aligned}
$$

Caso se realize uma aproximação de primeira ordem para esse gradiente de pressão, será necessário uma malha fina para se obter resultados com precisão satisfatória, o que requer elevado custo computacional e, portanto, não é interessante. Dessa forma, utilizando-se diferenças centrais de segunda ordem para o termo à esquerda das eqs.(83) e (84):

$$
\begin{aligned}
& \left.\frac{\partial p}{\partial x}\right|_{i, j}=\frac{p_{i+1, j}-p_{i-1, j}}{2 \Delta x}+O(\Delta x)^{2} \\
& \left.\frac{\partial p}{\partial y}\right|_{i, j}=\frac{p_{i, j+1}-p_{i, j-1}}{2 \Delta y}+O(\Delta y)^{2}
\end{aligned}
$$

Discretizando-se as eqs.(85) e (86) por diferenças centrais de segunda ordem:

$$
\frac{\partial}{\partial x}\left(\frac{p_{i+1, j}-p_{i-1, j}}{2 \Delta x}\right)=\frac{\frac{p_{i+2, j}-p_{i, j}}{2 \Delta x}-\frac{p_{i, j}-p_{i-2, j}}{2 \Delta x}}{2 \Delta x}=\frac{p_{i+2, j}-2 p_{i, j}+p_{i-2, j}}{4(\Delta x)^{2}}
$$




$$
\frac{\partial}{\partial y}\left(\frac{p_{i, j+1}-p_{i, j-1}}{2 \Delta y}\right)=\frac{\frac{p_{i, j+2}-p_{i, j}}{2 \Delta y}-\frac{p_{i, j}-p_{i, j-2}}{2 \Delta y}}{2 \Delta y}=\frac{p_{i, j+2}-2 p_{i, j}+p_{i, j-2}}{4(\Delta y)^{2}}
$$

Assim, a forma discreta da equação de Poisson para a discretização com diferenças centrais de segunda ordem pode ser escrita:

$$
\left(\frac{\partial^{2} p}{\partial x^{2}}\right)+\left(\frac{\partial^{2} p}{\partial y^{2}}\right)=\frac{p_{i+2, j}-2 p_{i, j}+p_{i-2, j}}{4(\Delta x)^{2}}+\frac{p_{i, j+2}-2 p_{i, j}+p_{i, j-2}}{4(\Delta y)^{2}}
$$

Observa-se que a eq.(89) utiliza pontos espaçados de $2 \Delta x$ e $2 \Delta y$. Isso origina quatro grupos de equações desacopladas entre si, conforme apresenta a Figura 28.

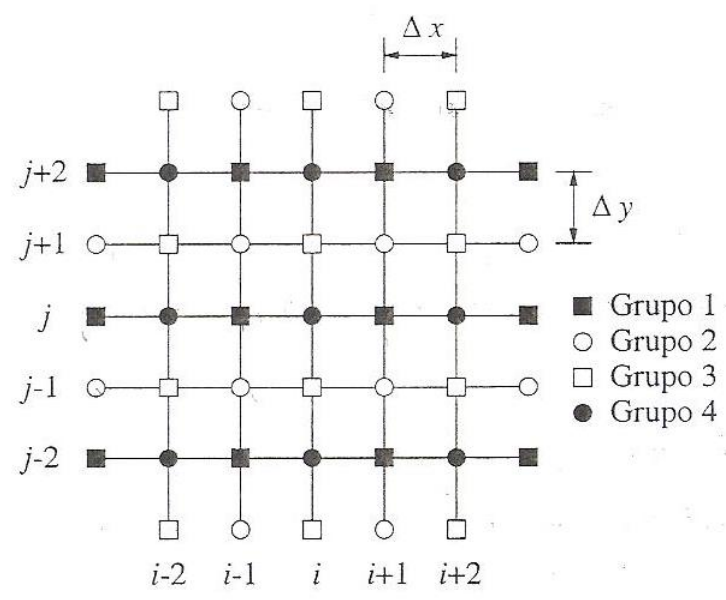

Figura 28 - Estêncil das equações desacopladas. Fonte: Fortuna (2000).

Cada um desses grupos pode, potencialmente, fornecer uma solução diferente para o campo de pressões, originando campos oscilatórios, como o apresentado na Figura 29, que são inaceitáveis.

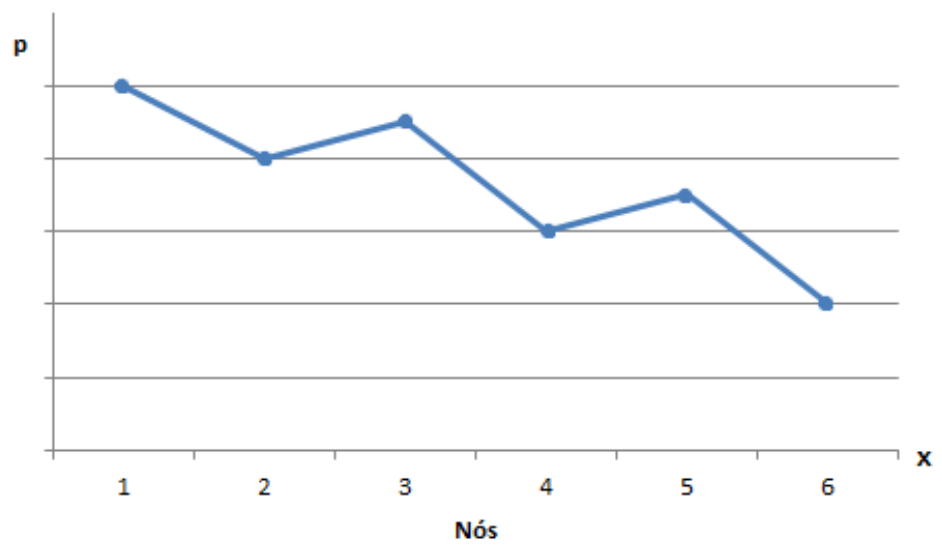

Figura 29 - Campo de pressão oscilatório.

Para resolver esta questão foi desenvolvido o arranjo desencontrado, também conhecido como malha deslocada, que utiliza diferentes nós para calcular as 
velocidades e pressões, possibilitando a utilização de discretizações de segunda ordem, eliminando o risco do problema do campo de pressão oscilatório. Existem diversas maneiras de se distribuir as incógnitas na malha deslocada, porém, em cálculos de escoamentos incompressíveis é padrão que a pressão seja definida no centro da célula e as velocidades nas faces laterais, assim como apresentado na Figura 30. Ao observar a figura infere-se que para células adjacentes à uma fronteira serão necessários pontos fora do domínio computacional para a adequada discretização dos termos convectivos. Na literatura podem ser encontradas técnicas que utilizam os pontos internos para obter valores dos pontos externos ao domínio computacional, porém, há métodos que não necessitam de pontos externos ao domínio.

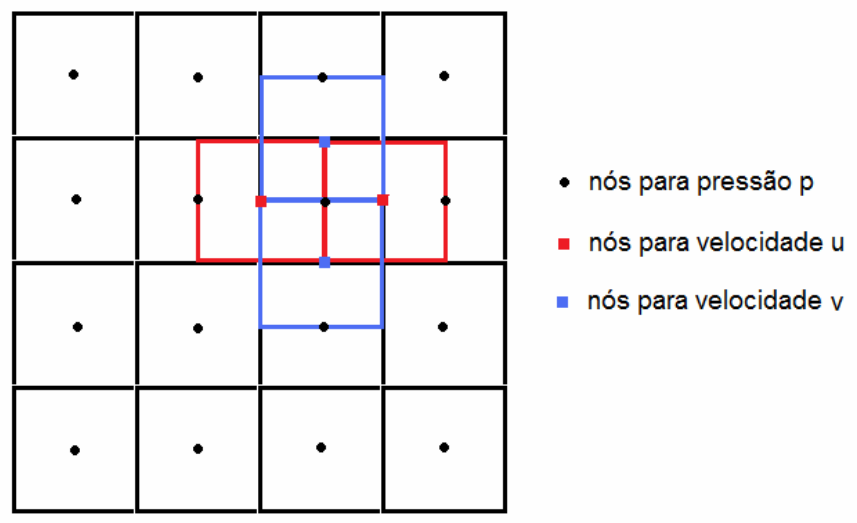

Figura 30 - Malha deslocada. Fonte: Saltara (2011).

Embora a malha deslocada seja uma solução para o campo oscilatório de pressão, a sua aplicação vem caindo em desuso devido à grande dificuldade de implementação quando se está trabalhando com malhas mais complexas, como as não-estruturadas tridimensionais. Outra maneira de contornar o problema da malha do campo oscilatório de pressão é a aplicação da interpolação de Rhie e Chow (1983).

Ao se integrar a equação de conservação da massa em um volume de controle, a avaliação das velocidades nas interfaces dos volumes passa a ser necessário, de forma a proceder ao balanço de massa. Conforme foi visto, no arranjo co-localizado as variáveis não estão presentes nessas interfaces. Então, neste caso, recomenda-se a realização de uma interpolação linear entre as equações de conservação da quantidade de movimento dos volumes vizinhos e assim criar uma pseudo-equação para as velocidades na interface, Maliska (2004). 
$\mathrm{Na}$ interpolação proposta por Rhie e Chow (1983), o gradiente de pressão médio nesta pseudo-equação deve ser substituído por um gradiente de pressão calculado localmente na interface, em função das pressões presentes nos centros dos volumes vizinhos. Isto, segundo os autores, evitaria o desacoplamento entre os campos de pressão e velocidade locais. Assim, a aplicação de Rhie e Chow, que originalmente foi concebido para resolver o problema do campo oscilatório de pressão, acabou sendo utilizado para acoplar pressão e velocidade, tornando o método de solução mais robusto.

\subsection{CONDIÇÕES AUXILIARES}

Outro ponto importante em análises via CFD é a determinação das condições auxiliares, que são fundamentais para a formulação de qualquer problema modelado por equações diferenciais. Nas fronteiras do domínio computacional são definidas condições de entrada e saída do domínio, condições em paredes sólidas e fronteiras de simetria se houver.

As condições de fronteira geralmente são do tipo Dirichlet na entrada ou na saída e de Neumann na fronteira de saída e sobre fronteiras sólidas. As primeiras definem os valores da grandeza nos pontos que definem a fronteira, enquanto que as segundas são obtidas a partir das equações de momento, projetadas na direção normal à fronteira. Assim, a especificação de condições Dirichlet para a pressão, por exemplo, em um dado trecho do domínio, implica que a pressão real do fluido nessa região seja conhecida. Porém, na maioria dos casos, a pressão não é conhecida e nesse caso devem-se utilizar apenas as condições de fronteira de Neumann. Além disso, não é aconselhável que as condições de Dirichlet sejam aplicadas simultaneamente nas fronteiras de entrada e saída do escoamento, pois pode gerar soluções fisicamente incorretas ou ocasionar divergências no método numérico.

Geralmente na região de entrada do domínio se conhece a velocidade média do fluido ou sua vazão, sendo que uma ou mais componentes da velocidade podem ser especificadas. As componentes não determinadas serão obtidas durante o cálculo do escoamento.

Uma das condições mais difíceis de ser tratada encontra-se na região de saída de fluido, pois a especificação inadequada nessa fronteira pode afetar todo o campo do escoamento. Caso o tratamento não seja apropriado, tanto o campo de 
velocidades como o de pressão pode ser incorretamente calculado. A menos que se conheça o valor das componentes da velocidade na região de saída do escoamento, a partir de dados experimentais ou considerações físicas, as velocidades nessa região devem ser determinadas pelo procedimento de cálculo.

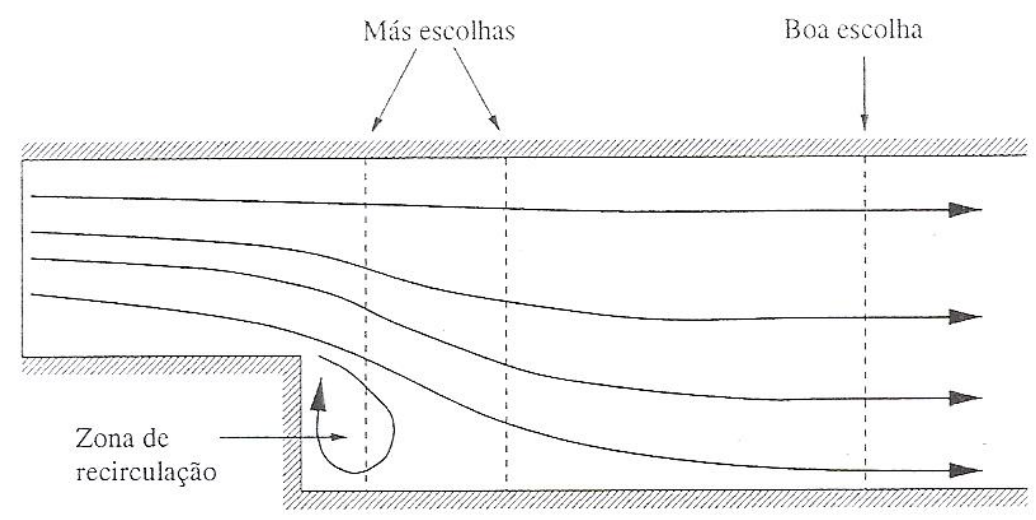

Figura 31 - Escolha da localização da fronteira de saída. Fonte: Fortuna (2000).

A fronteira de saída é imposta artificialmente ao problema, pois o domínio computacional é uma representação da realidade e, portanto, deve possuir dimensões finitas para que seja representado numericamente. A combinação da localização da fronteira de saída com a condição aplicada a essa região deve ser tal que o escoamento dentro do domínio seja independente da localização da fronteira de saída, isto é, ela deve ser posicionada em uma região na qual o escoamento apresente as suas propriedades com poucas variações. A Figura 31 exemplifica como definir a região de saída do fluido.

Muitas das fronteiras dentro de um escoamento são paredes sólidas. Quando há uma parede sólida em um escoamento viscoso, normalmente se define a velocidade tangencial do fluido em relação à parede como nula, isto é, vale o princípio da aderência completa e nesse caso, a fronteira é dita como nãoescorregadia $^{2}$. Além disso, a componente normal da velocidade do fluido também é nula, por conta das condições de impermeabilidade.

No caso de fronteiras de simetria, a velocidade normal à fronteira é nula, porém, a velocidade tangencial pode ser não nula, ditas como escorregadias ${ }^{3}$, podendo ser calculada pelo procedimento numérico de solução.

É importante observar que mesmo quando o domínio e as condições de fronteira são simétricos, o escoamento pode não apresentar simetria. Há muitos

\footnotetext{
${ }^{2}$ No Slip

${ }^{3}$ Free Slip
} 
casos na literatura que apresentam experimentos com geometrias e domínios simétricos, porém com escoamento assimétrico. Um típico exemplo é o caso de escoamento ao redor de cilindros em que, num determinado Reynolds, surgem desprendimentos de vórtices de forma alternada, gerando variações no campo de pressão à jusante, isto é, o escoamento à jusante do objeto se torna transiente, apresentando uma solução periódica no tempo. Um dos problemas práticos envolvendo escoamentos ao redor de cilindros é a análise de VIV em risers ou até mesmo de VIM em unidades flutuantes do tipo monocoluna.

$\mathrm{Em}$ análises que indicam a possibilidade de se utilizar fronteiras de simetria faz-se necessário o conhecimento das condições do escoamento antes de se impor tal condição, pois caso contrário os resultados serão incompatíveis com a dinâmica real.

\subsubsection{Modelagem de superfície livre}

As equações dominantes na modelagem da superfície livre são as equações de Navier-Stokes, sendo os efeitos de superfície livre considerados na forma de condições de contorno. As condições de superfície livre podem ser classificadas como cinemática ou dinâmica. A condição cinemática impõe que a partícula que se encontra na superfície livre esteja sempre aderida a mesma, enquanto que a condição dinâmica impõe que as tensões viscosas nos fluidos sejam constantes ao longo da interface. Tanto as componentes de velocidade normais quanto as tangenciais devem ser consideradas. Geralmente em aplicações de estudo hidrodinâmico de embarcações os efeitos de tensões superficiais podem ser desprezados, embora considerados em alguns casos.

Em problemas simples envolvendo a geração ou incidência de ondas, as equações de Navier-Stokes são suficientes para se obter o campo de velocidades da simulação, porém, modelagens adicionais são requeridas quando se foge à teoria linear de ondas como, por exemplo, durante o movimento de embarcações rombudas ou embarcações rápidas em que geralmente se observa ondas de alta declividade e eventuais quebras na região de popa. Esse é um problema complexo que envolve deformação da superfície livre, fluxo reverso, mistura de fluidos e dissipação de energia e que não foi objeto de estudo no presente trabalho. 
No caso de simulações com ondas incidentes, como quando se deseja estimar a resistência adicional em ondas, os modelos de ondas são necessários. A geração da onda é realizada através de condições de contorno apropriadas na região de entrada do escoamento. Do ponto de vista numérico a progressão das ondas sem as condições de amortecimento e a não reflexão na região de saída do domínio computacional são as principais questões a serem consideradas.

A modelagem da superfície livre pode ser categorizada em dois conceitos: Euleriano e Lagrangiano. O método Euleriano utiliza funções espaciais e temporais para definir o formato da superfície livre, além de realizar um ajuste de interface no qual a malha numérica é alinhada com o formato da superfície livre deformada através de uma função delineadora de interface definida como uma iso-surface. No método de Lagrange, que também é conhecido como método das partículas, geralmente as malhas computacionais não são utilizadas e a discretização do espaço é realizada utilizando-se um grande número de partículas distribuídas no domínio. Cada partícula se move de acordo com a velocidade local e o formato da superfície livre pode ser determinado pela distribuição das partículas. Em algumas aplicações, tal como análise de sea keeping, green water e sloshing, o método das partículas está se tornando cada vez mais frequente. As equações de quantidade de movimento são resolvidas de forma Lagrangeana, não sendo necessário malha computacional, que é uma grande vantagem sobre os métodos Eulerianos. Entretanto, condições de contorno em regiões sólidas necessitam de cuidado especial e muitas vezes são complexas de serem aplicadas no modelo Lagrangeano como, por exemplo, na resolução da camada limite.

Basicamente, há duas aproximações para a solução da superfície livre. O ajuste de interface oferece elevada precisão, pois as condições de superfície livre podem ser aplicadas de forma exata nos pontos de interface. Após a determinação do formato da superfície livre, a malha é deformada de tal maneira que um plano da mesma é alinhado com a superfície livre. Porém, alguns problemas podem ser observados quando a superfície livre sofre grandes deformações como, por exemplo, em casos de alta declividade de onda ou quebra da mesma.

A segunda aproximação é a de captura de interface, que pode ser utilizada quando a deformação da interface é grande, embora a acurácia das condições de contorno não seja tão boa quanto ao método de ajuste de interface. Outra vantagem do método de captura de interface, que é particularmente atrativa para malha não 
estruturada para geometrias complexas, é que não é necessário criar nova malha devido ao movimento da superfície livre. A captura de interface apresenta três funções para a definição da superfície livre: levelset-function, volume of fluid e função de densidade.

No método levelset-function uma iso-surface determina a posição da superfície livre, em que a equação convectiva é utilizada para rastrear a deformação da superfície. A função levelset é utilizada em todo o domínio, ou seja, na região fluida de ar e água. Além disso, a equação convectiva requerer que seja conhecida a velocidade de todo o domínio o que não é problema quando se trata de uma solução multi-fásica. Entretanto, se for utilizado uma aproximação monofásica na qual apenas a região da água é resolvida, a velocidade na região do ar deve ser extrapolada de forma adequada.

No método VOF, assim como na função densidade, utiliza-se a fração volumétrica da água em cada célula, onde o valor unitário indica que a célula está preenchida por água e o valor nulo corresponde ao preenchimento total com ar. Uma iso-superfície da função VOF de 0,5 define a superfície livre nesse caso. A equação convectiva da função VOF é resolvida para todo o domínio assim como na aproximação levelset. $\mathrm{Na}$ maioria das modelagens em CFD voltados para a área naval, utiliza-se o volume of fluid para descrever a superfície livre.

\subsection{SOLUÇÃO DOS SISTEMAS LINEARES}

Verifica-se que para o caso das discretizações de equações estacionárias e transientes, por meios de métodos implícitos ou semi-implícitos, visto o acoplamento existente, obtém-se um sistema de equações $A x=r$, em que na forma matricial $A$ seria a matriz de coeficientes e $r$ o vetor de constantes. Para a obtenção dos valores do vetor $x$, utilizam-se operações matemáticas através da inversa da matriz $A$, isto é, $x=A^{-1} r$. Embora a operação pareça simples a determinação de $A^{-1}$ não é trivial, por conta das inúmeras linhas da matriz, correspondente às equações obtidas para os pontos das malhas, podendo se tornar um problema computacional maior do que a obtenção da solução do sistema linear original. Dessa forma, procuram-se métodos de solução, que podem ser diretos ou iterativos e que não necessitem da inversão da matriz. 
Os métodos diretos transformam o sistema $A x=r$, eqs.(90), em outro equivalente, que é mais simples de ser resolvido e que apresenta as mesmas soluções do sistema original.

$$
\begin{aligned}
& a_{1,1} x_{1}+a_{1,2} x_{2}+a_{1,3} x_{3}=r_{1} \\
& a_{2,1} x_{1}+a_{2,2} x_{2}+a_{2,3} x_{3}=r_{2} \\
& a_{3,1} x_{1}+a_{3,2} x_{2}+a_{3,3} x_{3}=r_{3}
\end{aligned}
$$

O método direto mais comum é o da eliminação de Gauss, em que através de operações elementares transforma a matriz dos coeficientes em um sistema triangular superior, eqs.(91), facilmente resolvido por substituição reversa.

$$
\begin{gathered}
a_{1,1} x_{1}+a_{1,2} x_{2}+a_{1,3} x_{3}=r_{1} \\
a_{2,2}^{\prime} x_{2}+a_{2,3}^{\prime} x_{3}=r_{2}^{\prime} \\
a_{3,3}^{\prime \prime} x_{3}=r_{3}^{\prime \prime}
\end{gathered}
$$

Embora seja um método relativamente simples, ele não apresenta boa eficiência computacional, pois não aproveita a esparsidade da matriz de coeficientes para agilizar a determinação da solução, fazendo com que elementos nulos deixassem de sê-los, impossibilitando a sua desconsideração. Assim, métodos diretos de solução, geralmente, não são empregados em situações com grande número de incógnitas, optando-se nesses casos pelo método iterativos.

No método iterativo a solução do sistema $A x=r$ é obtida através de uma sequencia de correções aplicadas a uma aproximação inicial do vetor solução, $x^{(0)}=\left(x_{1}{ }^{(0)}, x_{2}{ }^{(0)}, \ldots x_{N}{ }^{(0)}\right)$. A partir do vetor inicial, gera-se uma sequencia de vetores que se satisfizer: $\lim _{k \rightarrow \infty} X^{(k)}=x$, diz-se que o método convergiu para a solução do sistema de equações, caso ela exista. Entretanto, como se trata de um número finito de iterações, o processo terminará quando um critério de parada for satisfeito. Tal critério indica se a solução obtida na k-ésima iteração é representativa, dentro de uma dada tolerância, da solução exata, a menos de erro de arredondamento do sistema linear. Adotando-se dois vetores consecutivos de $N$ elementos cada, $x^{(k)} \mathrm{e}$ $x^{(k-1)}$, e um valor de tolerância para a diferença entre as soluções, $€>0$, pode-se mencionar alguns critérios de parada frequentemente adotados como, por exemplo, a máxima diferença absoluta, o erro relativo e a soma das diferenças absolutas, apresentadas a seguir, respectivamente:

$$
D^{(k)}=\max _{1 \leq i \leq N}\left|x_{i}^{(k)}-x_{i}^{(k-1)}\right|
$$




$$
\begin{gathered}
E^{(k)}=\frac{D^{(k)}}{M^{(k)}}, \quad M^{(k)}=\max _{1 \leq i \leq N}\left|x_{i}^{(k)}\right| \\
S^{(k)}=\sum_{i=1}^{N}\left|x_{i}^{(k)}-x_{i}^{(k-1)}\right|
\end{gathered}
$$

O método iterativo é aplicado até que um dos critérios de parada mencionados seja satisfeito, ou seja, que dois vetores sucessivos façam com que as relações (92), (93) ou (94) sejam menores que $€$, cujo valor depende do problema estudado. Geralmente, os cálculos são repetidos até que a diferença entre dois resultados numéricos consecutivos de $€$ seja desprezível.

Em comparação com os métodos diretos, os iterativos são de implementação direta e podem ser utilizados quando o sistema de equações não for linear, além de não serem afetados de forma significativa por erros de arredondamento. Os métodos mais comuns para a solução numérica é o de Gauss-Seidel e o SOR. Escrevendose as equações do sistema (90) como:

$$
\begin{aligned}
& x_{1}=\frac{r_{1}-a_{1,2} x_{2}-a_{1,3} x_{3}}{a_{1,1}} \\
& x_{2}=\frac{r_{2}-a_{2,1} x_{1}-a_{2,3} x_{3}}{a_{2,2}} \\
& x_{3}=\frac{r_{3}-a_{3,1} x_{1}-a_{3,2} x_{2}}{a_{3,3}}
\end{aligned}
$$

É possível obter o método iterativo de Gauss-Seidel:

$$
\begin{gathered}
x_{1}^{(k+1)}=\frac{r_{1}-a_{1,2} x_{2}^{(k)}-a_{1,3} x_{3}^{(k)}}{a_{1,1}} \\
x_{2}^{(k+1)}=\frac{r_{2}-a_{2,1} x_{1}^{(k+1)}-a_{2,3} x_{3}^{(k)}}{a_{2,2}} \\
x_{3}^{(k+1)}=\frac{r_{3}-a_{3,1} x_{1}^{(k+1)}-a_{3,2} x_{2}^{(k+1)}}{a_{3,3}}
\end{gathered}
$$

Em que a incógnita $x_{i}^{(k+1)}$ é calculada a partir da $i$-ésima equação. Partindo-se do vetor inicial $x^{(0)}=\left(x_{1}{ }^{(0)}, x_{2}{ }^{(0)}, x_{3}{ }^{(0)}\right)$, as eqs.(96) fornecem os valores de $x^{(1)}=\left(x_{1}{ }^{(1)}, x_{2}{ }^{(1)}\right.$, $\left.x_{3}{ }^{(1)}\right)$, e assim o processo iterativo é repetido até que o critério de parada estabelecido seja satisfeito.

Conforme as iterações do método de Gauss-Seidel progridem, espera-se que a diferença entre as aproximações sucessivas $x_{i}^{(k+1)}$ e $x_{i}^{(k)}$ diminuam. Para que se obtenha uma boa solução numérica, muitas vezes se faz necessário um grande 
número de iterações até que a convergência seja atingida. Os métodos do tipo SOR fazem com que a aproximação $x_{i}^{(k+1)}$ se aproxime da solução numérica, através da sobre relaxação, ou seja, atinge-se a convergência com um menor número de iterações. A Figura 32 ilustra o mencionado.

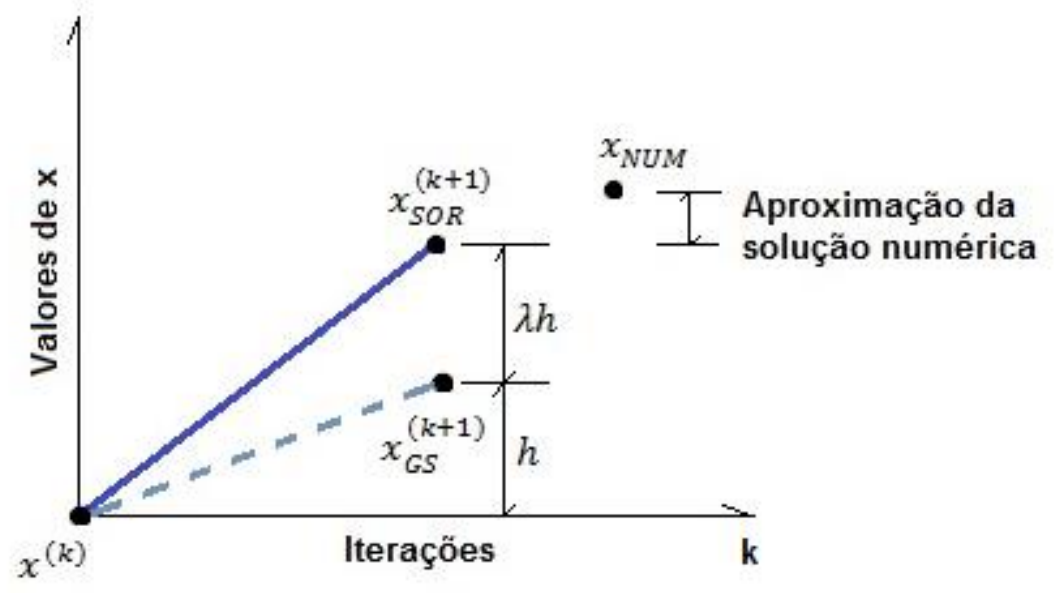

Figura 32 - llustração do método SOR

A desvantagem dos métodos iterativos é que, para alguns sistemas lineares, eles podem não convergir ou apresentar baixa taxa de convergência. 


\section{SIMULAÇÕES NUMÉRICAS}

\subsection{GENERALIDADES}

\subsubsection{Geometrias utilizadas nas simulações}

Antes de se iniciar as simulações em volumes finitos é necessário que a geometria a ser analisada, como o casco do modelo DTMB5415, seja geometricamente semelhante ao protótipo, para que não haja discrepâncias nos resultados. Embora pareça simples, a geração de uma geometria adequada é trabalhosa e exige certa habilidade com softwares de desenho (CAD). Dependendo da restrição do programa de CFD utilizado, a geometria deve ser um corpo sólido ou composto apenas por superfícies.

Foram definidos sistemas de coordenadas para ambas as geometrias utilizadas nas análises numéricas, sendo que a origem para o estudo de placa plana foi adotada no centro geométrico da menor face, enquanto que para o caso do casco a origem estava posicionada na quilha, conforme pode ser verificado na Figura 33

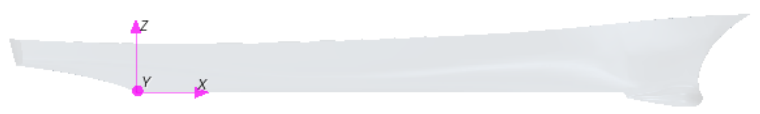

(a)

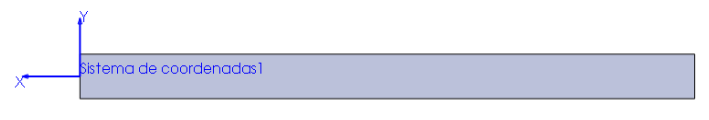

(b)

Figura 33 - Sistema de coordenadas adotado: a) Casco DTMB5415 e b) Placa plana

Para todos os casos o eixo $X$ é coincidente com o eixo longitudinal das geometrias, com sentido oposto ao escoamento. $O$ eixo $Y$ é paralelo à aresta referente à largura, no caso de placa plana, e para o bordo de bombordo, no caso do casco. $O$ eixo $Z$ foi estabelecido pela regra da mão direita.

\subsubsection{Definição do domínio computacional}

Em escoamentos externos é necessário limitar as dimensões do domínio computacional, tornando-o uma região fechada. A escolha dessas dimensões, no entanto, não é arbitrária, uma vez que nas fronteiras do domínio computacional são impostas condições de contorno que influem em toda a solução do escoamento. 
Assim, a escolha de um domínio computacional muito pequeno implica em condições de escoamento errôneas e, portanto, usualmente levam a um resultado ruim, Figura 31, ao passo que a escolha de um domínio computacional muito grande causa um aumento do tempo de processamento sem que haja melhoria significativa do resultado. A Tabela 5 apresenta os valores, em função do $L p p$, do domínio computacional de algumas publicações que realizaram análises com embarcações.

Tabela 5 - Dimensões de domínios computacionais em função do Lpp da embarcação, encontrados na literatura.

\begin{tabular}{c|c|c|c|c|c|c|c|c}
\hline Posição & $\begin{array}{c}\text { Péric } \\
\text { et al. } \\
(2010)\end{array}$ & $\begin{array}{c}\text { Péric } \\
(2010 a)\end{array}$ & $\begin{array}{c}\text { Péric } \\
(2010 b)\end{array}$ & $\begin{array}{c}\text { Ahmed. } \\
(2011)\end{array}$ & $\begin{array}{c}\text { Baos } \\
\text { et al. } \\
(2011)\end{array}$ & $\begin{array}{c}\text { Dávila } \\
\text { et al. } \\
(2011)\end{array}$ & $\begin{array}{c}\text { Salas } \\
\text { et al. } \\
(2011)\end{array}$ & $\begin{array}{c}\text { Bucan } \\
\text { et al. } \\
(2011)\end{array}$ \\
\hline Vante & 1,5 & 1,4 & 1 & 1,5 & 0,5 & 1 & 0,5 & 1 \\
\hline Ré & 2,5 & 1,6 & 1,5 & 2,5 & 1,5 & 2 & 2 & 2 \\
\hline Lateral & 2,5 & 1,75 & 1,5 & 1,5 & 1 & 1 & 1,5 & 1 \\
\hline Fundo & 2,5 & 1,75 & 1,25 & 1,2 & 1 & 2,5 & 1 & 1 \\
\hline Topo & 1,25 & 1,25 & 1 & 0,125 & 0,4 & 0,5 & 0 & 0,5
\end{tabular}

Os valores Lateral tem como referência a linha de centro enquanto que os valores Fundo e Topo têm como referência a linha da água.

Com base na Tabela 5, definiu-se parametricamente os valores para 0 domínio computacional que foi utilizado nas simulações do DTMB5415, Figura 34. Já no caso da placa plana foi realizada uma breve análise para a sua definição, cujo resultado final encontra-se na Figura 35.

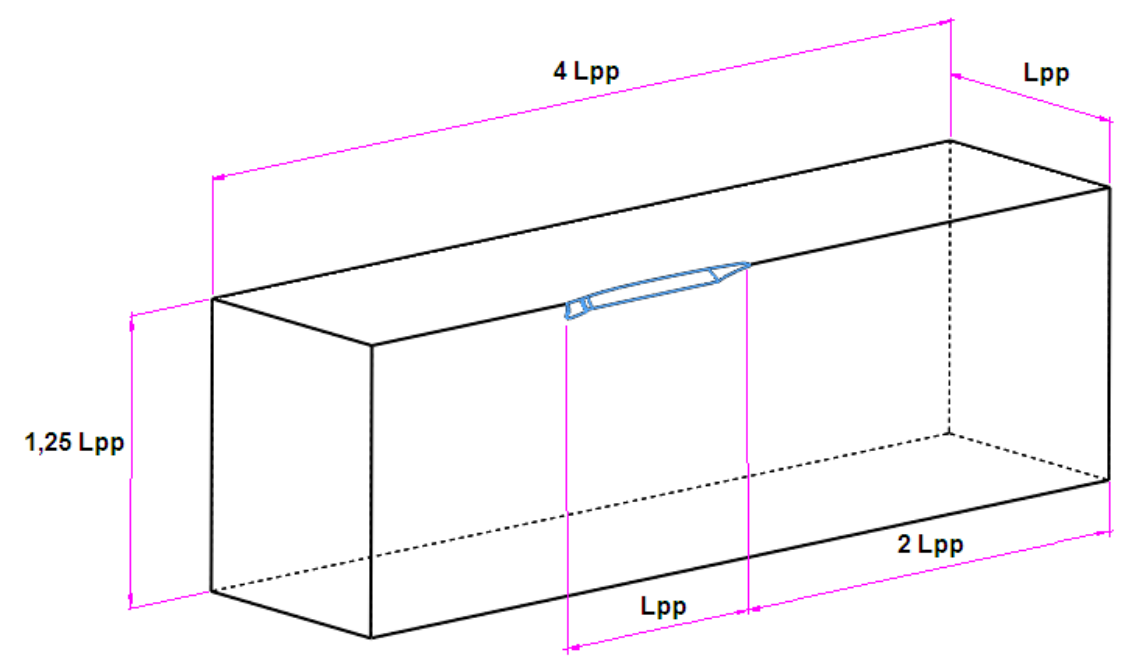

Figura 34 - Dimensões do domínio computacional nas simulações de casco: análise doublemodel. 
Vale mencionar que, nas simulações em que se considerou a superfície livre, foram utilizadas as mesmas dimensões do tanque de provas do IPT, isto é, largura e profundidade, enquanto que se mantiveram as mesmas dimensões expostas na Figura 34 para as regiões a vante e a ré do casco.

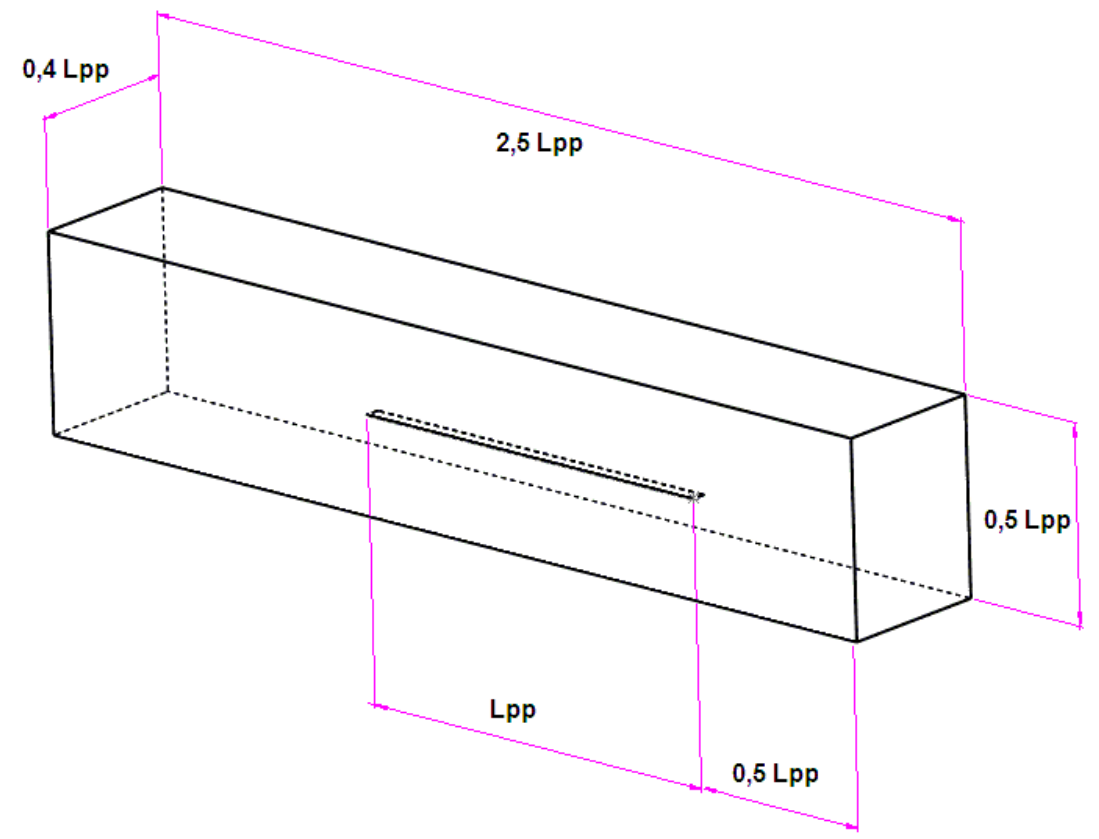

Figura 35 - Dimensões do domínio computacional nas simulações com placa plana.

\subsubsection{Malha numérica}

Todas as simulações foram realizadas através do software StarCCM+, que utiliza o método dos volumes finitos e a metodologia RANSE de solução. As malhas numéricas foram criadas pelo programa, que fornece ao usuário diferentes opções de geometria para os volumes de controle. O processo de geração da malha é ditado pela especificação do base size das células, sendo que todos os demais espaçamentos são definidos em relação ao último, assim, malhas mais refinadas podem ser criadas apenas com a alteração do tamanho base dos elementos. Além disso, é possível criar regiões com maior grau de refino como, por exemplo, locais em que há elevados gradientes da grandeza física analisada ou que necessitam de grande quantidade de elementos para que haja boa resolução do fenômeno, como quando se deseja avaliar a elevação da superfície livre (padrão de ondas) causada pelo avanço de uma embarcação. 
A decisão pelo tipo de malha depende de certos fatores como o nível de complexidade da geometria do corpo que foi submetido à análise. Nas simulações com placas planas optou-se pela malha hexaédrica, já que o formato do objeto é relativamente simples, enquanto que para as análises do casco, nas suas diferentes escalas, foi utilizado a malha poliédrica, Figura 36. A escolha da malha poliédrica à tetraédrica foi por conta da eficiência computacional, conforme apresentado anteriormente na Figura 26.

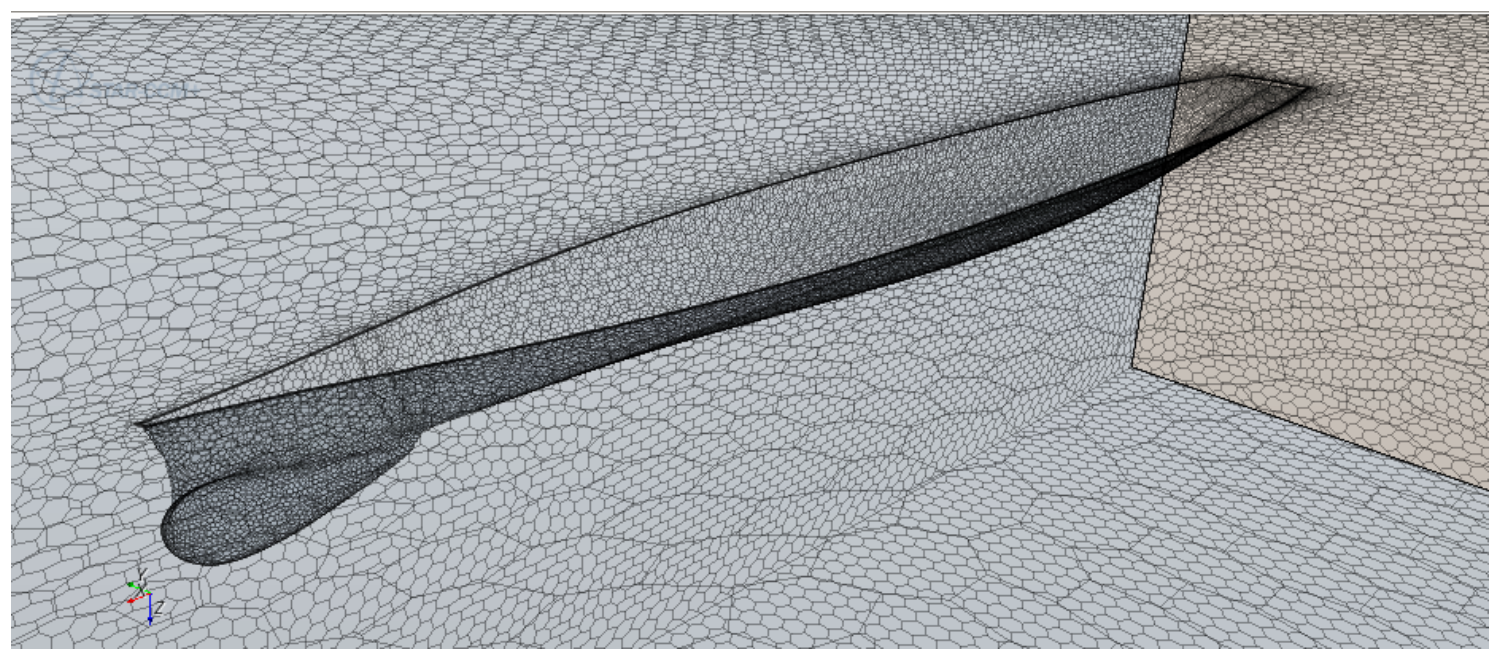

(a) Malha poliédrica

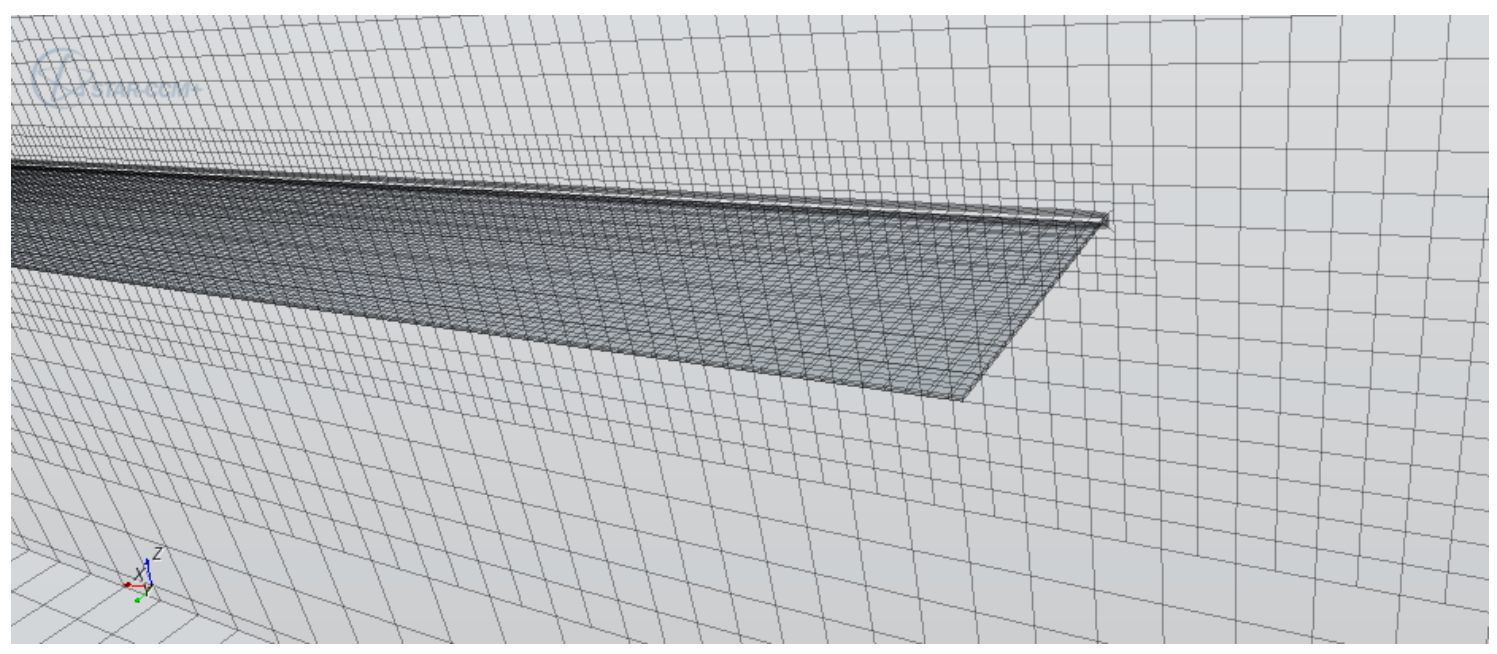

(b) Malha hexaédrica

Figura 36 - Tipos de malhas utilizadas nas: a) Simulações do modelo DTMB5415: doublemodel; b) Simulações de placa plana.

Outro fator que pode definir o tipo de malha a ser utilizado está atrelado à distribuição dos pontos na malha e, consequentemente, à estabilidade da solução numérica. Dessa forma, embora a malha poliédrica tenha sido utilizada nas simulações com o casco em double-model, nas simulações que consideraram a superfície livre foi adotada a malha hexaédrica, facilitando a utilização do VOF. A 
Figura 37 ilustra a malha utilizada nas simulações que consideraram a superfície livre. Nota-se que, na região correspondente à superfície livre, foram criados volumes de refino gradual e decrescentes desde a proximidade da superfície do casco até os limites do domínio computacional. A utilização da malha hexaédrica facilitou a discretização da superfície livre por permitir o refino anisotrópico, isto é, as células que compuseram a região da superfície livre apresentaram refinamento distinto nas três dimensões, sendo mais acentuado na direção da altura das ondas geradas. Isso permitiu com que o padrão de ondas fosse obtido com melhor precisão.

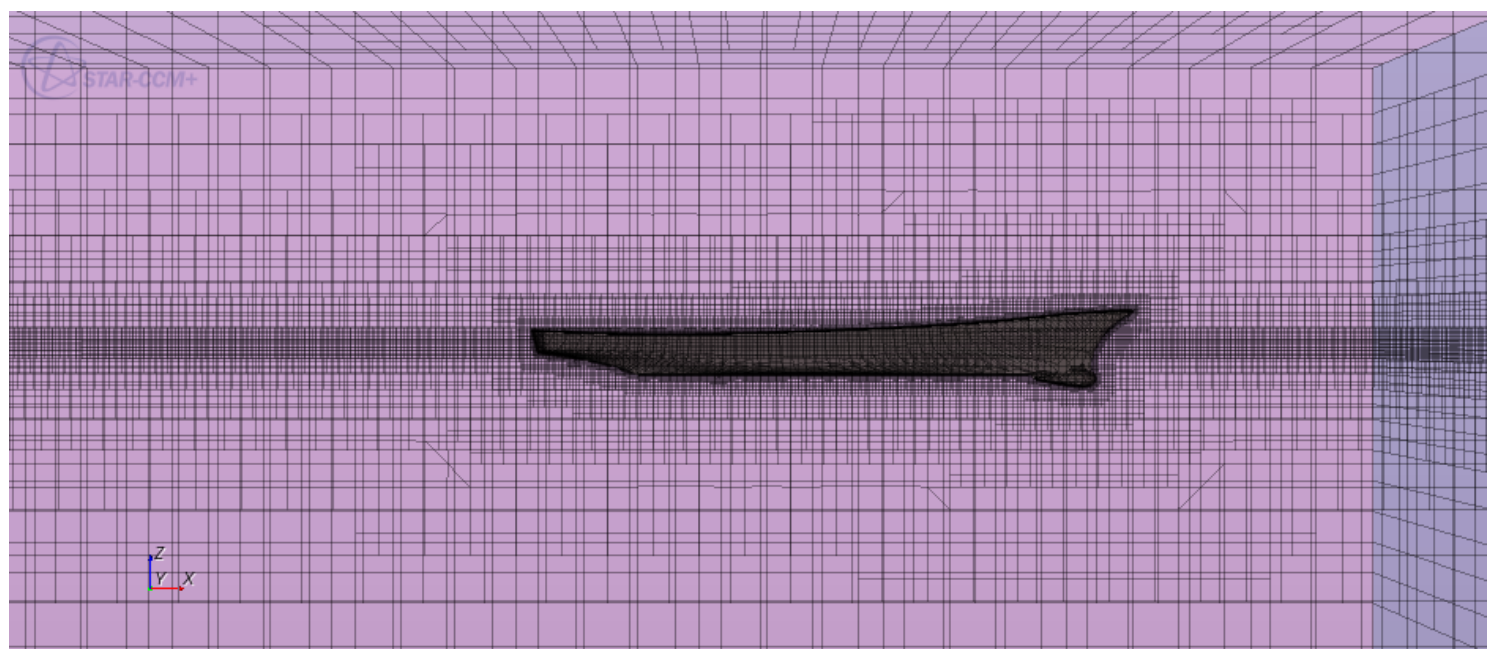

Figura 37 - Exemplo de malha utilizada nas simulações com superfície livre.

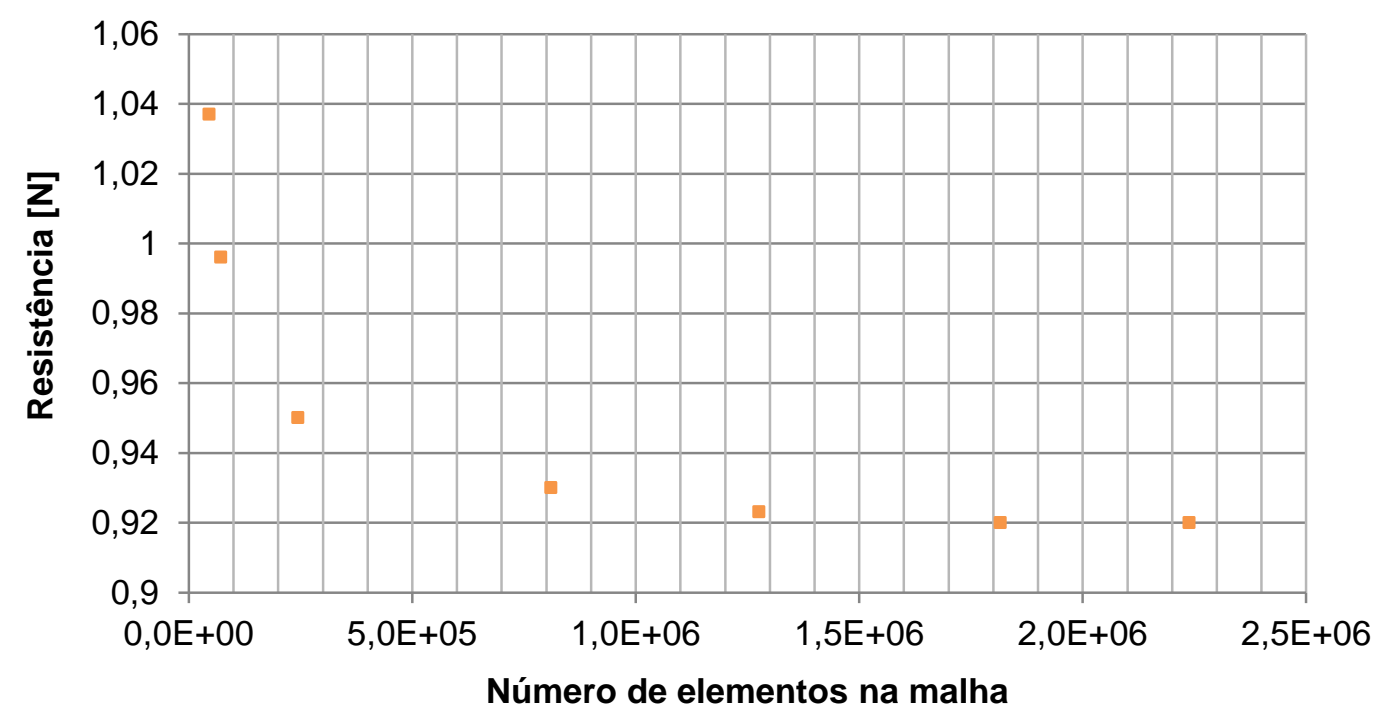

Figura 38 - Pontos da análise de convergência numérica para o caso do modelo DTMB5415 de $3,05 \mathrm{~m}$ de $L p p$ e velocidade de avanço de $0,55 \mathrm{~m} / \mathrm{s}$. 
O efeito da quantidade de elementos das malhas sobre os resultados também foi analisado, através do refino sistemático das malhas, ou seja, para todos os casos estudados foram realizadas análises de convergência numérica, em que se buscou soluções que fossem independentes da malha. A Figura 38 ilustra a convergência numérica para um dos casos analisados do modelo DTMB5415. Observa-se que praticamente já há convergência no valor de resistência total a partir de 1,8E+06 elementos. Assim, o valor de resistência obtido para o caso apresentado na Figura 38 é de $0,92 \mathrm{~N}$.

A quantidade de elementos utilizados nas simulações para os casos que consideraram a superfície livre pode ser verificada na Tabela 6, que também apresenta a quantidade de processadores e o tempo para se atingir a convergência da solução, considerando-se o critério de parada adotado. O servidor do laboratório utiliza o sistema operacional Microsoft Windows 2008 R2 Enterprise Edition de 64 bits cujo hardware é composto por processadores da Intel®, modelo Intel(R) Xeon E5410 de 2.33GHz (2 processadores com 4 núcleos de processamento cada) e possui 64 GB de memória RAM.

Tabela 6 - Quantidade de elementos e tempo para a solução no caso das simulações com superfície livre - análises com simetria.

\begin{tabular}{c|c|c|c|c}
\hline Condição & Froude & $\begin{array}{c}\text { Número de } \\
\text { Elementos na Malha }\end{array}$ & $\begin{array}{c}\text { Tempo do } \\
\text { Solver [horas] }\end{array}$ & $\begin{array}{c}\text { Número de } \\
\text { Processadores }\end{array}$ \\
\hline $\begin{array}{c}\text { Superfície Livre: } \\
\text { Afundamento e } \\
\text { Trim }\end{array}$ & 0,28 & 827876 & 91,4 & $2 / 3$ \\
\hline $\begin{array}{c}\text { Superfície Livre: } \\
\text { Afundamento e } \\
\text { Trim }\end{array}$ & 0,41 & 841204 & 149,7 & 2 \\
\hline Superfície Livre & 0,1 & 1816040 & 107,4 & 2 \\
\hline Superfície Livre & 0,28 & 821523 & 116,8 & 2 \\
\hline Superfície Livre & 0,41 & 821523 & 140,5 & 2
\end{tabular}

\subsubsection{Condições auxiliares}

No caso das simulações que não consideraram a superfície livre, isto é, para o modelo DTMB5415 em double-model e para a placa plana, as condições impostas 
nas fronteiras do domínio computacional foram a de velocidade constante na região de entrada, pressão atmosférica na região de saída e impermeabilidade nas paredes do domínio, sem considerar a rugosidade, ou seja, aplicou-se a condição de free-slip. A condição adotada para a superfície do casco e da placa plana também foi a de impermeabilidade, porém, considerando a rugosidade, ou seja, aplicou-se a condição de no-slip.

Embora o regime transiente tenha sido utilizado nas simulações, buscam-se os resultados do regime permanente, que é a situação alcançada nos ensaios de resistência ao avanço, após certo intervalo de tempo. Segundo Pimenta (2011), os resultados encontrados nas análises de fenômenos que ocorrem em regime permanente também serão atingidos ao final das simulações transientes, porém, as simulações em regime permanente estão mais suscetíveis às instabilidades numéricas, que podem trazer dificuldades para a aquisição dos resultados.

Quando se adota o regime transiente é importante que haja conhecimento prévio das características gerais do escoamento, para que seja avaliada a aplicação da condição de simetria. Nos casos estudados no presente trabalho a adoção da condição de simetria foi adequada.

A placa plana apresenta geometria esbelta, que pouco altera o fluxo incidente, exceto pela região de montante, em que a espessura influi no escoamento, mesmo que minimamente, Figura 39 (a). Entretanto, não há como desconsiderar a espessura nas simulações, visto que uma das restrições do software é que se trabalhe com três dimensões e, além disso, a partir de certo ponto a redução da espessura afeta a qualidade das células ou faz com que haja mais elementos desnecessariamente. Por conta da baixa espessura das placas, assumiu-se que não haveria parcelas de resistência relativas à forma e consequentemente as linhas de fluxo contornariam a placa de maneira simétrica, sem a presença de fenômenos transientes, Figura 40 (a).

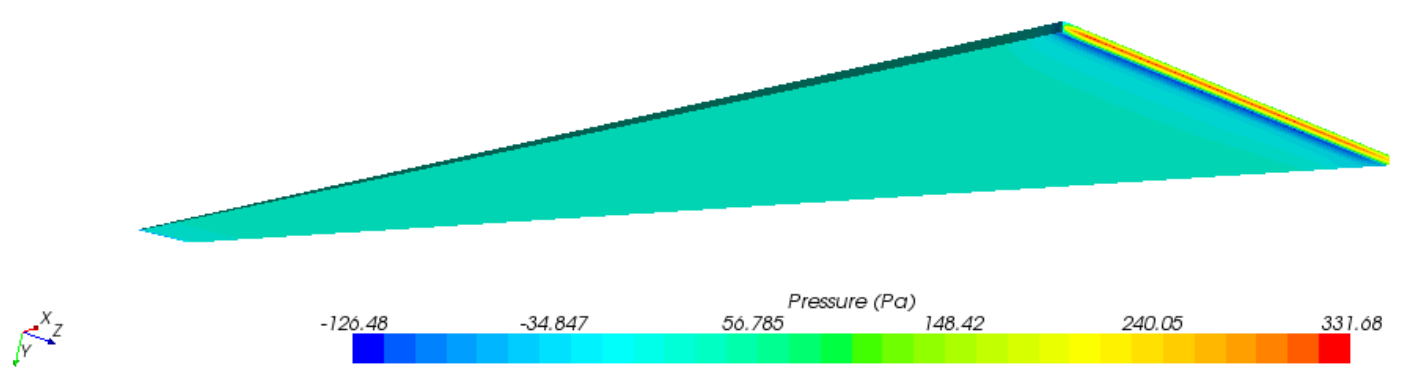

(a) Distribuição de pressão na placa plana na região de montante 


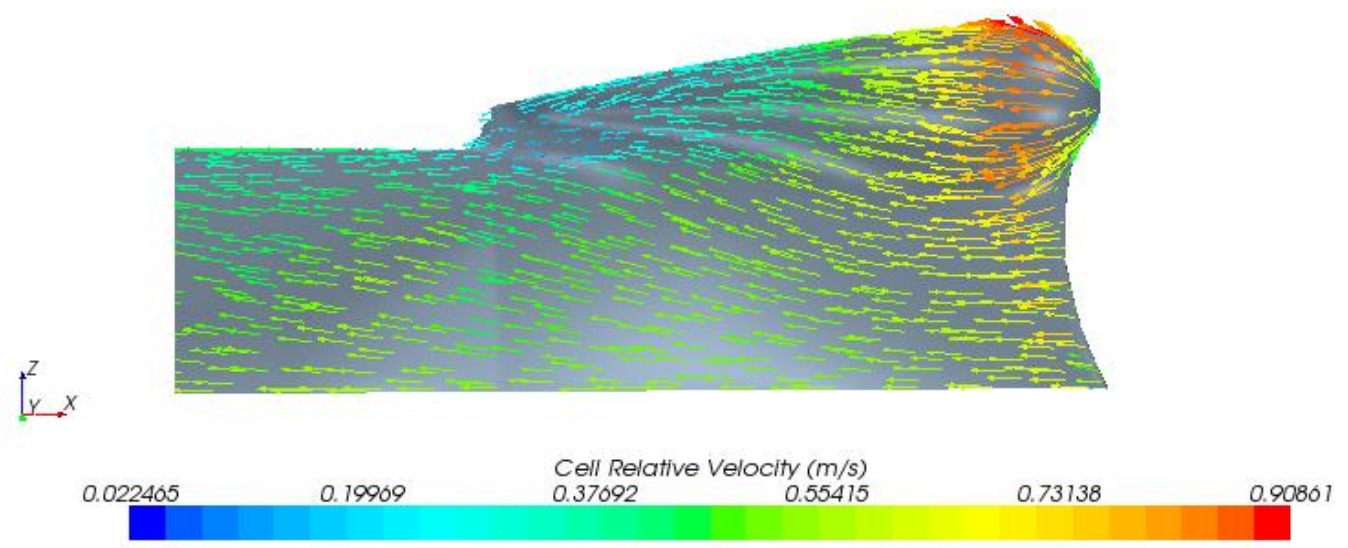

(b) Vetores velocidade na região de proa do modelo DTMB5415

Figura 39 - Distribuição de pressão e velocidade do escoamento à montante: a) Placa plana; b) Casco DTMB5415.

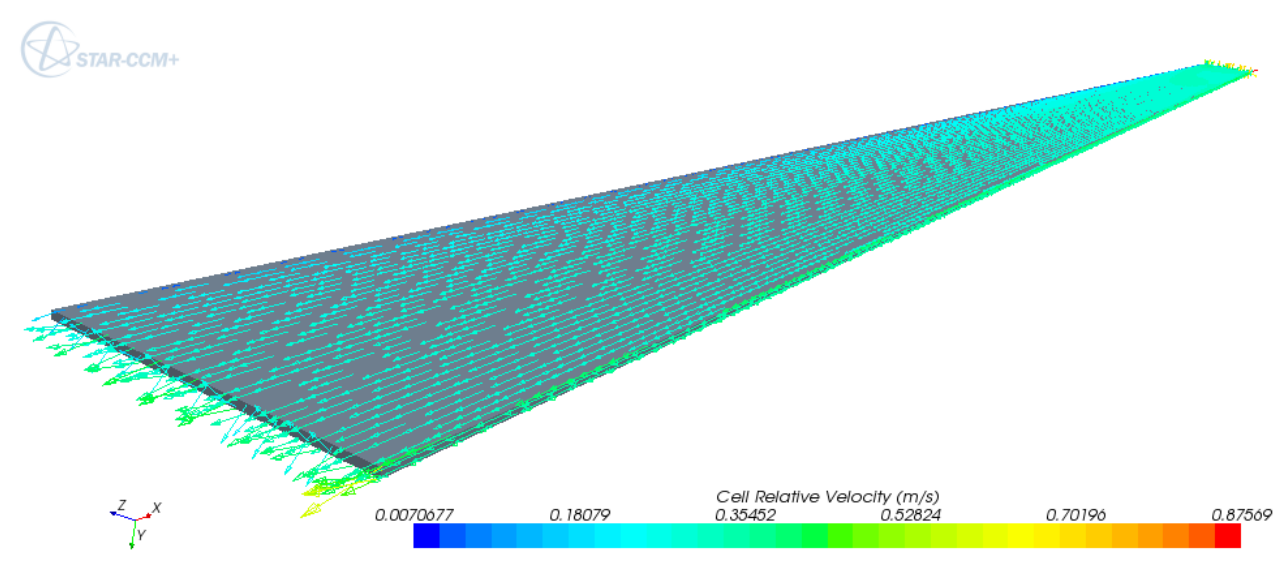

a) Região a jusante da placa plana

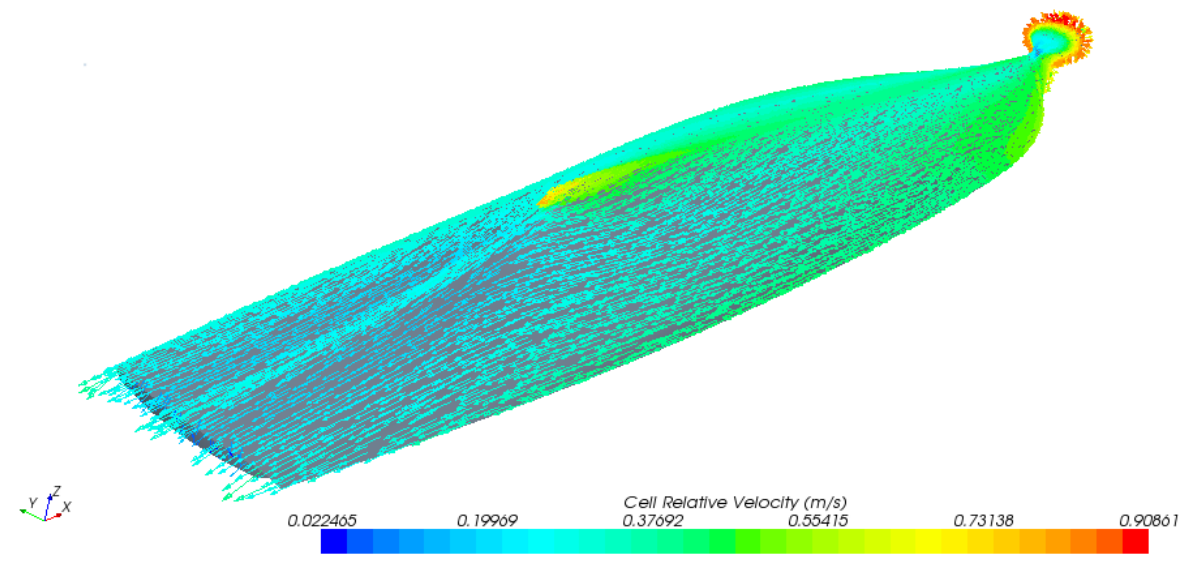

b) Região a jusante do modelo DTMB5415 (double-model)

Figura 40 - Vetores velocidade nas regiões de jusante: a) Placa plana e b) Casco DTMB5415. Ambos para o comprimento de $5.72 \mathrm{~m}$. 
O casco utilizado também apresenta geometria esbelta e dessa forma os gradientes de velocidade e pressão não são acentuados, com exceção da região do sonar, na proa, que proporciona elevada aceleração do fluido, Figura 39 (b). Segundo Repetto (2001), na maioria dos casos de embarcações em avanço o escoamento é simétrico, podendo-se utilizar nas análises apenas metade da geometria, conforme foi realizado com o modelo DTMB5415. Geralmente a assimetria do escoamento, se houver, ocorre na região de jusante do casco. Pôdese observar na região de popa que o fluido acompanhou as linhas do casco devido as suas curvaturas suaves, resultando em um escoamento simétrico, Figura 40 (b).

No caso de simulações com superfície livre a velocidade de entrada foi definida para ambos os fluidos, ou seja, água e ar. A pressão na região de saída foi definida como uma função da fração volumétrica de água. Além disso, a posição inicial da superfície livre foi imposta através da definição da fração volumétrica de água e ar nas regiões de entrada e saída do domínio. A pressão atmosférica foi utilizada como referência. Para as demais condições utilizou-se o mesmo que foi definido para a situação de ausência de superfície livre.

Para todos os casos simulados, os valores adotados para a temperatura, densidade e viscosidade do fluido inseridos no software foram os mesmos que encontrados nos ensaios realizados no tanque de provas do IPT. A Tabela 7 apresenta os valores das grandezas mencionadas além da aceleração da gravidade utilizada.

Tabela 7 - Dados do fluido e aceleração da gravidade utilizados nas simulações.

\begin{tabular}{c|c|c|c}
\hline Temperatura $\left[{ }^{\circ} \mathrm{C}\right]$ & $\begin{array}{c}\text { Densidade } \\
{\left[\mathrm{kg} / \mathrm{m}^{3}\right]}\end{array}$ & $\begin{array}{c}\text { Viscosidade } \\
\text { cinemática }\left[\mathrm{m}^{2} / \mathrm{s}^{2}\right]\end{array}$ & $\begin{array}{c}\text { Aceleração da } \\
\text { gravidade }\left[\mathrm{m} / \mathrm{s}^{2}\right]\end{array}$ \\
\hline 18,8 & 996,15 & $1,03 \mathrm{E}-06$ & 9,876
\end{tabular}

\subsubsection{Software}

A partir do que foi exposto nos itens anteriores é possível compreender melhor as condições que foram adotadas nas análises numéricas realizadas e que serão descritas brevemente a seguir.

As equações de conservação de massa e momento, juntamente com as equações que descrevem a turbulência, foram resolvidas através de métodos iterativos e segregados, com base no algoritmo SIMPLE. Todas as integrais de superfície e de volume foram aproximadas usando a regra do ponto médio e as 
aproximações da interpolação e do gradiente foram baseadas em funções lineares. Uma vez que a precisão temporal dos casos estudados aqui não é de importância significativa, o esquema implícito de Euler de primeira ordem foi utilizado para integração no tempo.

O número de iterações entre cada time-step é definido com base na busca pela melhor convergência durante as simulações, isto é, não há um meio direto que defina a variável em questão. Assim, a média da quantidade de iterações para cada avanço temporal, obtido dentre as simulações realizadas, foi de aproximadamente dez.

O valor do time-step foi definido buscando-se uma solução estável, definida através do número de Courant, que fornece a informação do escoamento em relação à uma célula da malha:

$$
\text { Co }=\frac{v \Delta t}{\Delta x}
$$

O valor de $\Delta x$ utilizado na eq.(97) foi obtido pela análise de convergência numérica e o valor da velocidade é conhecido, assim, para se encontrar o número de Courant resta definir $\Delta$ t. De acordo com Fortuna (2000), quando os fenômenos são regidos por equações hiperbólicas, como no caso dos termos convectivos, o valor da velocidade depende das condições iniciais que se propagam através do domínio computacional. Quando Co > 1 o domínio de dependência numérico não inclui o valor da condição inicial $\left(x_{0}, t_{0}\right)$, destruindo a propagação de informações e violando a física do problema, ou seja, uma alteração da condição inicial não alteraria a solução. Isso é fonte de instabilidade numérica, que eventualmente destrói a solução. No caso de $C o=1$, calcular-se-ia o valor exato da solução e quando Co $<1$ o domínio de dependência incluiria o ponto $\left(x_{0}, t_{0}\right)$, sem incorrer em erros que causem instabilidade numérica, porém, os valores obtidos não seriam os mesmos daqueles calculados quando $C o=1$. Dessa forma, buscou-se valores de $\Delta t$ que fornecessem $\mathrm{Co} \leq 1$.

Os valores de $y^{+}$utilizados nas simulações variaram de 30 à 50 , faixa esta considerada adequada por Péric (2010) e Repetto (2001). A Figura 41 ilustra um exemplo de mapeamento de $y+$ para um dos casos analisados. 


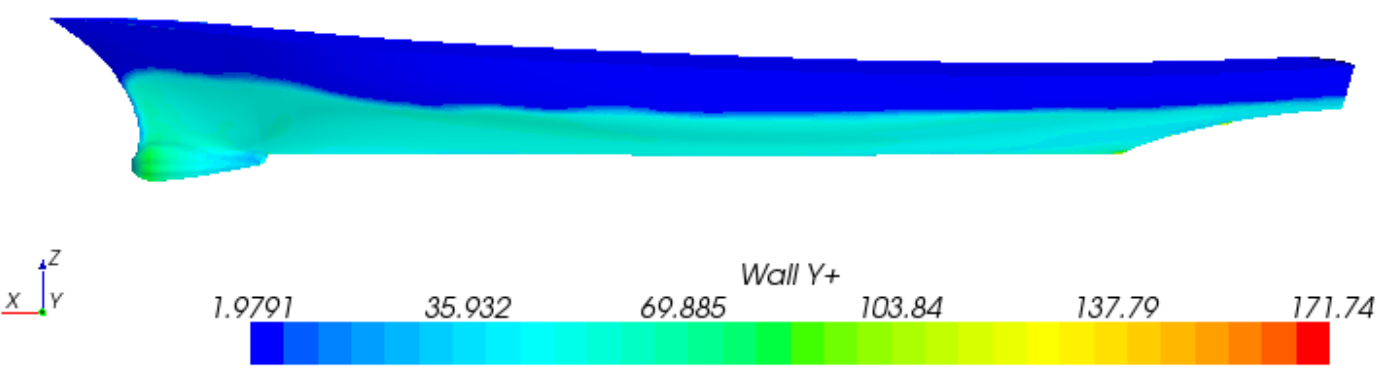

Figura 41 - Valor de $y+$ para o caso de velocidade de $2,24 \mathrm{~m} / \mathrm{s}$.

Nota-se, na Figura 42, mais algumas características do escoamento em torno do casco como, por exemplo, a aceleração do fluido por conta da geometria do modelo e o crescimento da camada limite ao longo do comprimento do casco sem que houvesse o fenômeno de separação.

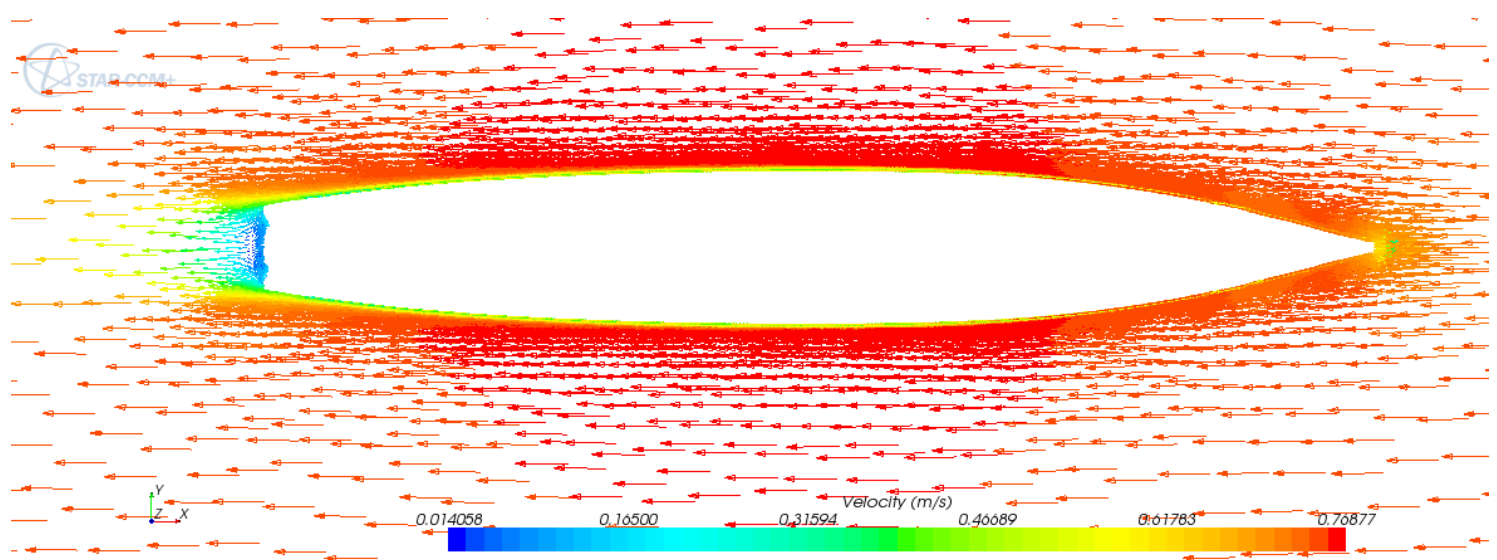

Figura 42 - Escoamento ao redor do casco do modelo DTMB5415 para a condição de doublemodel, $L p p=5,72$ e $0,75 \mathrm{~m} / \mathrm{s}$.

Adotou-se 0 modelo de turbulência $k-\varepsilon$, pois conforme apresentado anteriormente o escoamento em torno dos dois corpos em estudo não geraram gradientes elevados ou turbilhões, que demandariam o modelo de turbulência $k-\omega$. Além disso, a maioria dos trabalhos encontrados, que avaliaram a resistência ao avanço de cascos, utilizaram o modelo $k-\varepsilon$, tais como Péric (2010a), Ahmed (2011), Baos (2011), Salas (2011) e Péric (2010b), ratificando o uso adequado do modelo de turbulência adotado Os valores das constantes do modelo $k$ - $\varepsilon$ utilizadas nas simulações foram os mesmos do defaut do software, pois não encontrou-se referências para o caso em questão e não foi possível obter os coeficientes experimentalmente.

A condição de parada utilizada nas simulações foi o erro absoluto, cujo valor de referência adotado foi de $€=1,0 E-04$. A Figura 43 apresenta o monitoramento da 
resistência de uma das análises executadas. O número de passos no tempo e o valor do tempo físico devem ser definidos e também poderiam ter sido usados como critério de parada, mas não apresentariam utilidade prática.

Force 1 Monitor Plot

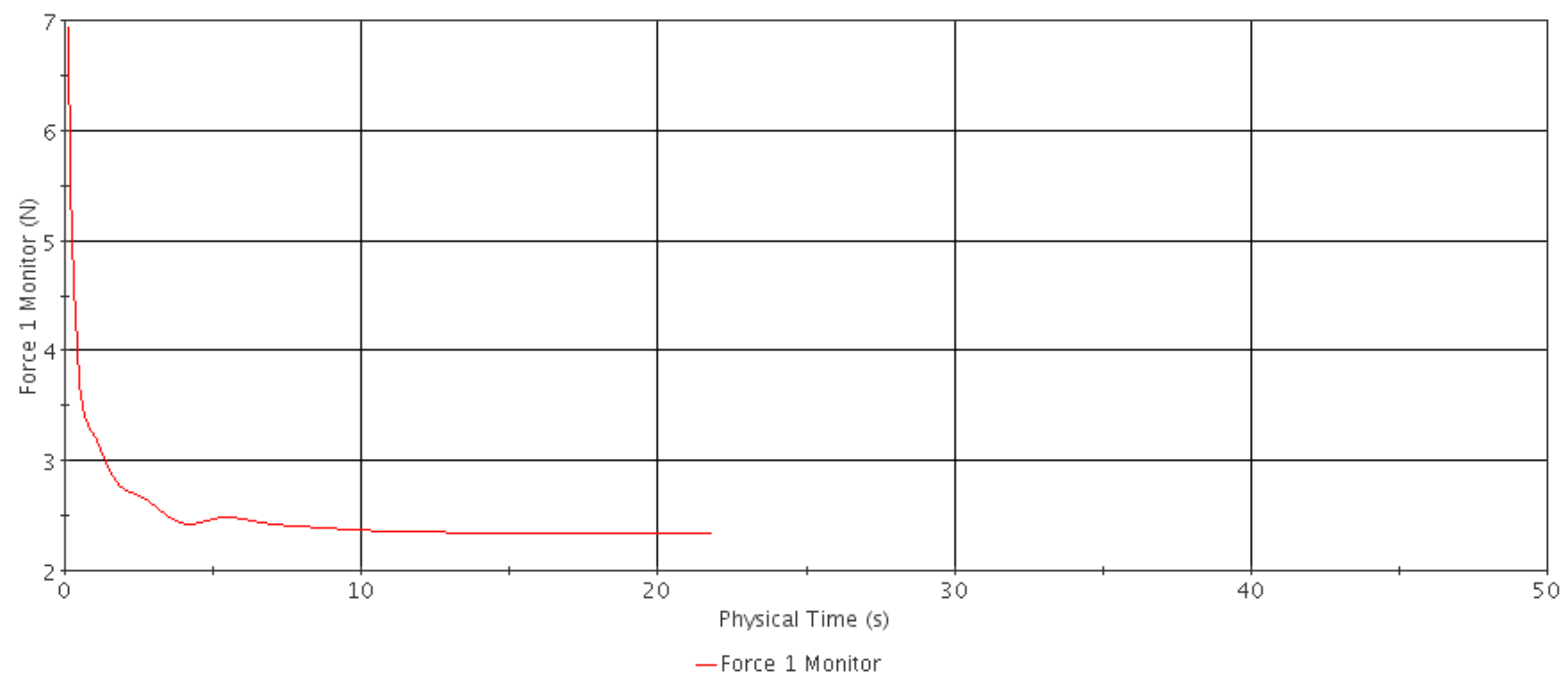

Figura 43 - Monitoramento da convergência da resistência da simulação de placa plana de 5,72 $\mathrm{m}$ de $L p p$ e $0,75 \mathrm{~m} / \mathrm{s}$.

Vale ressaltar que a curva da Figura 43 apresenta o valor da força de arrasto para metade da geometria, devido à condição de simetria utilizada nas simulações. Assim, o valor encontrado após o critério de parada ter sido atingido deverá ser multiplicado por dois.

\subsection{RESULTADOS}

\subsubsection{Fator de Forma}

Foram realizadas simulações de resistência ao avanço, utilizando a metodologia de double-model, para nove valores de escalas reduzidas do casco DTMB5415, de forma a manter Froude constante. O valor de Froude considerado foi de 0,1 , pois se trata de situações em que não há efeitos significativos de geração de ondas e com isso pretendeu-se minimizar os efeitos da desconsideração da superfície livre. Para cada caso foi obtido o valor do coeficiente de resistência total, que, de acordo com a eq.(12), é equivalente ao valor do coeficiente viscoso. A Tabela 8 apresenta os valores de resistência para cada caso analisado. 
Tabela 8 - Valores de resistência numérica (double-model) do modelo DTMB5415 para diferentes escalas e Froude constante $(F r=0,1)$.

\begin{tabular}{c|c|c|c}
\hline Lpp [m] & Área $\left[\mathrm{m}^{2}\right]$ & Velocidade $[\mathrm{m} / \mathrm{s}]$ & Resistência [N] \\
\hline 1,624 & 0,389 & 0,399 & 0,16 \\
\hline 3,048 & 1,371 & 0,548 & 0,9 \\
\hline 5,719 & 4,822 & 0,748 & 4,946 \\
\hline 10,73 & 16,974 & 1,024 & 30,47 \\
\hline 20,13 & 59,76 & 1,404 & 177,79 \\
\hline 37,77 & 210,36 & 1,922 & 1050,15 \\
\hline 47,79 & 336,79 & 2,163 & 2201,77 \\
\hline 62,63 & 578,26 & 2,476 & 5008,12 \\
\hline 70,88 & 740,43 & 2,634 & 6529,1
\end{tabular}

O mesmo tipo de ensaio e quantidade de simulações também foi realizado com placas planas, que apresentaram equivalências nos comprimentos e áreas molhadas dos cascos em suas diferentes escalas. Devido à pequena espessura da chapa, considerada como desprezível, os valores de resistência total obtidos nesses casos foram considerados iguais à resistência friccional, pois não há influência de forma, tais como geração de vórtices, conforme pôde ser verificado na Figura 40.

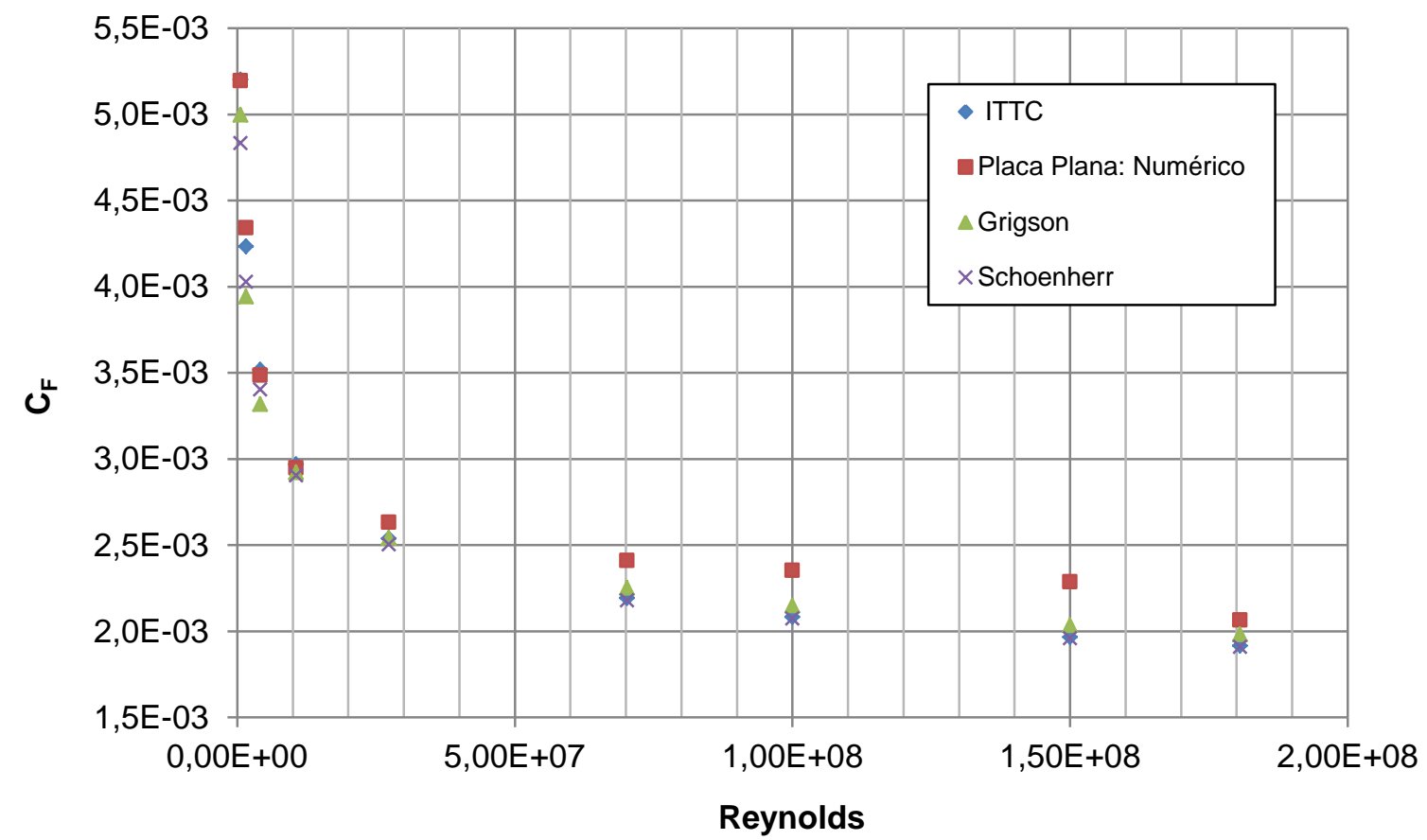

Figura 44 - Gráfico de $C_{F}$ por Reynolds, obtido numericamente e pela linha de correlação da ITTC'57, Grigson e Schoenherr.

Para cada resultado encontrado através das simulações com placas planas, todas considerando Froude de 0,1 , o correspondente coeficiente friccional foi 
comparado com a linha de correlação da ITTC. O gráfico da Figura 44 ilustra a comparação mencionada.

Observa-se que para valores de Reynolds maiores que 2,0E+07 os pontos obtidos numericamente são superiores aos fornecidos pela ITTC, enquanto que para valores até o mencionado Reynolds, isto é, o máximo valor comumente encontrado em tanques de provas, os pontos são semelhantes.

Outras linhas de correlação, tais como a de Schoenherr e Grigson, também foram avaliadas. A primeira é dada por:

$$
C_{F}=\left[\frac{0,242}{\log \left(\operatorname{Re} C_{F}\right)}\right]^{2}
$$

A formulação de Grigson utiliza em sua composição a correlação da ITTC'57 e divide a análise em duas faixas de Reynolds, conforme apresentado nas eqs. (99) e (100):

$$
C_{F}=\left[0,93+0,1377(\log R e-6,3)^{2}-0,06334(\log R e-6,3)^{4} C_{F(I T T C)}\right]
$$

Para 1,5E+06 $<\mathrm{Re}<2,0 \mathrm{E}+07$

$$
C_{F}=\left[1,032+0,02816(\log R e-8)-0,06273(\log R e-8)^{2} C_{F(I T T C)}\right]
$$

Para 1,0E+08<Re $<4,0 \mathrm{E}+09$

Os pontos obtidos pelas duas últimas correlações também estão apresentadas no gráfico da Figura 44. Os pontos calculados por Schoenherr praticamente coincidem com os da ITTC a partir de Reynolds $7,0 \mathrm{E}+07$, enquanto que os pontos calculados por Grigson são superiores ao de Schoenherr e ITTC, sendo mais próximos aos valores numéricos.

Sabe-se que a formulação da ITTC'57 foi concebida baseada em ensaios experimentais realizados com modelos de pequeno comprimento, e que os valores obtidos são estimativas para $C_{F}$, principalmente para o caso de grandes escalas. Assim, por conta da proximidade entre os valores de coeficiente friccional fornecidos pela ITTC'57 e pelas simulações numéricas, para a faixa de Reynolds utilizadas em laboratórios, pode-se inferir que os resultados via CFD são satisfatórios.

Dado o exposto, pode-se dizer que, para o caso de modelos em escala reduzida, a correlação da ITTC'57 é adequada, porém talvez não o seja para Reynolds elevados. Há a possibilidade de que, durante a extrapolação para a escala real, o valor de $C_{F S}$ e, consequentemente, o valor de $C_{T S}$ sejam subestimados, ocasionando erros no dimensionamento da instalação propulsora. Assim, para faixas 
de Reynolds acima daquelas utilizadas em tanques de provas poderia se utilizar, por exemplo, a linha de correlação de Grigson.

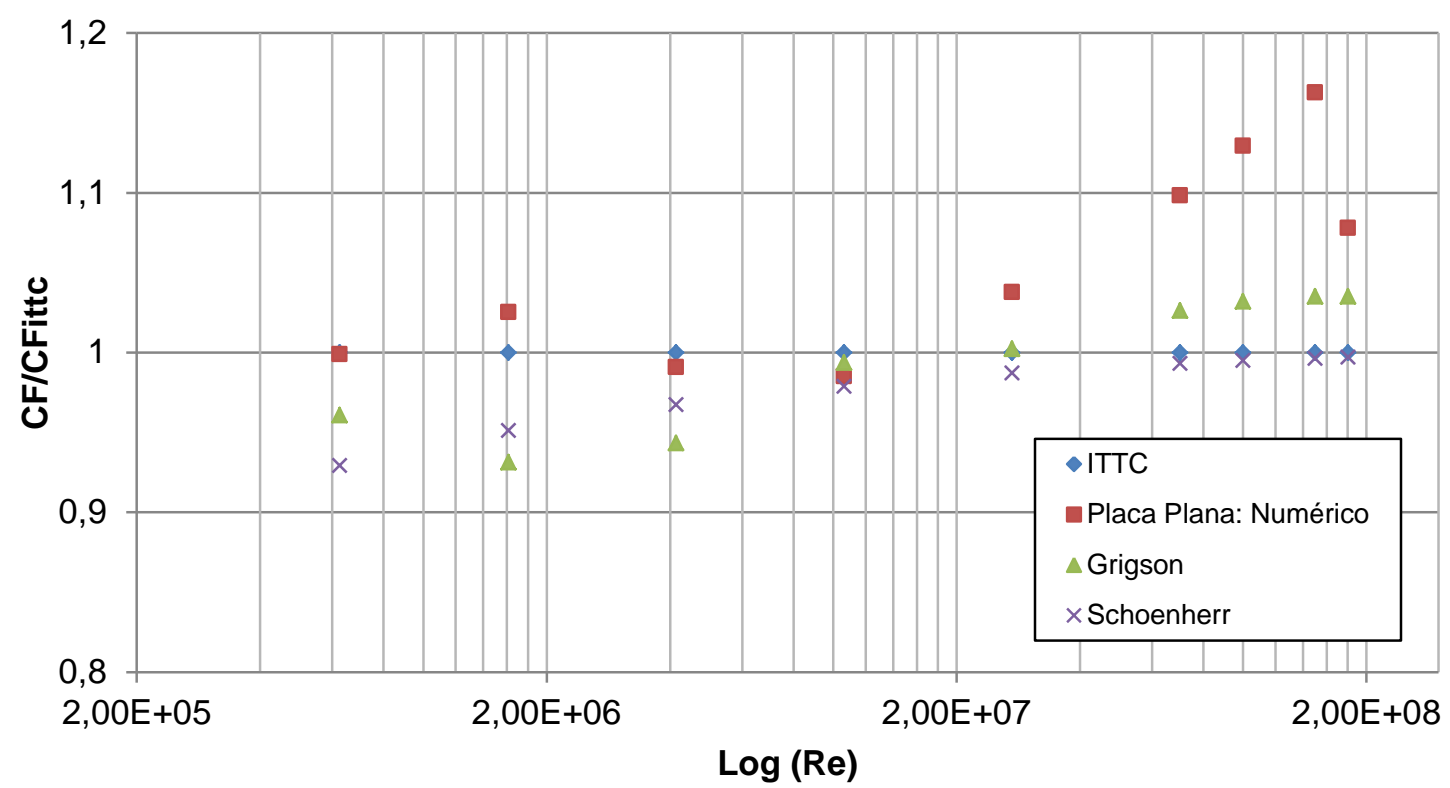

Figura 45 - Comparação entre valores de $C_{F}$ em relação à linha de correlação da ITTC'57, em função de Reynolds.

Outra proposta de apresentação de comparação entre os valores de $C_{F}$ foi realizada por Gomez (2000), e que no caso do presente trabalho pode ser verificada no gráfico da Figura 45. Verifica-se que os valores obtidos por Schoenherr são superiores à Grigson até 0 valor de Reynolds $4,0 \mathrm{E}+6$ e a partir de então o quadro se inverte. A mesma tendência foi constatada no trabalho de Gomez (2000), Figura 13 (a).

Realizando-se uma nova comparação entre os coeficientes friccionais, obtidos tanto pela ITTC'57 quanto pelas simulações numéricas de placa plana, e o coeficiente de resistência total do casco DTMB5415 (double-model), é possível notar a influência da forma, através da relação entre $C_{T}$ e $C_{F}$, uma vez que a superfície livre foi desconsiderada, eq. (12). Observa-se no gráfico da Figura 46 que conforme o número de Reynolds aumenta, as diferenças entre $C_{T}$ e $C_{F}$ se tornam maiores e consequentemente haverá diferenças no o valor do fator de forma, conforme pode ser verificado na Figura 47. 


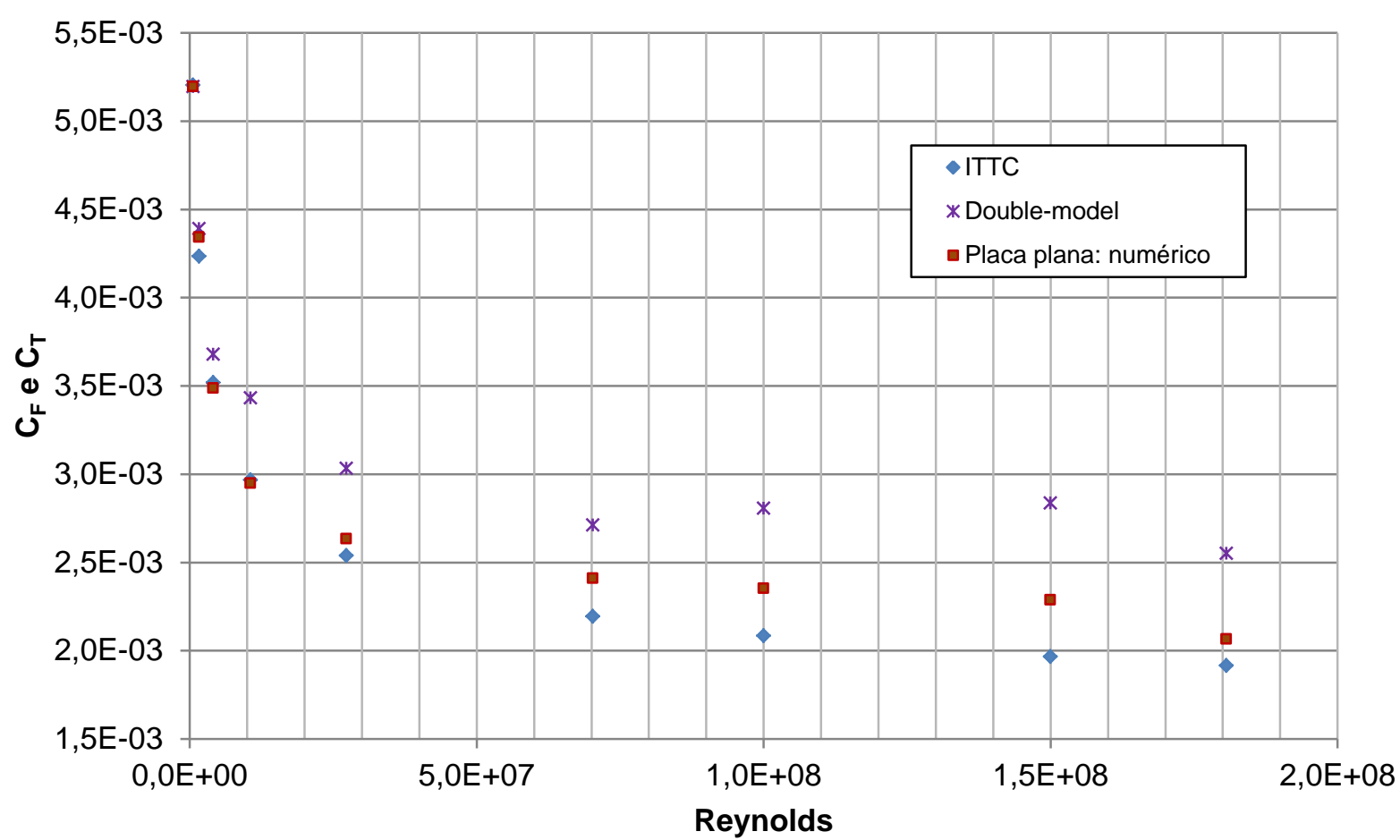

Figura 46 - Comparação entre o coeficiente de resistência total das diferentes escalas do DTMB5415 (double-model) e os coeficientes friccionais obtidos pela ITTC'57 e pelas simulações de placas planas.

O valor do fator de forma do modelo DTMB5415 obtido nos ensaios de resistência ao avanço realizados no tanque de provas do IPT foi de 1,24, o qual foi definido através do método indireto. Nota-se no gráfico da Figura 47 que o mesmo valor de $(1+k)$ obtido nos ensaios do IPT pôde ser observado para Reynolds de $7,0 \mathrm{E}+07$, no caso de $C_{T_{-} \text {DoubleModel }} / C_{F_{-} I T T C}$, enquanto que para a relação $C_{T_{-} \text {DoubeModel }} / C_{F_{-} \text {Numérico }}$ foi verificado para os Reynolds $1,5 \mathrm{E}+08$ e $1,8 \mathrm{E}+08$.

A tendência observada nos pontos do gráfico da Figura 47 apresenta, de maneira geral, um crescimento no fator de forma com o aumento de Reynolds. $O$ trabalho de Jen-Shiang, Yen-Jen e Shiu-Wu (2009) apresentou curvas do fator de forma para alguns modelos estudados, inclusive para o DTMB5415, Figura 15, em que constataram que o fator de forma é crescente com Reynolds. Assim, de acordo com os resultados obtidos pode-se concluir que o fator de forma não é independente da escala conforme proposto pela ITTC. 


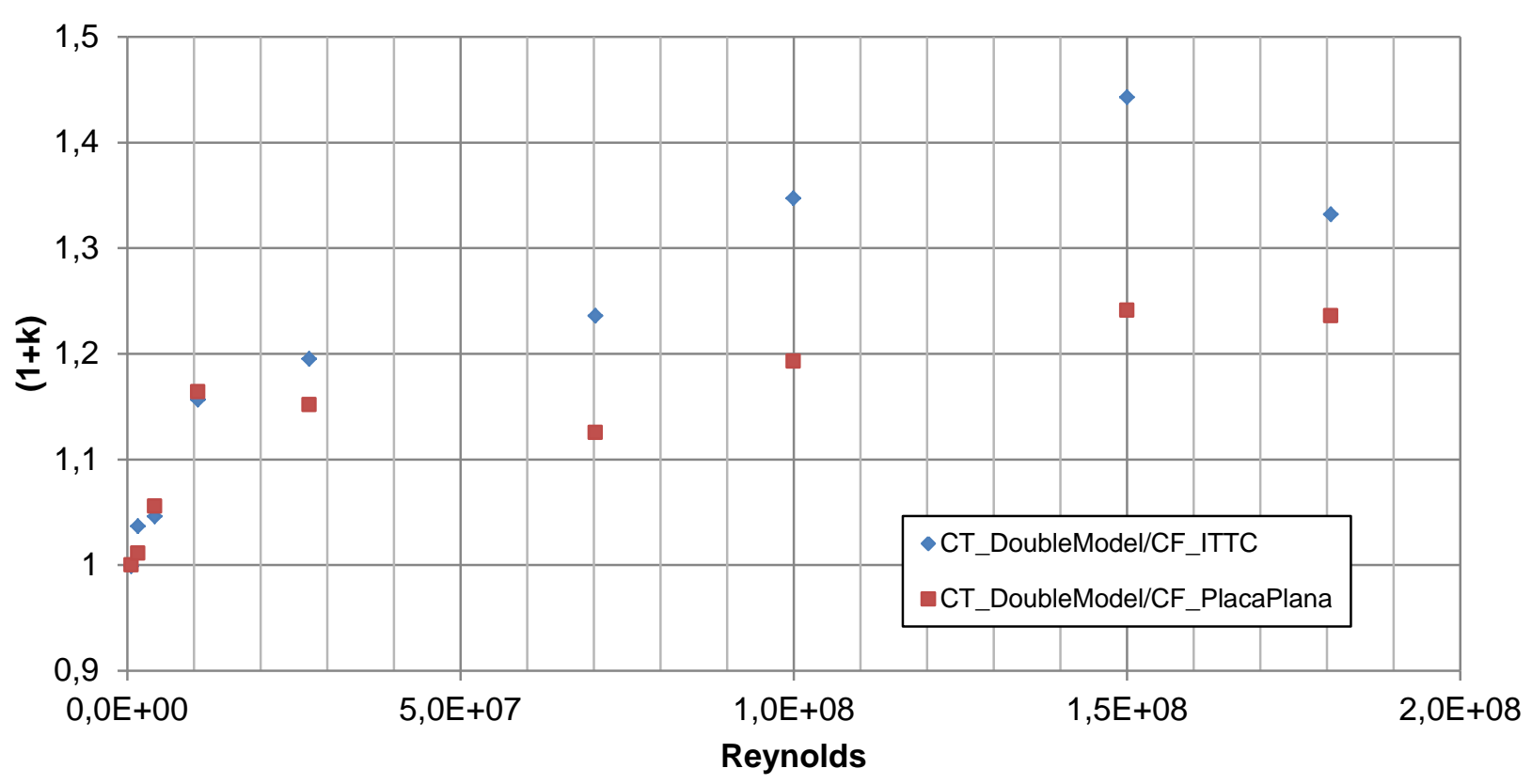

Figura 47 - Fator de forma do modelo DTMB5415 para escalas distintas, calculado numericamente utilizando a formulação da ITTC' 57 e os resultados das simulações de placas planas.

O $23^{\circ}$ comitê da ITTC de propulsão, realizado em 1996, apontou que o efeito da escala no fator de forma é provavelmente causado pela estimativa do coeficiente friccional da resistência de placa plana. Foi proposto no referido comitê que se a linha de correlação de Grigson fosse utilizada ao invés da tradicionalmente aplicada, o efeito da escala seria menos significativo. Entretanto, o efeito da escala no fator de forma não foi amplamente avaliado até então e o estudo da dependência do fator de forma na predição do valor de resistência ainda está em incompleto. Caso o fator de forma cresça com a escala, conforme previsto pelo presente trabalho e pelo referido comitê, a resistência ao avanço de navios na escala real, baseada na hipótese de fator de forma constante, será subestimada.

Ao analisar o valor de $(1+k)$ para o modelo ensaiado no IPT, verificou-se que o fator de forma é distinto para cada Froude adotado e é crescente com Reynolds, Figura 48, isto é, o fator de forma não é independente da velocidade de avanço. Nota-se que a avaliação foi feita considerando-se três pontos, porém, acredita-se que $(1+k)$ continuará crescendo até um valor de Reynolds em que a camada limite esteja plenamente desenvolvida. 


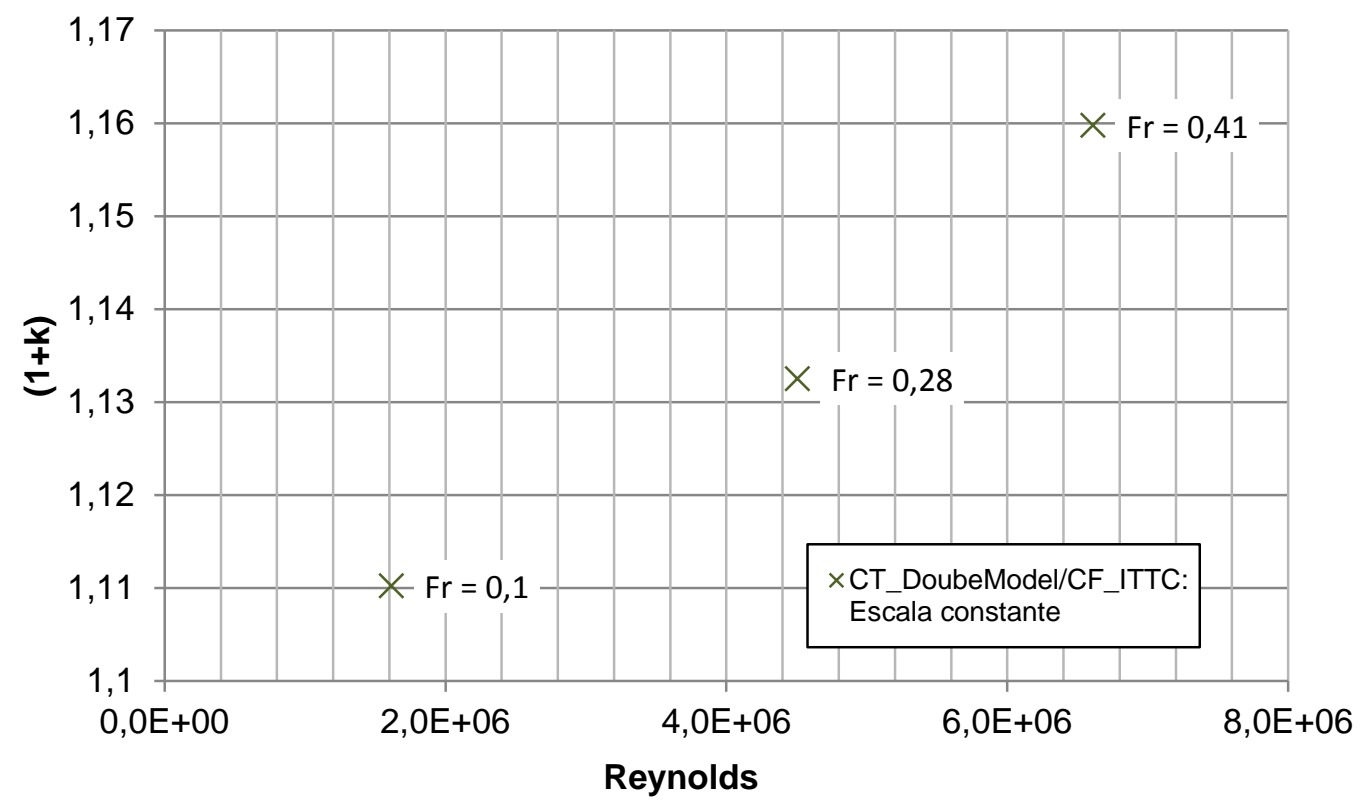

Figura 48 - Fator de forma do modelo DTMB5415 para a escala ensaiada no IPT, calculado numericamente utilizando a formulação da ITTC'57

\subsubsection{Estimativa de resistência ao avanço}

Outro objetivo do presente trabalho foi realizar estimativas numéricas da resistência ao avanço do modelo DTMB5415. Durante as simulações foram utilizados a mesma escala e números de Froude ensaiados no tanque de provas do IPT. A Tabela 9 apresenta os valores da resistência total, obtidos através do StarCCM+, além das diferenças entre as estimativas numéricas e os dados colhidos nos ensaios realizado no IPT. Vale mencionar que os valores contidos na coluna referente aos ensaios em tanque de provas são as médias dos resultados apresentados anteriormente na Tabela 4.

Tabela 9 - Valores de resistência ao avanço obtidos através de ensaios em tanque de provas e via StarCCM+.

\begin{tabular}{c|c|c|c}
\hline Froude & $\begin{array}{c}\text { Resistência em } \\
\text { Tanque de Provas [N] }\end{array}$ & $\begin{array}{c}\text { Resistência via } \\
\text { StarCCM+[N] }\end{array}$ & $\begin{array}{c}\text { Diferença entre } \\
\text { resistência numérica } \\
\text { e experimental [\%] }\end{array}$ \\
\hline 0,1 & 1,01 & 0,92 & 8,51 \\
\hline 0,28 & 8,27 & 7,32 & 11,46 \\
\hline 0,41 & 25,57 & 20,99 & 17,9
\end{tabular}

As restrições de movimento impostas nas simulações fixaram os seis graus de liberdade, isto é, não havia afundamento e trim, diferentemente do observado nos ensaios experimentais, em que estão presentes os movimentos de heave e pitch. NI 
et al.(2011) mencionaram em seu trabalho que ignorar a influência do comportamento do casco durante o seu avanço é fonte para erros na estimativa da resistência, principalmente para embarcações rápidas. O mesmo pôde ser verificado por Alho e Costa (2010), que encontraram uma diferença elevada no valor de resistência numérica, por conta de restrições de afundamento e trim. Dessa forma, era esperado que para o caso em estudo se constatassem diferenças entre os valores de resistência encontrados através do software e daqueles obtidos experimentalmente, conforme apresentado na Tabela 9. Na Figura 9, introduzida anteriormente, é possível notar, através de uma análise mais detalhada, que a ordem de grandeza das diferenças entre os valores de resistência numérica e experimental, considerando-se o modelo fixo, são semelhantes às obtidas no presente trabalho.

Embora a restrição dos graus de liberdade tenha sido a principal causa das diferenças em questão, ainda há a parcela relativa ao erro numérico, que geralmente estão na ordem de 3 à 4\% para estimativas de resistência ao avanço. Dávila, Mendonza e Villagómez (2011) e Aiguo et al. (2012), encontraram em seus trabalhos os valores de $3,9 \%$ e $3,56 \%$, respectivamente, considerados satisfatórios pelos autores.

Tabela 10 - Afundamento e trim para os ensaios realizados no tanque de provas do IPT.

\begin{tabular}{c|c|c|c|c}
\hline Ensaio & Froude & $\begin{array}{c}\text { Afundamento } \\
\text { Proa [mm] }\end{array}$ & $\begin{array}{c}\text { Afundamento } \\
\text { Popa [mm] }\end{array}$ & Trim [mm] \\
\hline \multirow{4}{*}{ Dia1 } & 0,1 & $-0,53$ & 0,35 & 0,88 \\
\cline { 2 - 5 } & 0,28 & $-7,25$ & $-2,29$ & 4,96 \\
\cline { 2 - 5 } & 0,41 & $-5,70$ & $-22,74$ & $-17,04$ \\
\hline \multirow{4}{*}{ Dia2 } & 0,1 & $-0,75$ & 0,41 & 1,16 \\
\cline { 2 - 5 } & 0,28 & $-7,59$ & $-2,23$ & 5,36 \\
\cline { 2 - 5 } & 0,41 & $-6,03$ & $-22,48$ & $-16,45$ \\
\hline \multirow{4}{*}{ Dia3 } & 0,1 & $-0,52$ & 0,58 & 1,10 \\
\cline { 2 - 5 } & 0,28 & $-7,30$ & $-2,00$ & 5,30 \\
\cline { 2 - 5 } & 0,41 & $-5,80$ & $-22,88$ & $-17,08$ \\
\hline \multirow{4}{*}{ Dia4 } & 0,1 & $-0,75$ & 0,36 & 1,11 \\
\cline { 2 - 5 } & 0,28 & $-7,38$ & $-2,03$ & 5,35 \\
\cline { 2 - 5 } & 0,41 & $-5,99$ & $-22,50$ & $-16,51$
\end{tabular}

A Tabela 10 apresenta os dados de afundamento e trim médios do DTMB5415, para os ensaios realizado no IPT. Observa-se que, com o crescimento de Froude, houve um aumento nos valores de afundamento e inversão no comportamento do trim. Conforme o casco afunda, há um aumento da área molhada 
e alterações na geometria submersa, que provavelmente ocasionaram um acréscimo no valor da resistência. Para os dois Froudes mais elevados o afundamento foi significativo, justificando as elevadas diferenças obtidas, Tabela 9.

Através dos dados fornecidos na Tabela 10 é possível realizar simulações considerando as condições de afundamento e trim, embora o modelo esteja restrito nos graus de liberdade de heave e pitch, isto é, altera-se a posição relativa do casco em relação à superfície livre, de forma a representar a mesma configuração final do ensaio experimental, assim que a convergência da solução for atingida. As posições dos dispositivos de medição de afundamento em relação ao casco encontram-se na Figura 49.

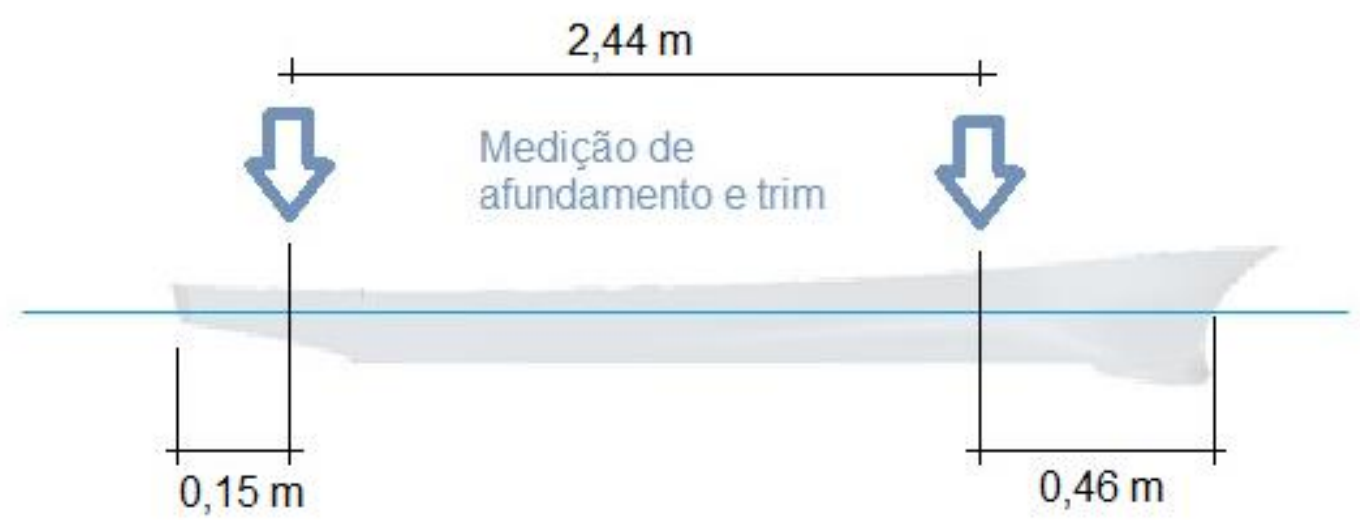

Figura 49 - Posição relativa ao casco dos dispositivos de medição de afundamento.

Para as análises considerando o afundamento e trim o número de Froude 0,1 não foi utilizado, tendo em vista que pequenas variações das grandezas mencionadas não seriam tão notórias como nos demais casos. A Tabela 11 apresenta as novas diferenças entre os valores numéricos e experimentais, em que se observa uma melhoria relevante nos resultados, indicando a importância de se representar da melhor maneira possível a física do ensaio experimental. Levando-se em consideração os erros numéricos que estão embutidos na modelagem numérica, os resultados encontrados foram satisfatórios, corroborando a potencialidade da utilização de CFD em projetos navais.

Vale ressaltar que caso os dados de afundamento e trim não fossem disponibilizados, a melhor representatividade dos ensaios experimentais se daria pela simulação com heave e pitch livres, sendo necessário informações adicionais para a realização das simulações como, por exemplo, a inércia do modelo. 
Tabela 11 - Valores de resistência ao avanço obtidos através de ensaios em tanque de provas e via StarCCM+, considerando o afundamento e trim.

\begin{tabular}{c|c|c|c}
\hline Froude & $\begin{array}{c}\text { Resistência em } \\
\text { Tanque de Provas [N] }\end{array}$ & $\begin{array}{c}\text { Resistência via } \\
\text { StarCCM+[N] }\end{array}$ & $\begin{array}{c}\text { Diferença entre } \\
\text { resistência numérica } \\
\text { e experimental [\%] }\end{array}$ \\
\hline 0,28 & 8,27 & 7,88 & 4,95 \\
\hline 0,41 & 25,57 & 24,75 & 3,31
\end{tabular}

\subsubsection{Avaliação do padrão e perfil de ondas}

Ao realizar uma comparação entre os valores de resistência total, obtidos pelos ensaios laboratoriais e simulações (double-model), verifica-se, através da diferença dos resultados, uma aproximação para a parcela da resistência de ondas.

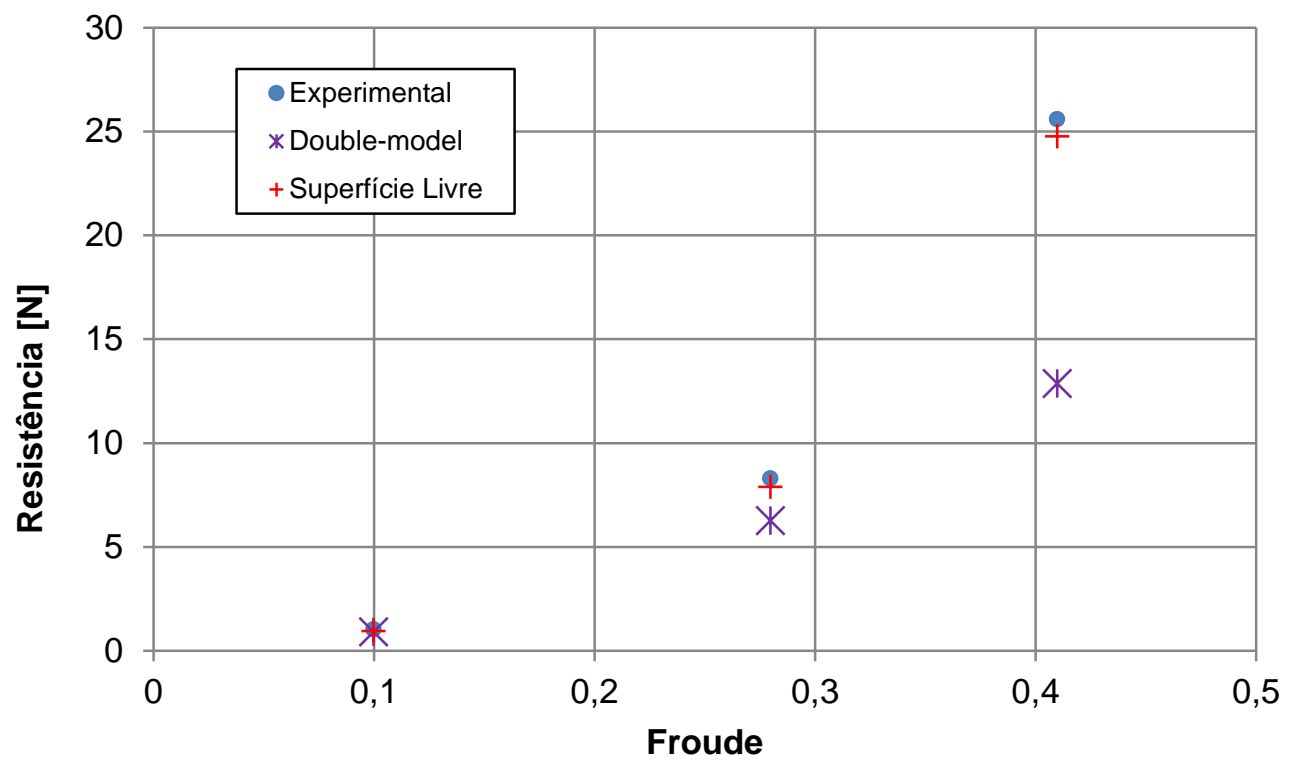

Figura 50 - Comparação entre resistência total e viscosa: Estimativa para a resistência de ondas.

Nota-se no gráfico da Figura 50, que para o menor Froude a influência da superfície livre é pequena, pois os três pontos referentes ao ensaio e às simulações, com e sem a presença da superfície livre, são semelhantes. Na medida que o Froude aumenta, as diferenças tornam-se visíveis, por conta da geração de ondas causada pelo avanço do casco. Para Froude 0,41 o valor da resistência total é praticamente o dobro da resistência viscosa, isto é, pode se inferir, para a velocidade de avanço em questão, que $50 \%$ do valor da resistência total é causada pela presença da superfície livre. 


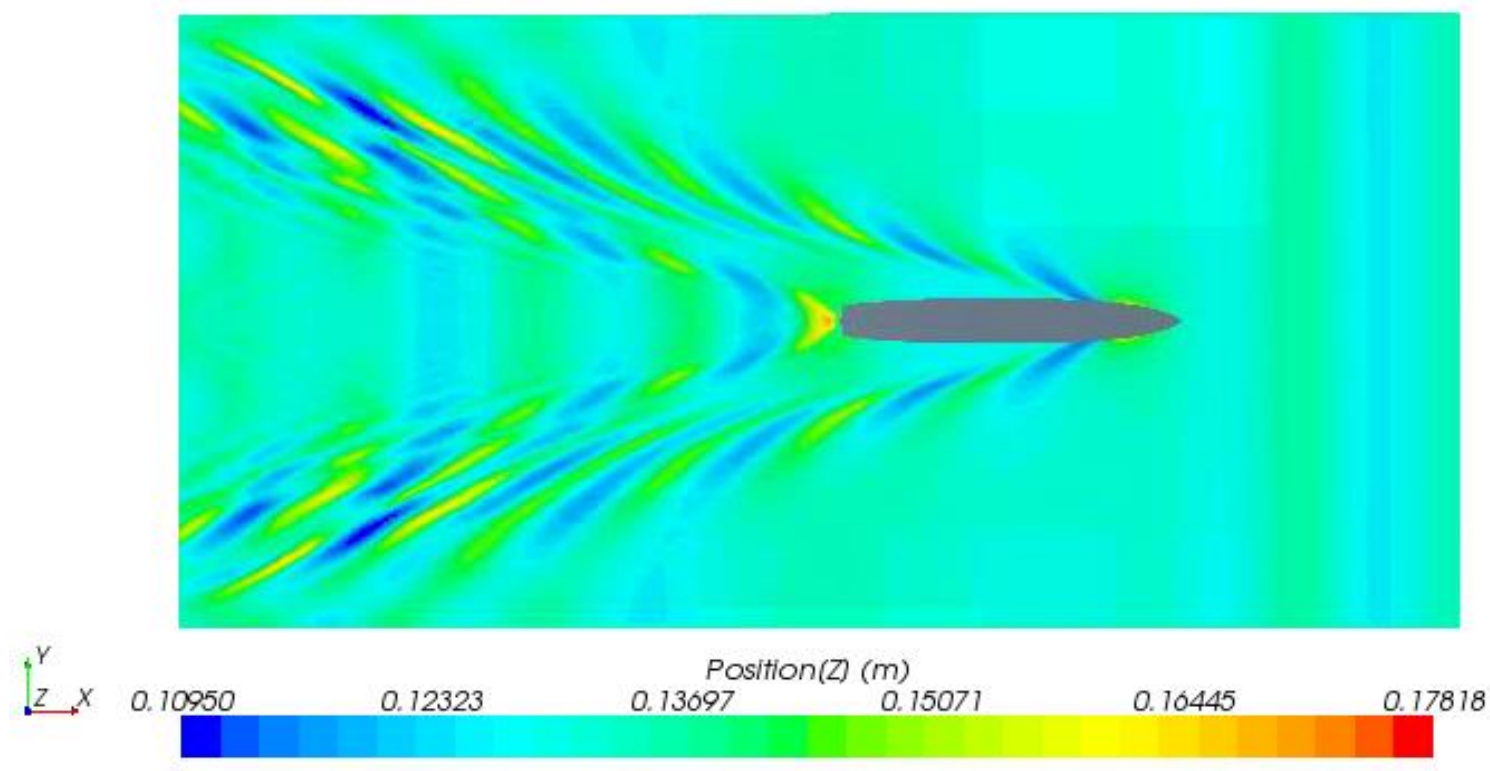

a) Considerando-se o afundamento e trim.

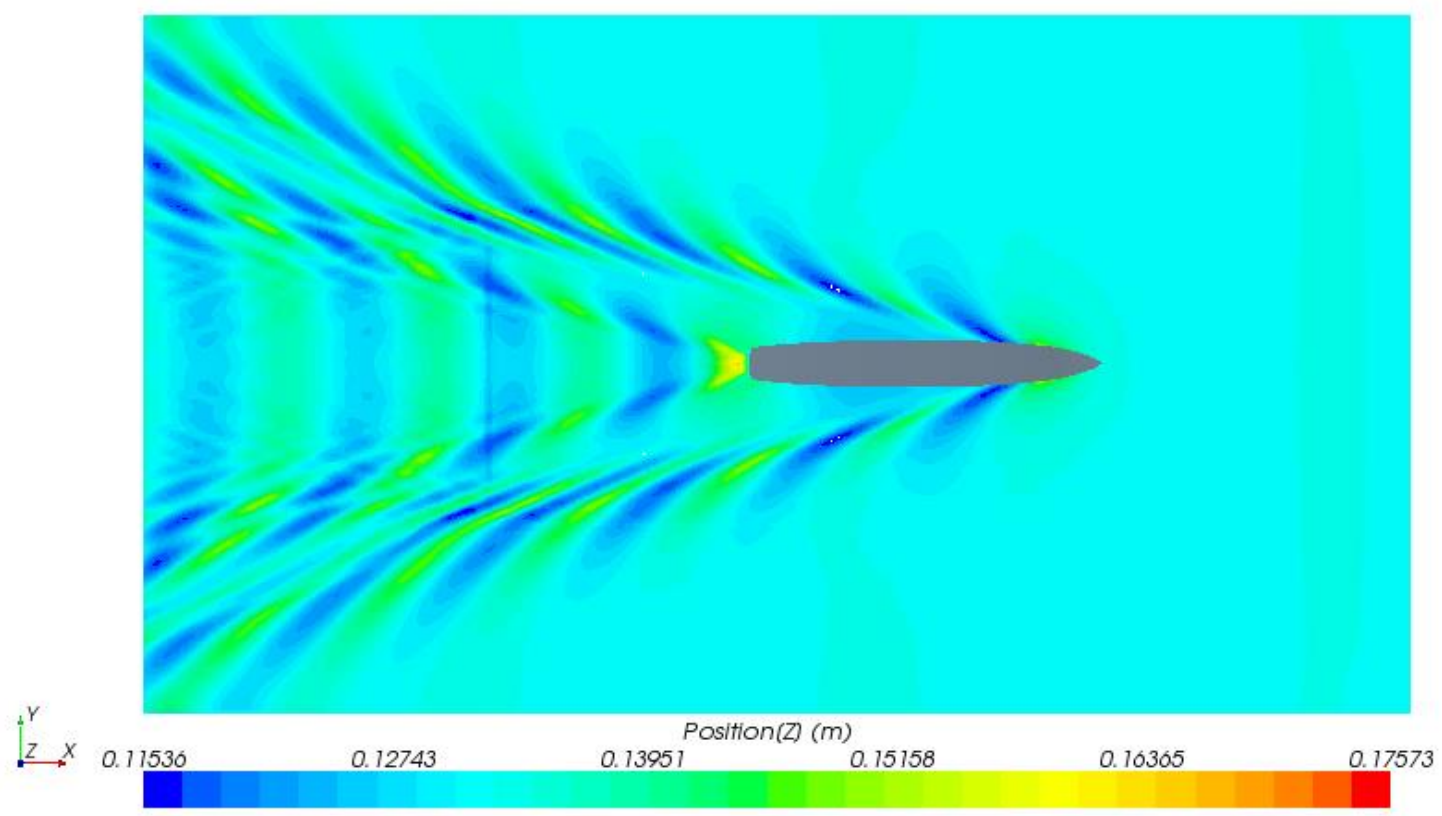

b) Ausência de afundamento e trim.

Figura 51 - Padrão de ondas gerado pelo casco DTMB5415. Simulação do modelo de $L p p=$ $3,05 \mathrm{~m}$ e velocidade de avanço de $1,53 \mathrm{~m} / \mathrm{s}$; Froude 0,28.

O padrão de ondas gerado pelo avanço do casco DTMB5415 foi obtido numericamente, tanto para as soluções que desconsideraram o afundamento e trim, quanto para aquelas que os levaram em consideração, conforme apresentado na Figura 51 e Figura 52. Observa-se que os padrões de ondas são semelhantes, mas para o caso com afundamento e trim as amplitudes de ondas são maiores conforme mostram as escalas, ou seja, pelos resultados encontrados nota-se que as restrições impostas nos graus de liberdade de heave e pitch podem afetar de 
maneira significativa a parcela de resistência de ondas. Nota-se também que as ondas geradas quando Froude vale 0,41 possuem maior comprimento e amplitude do que aquelas para 0,28 , devido à transferência de energia do movimento da embarcação para o fluido.

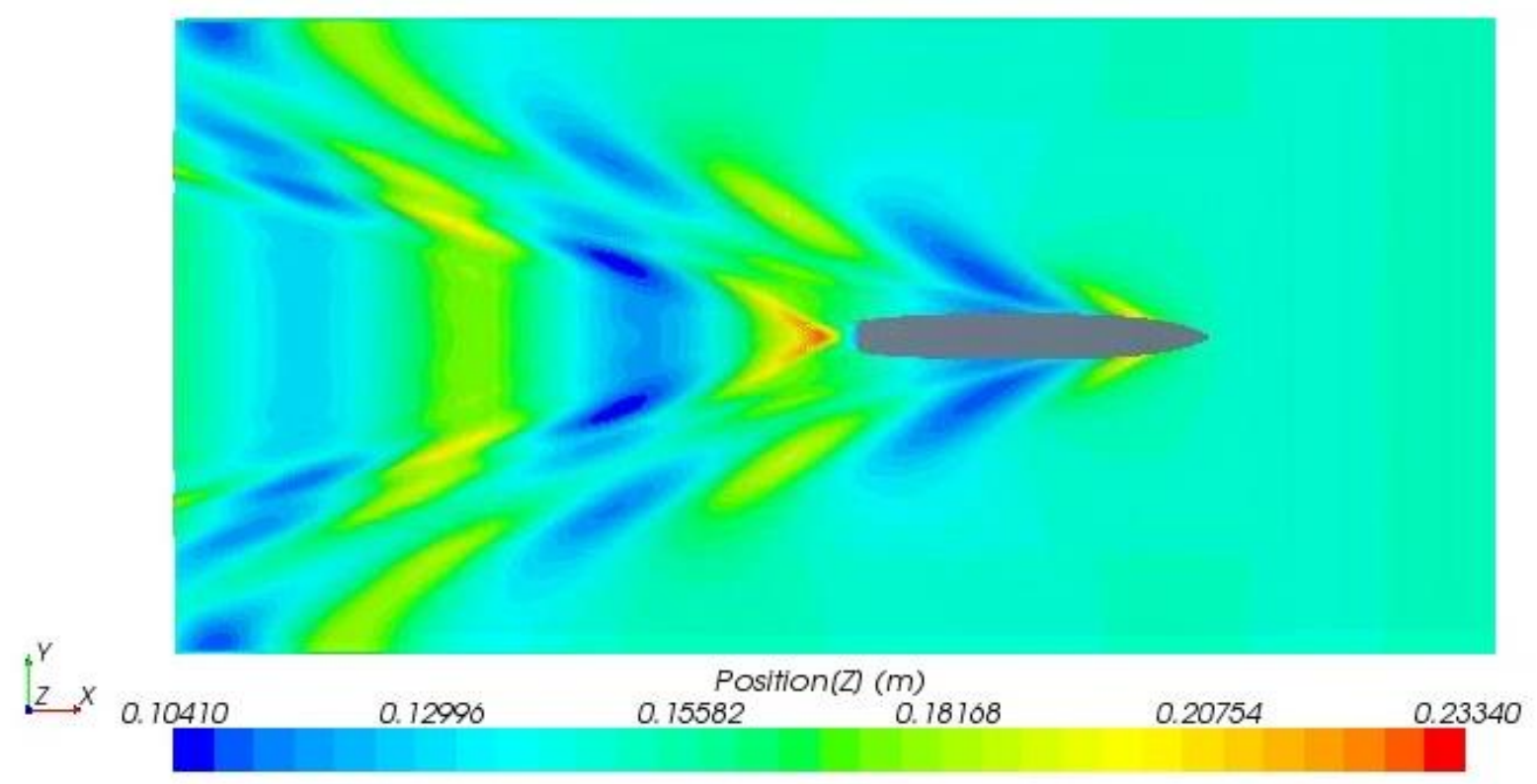

a) Considerando-se o afundamento e trim.

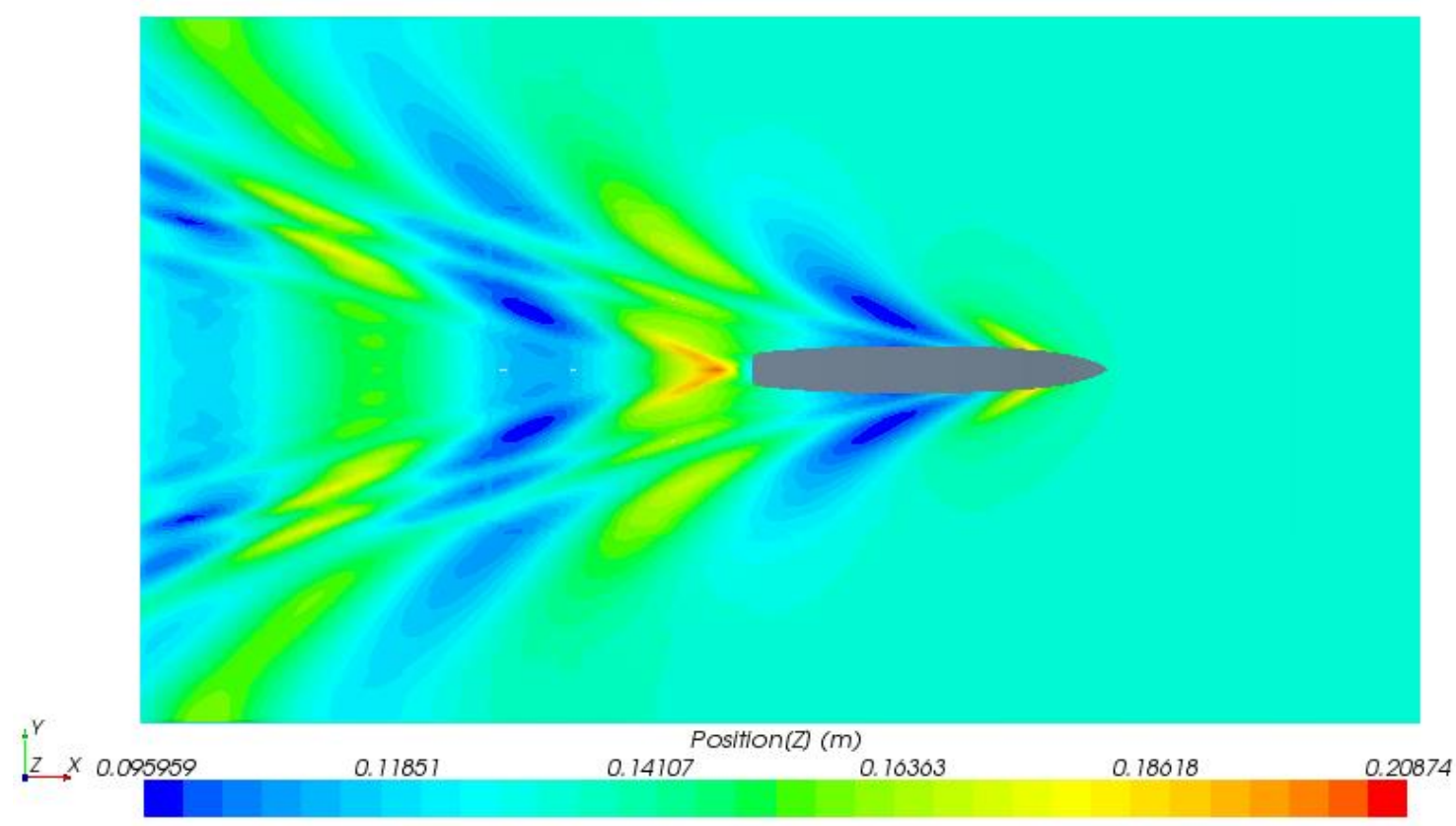

b) Ausência de afundamento e trim.

Figura 52 - Padrão de ondas gerado pelo casco DTMB5415. Simulação do modelo de $L p p=$ $3,05 \mathrm{~m}$ e velocidade de avanço de $2,24 \mathrm{~m} / \mathrm{s}$; Froude 0,41.

Não foi possível obter o padrão de ondas para Froude 0,1 , pois a geração de ondas nessa faixa é muito pequena. Para que fosse possível a obtenção da 
elevação da superfície livre seria necessário refinar, consideravelmente, a malha nessa região, o que acarretaria em aumento do custo computacional. Este problema é comumente enfrentado quando se utiliza softwares de solução viscosa. Ahmed (2011), por exemplo, também relatou a sua dificuldade em apresentar a elevação das ondas para baixos números de Froude.
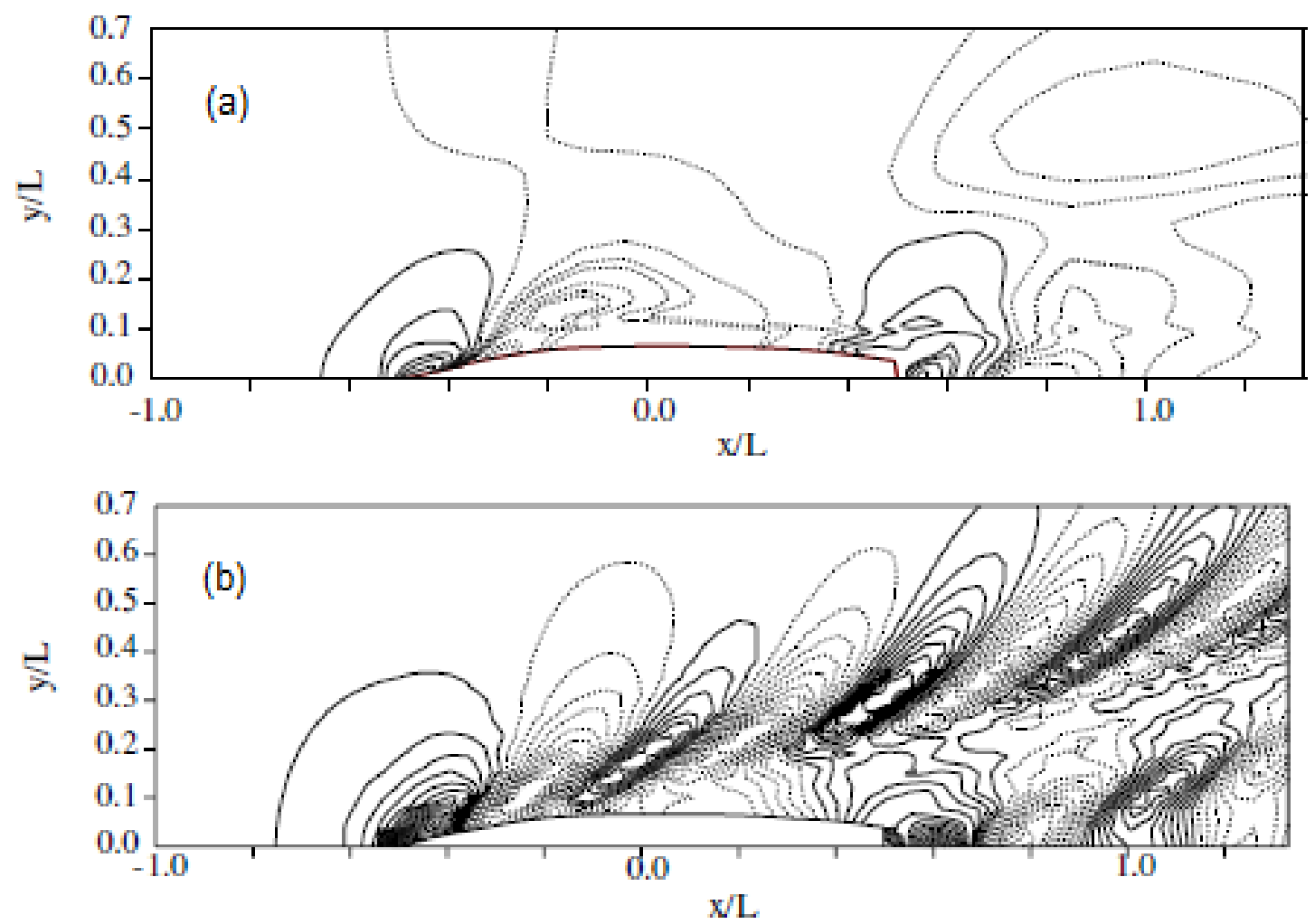

Figura 53 - Contornos das ondas para Froude 0,28, obtidos através do método: a) viscoso; b) potencial. Fonte: Ahmed (2011) - Adaptado.

As ondas produzidas pelo movimento da embarcação podem ser irradiadas para grandes distâncias ao longe do navio. Essas ondas contém energia que devem ser dissipadas para o fluido. Nas simulações numéricas o domínio computacional é restrito o que pode trazer problemas para a irradiação das ondas, tais como a reflexão nos limites do domínio. Uma maneira de contornar o problema é utilizar um amortecimento artificial, entretanto, na presente pesquisa foi utilizado uma segunda opção comumente encontrada em trabalhos envolvendo a geração de ondas, que é a dissipação ocasionada pela difusão numérica, através da aplicação de células de grandes dimensões próximos às fronteiras do domínio. Por este motivo que a malha foi gerada de forma a concentrar os menores volumes de controle próximos ao casco e os maiores mais distantes do mesmo. Dessa forma, o padrão de ondas é 
melhor capturado nas proximidades do casco e a reflexão de ondas nos domínios é minimizada.

Infelizmente, não houve registros da elevação da superfície livre nos ensaios realizados no tanque de provas do IPT, para que se realizassem comparações entre resultados numéricos e experimentais. No entanto, o trabalho de Ahmed (2011), já mencionado anteriormente, apresenta o contorno das ondas geradas pelo DTMB5415 que foi obtido numericamente através dos métodos viscoso e potencial, para os números de Froude 0,28 e 0,41, e $L p p=5,72$ m. A Figura 53 e a Figura 54 podem ser utilizadas como um meio alternativo para avaliar os resultados encontrados via StarCCM+.
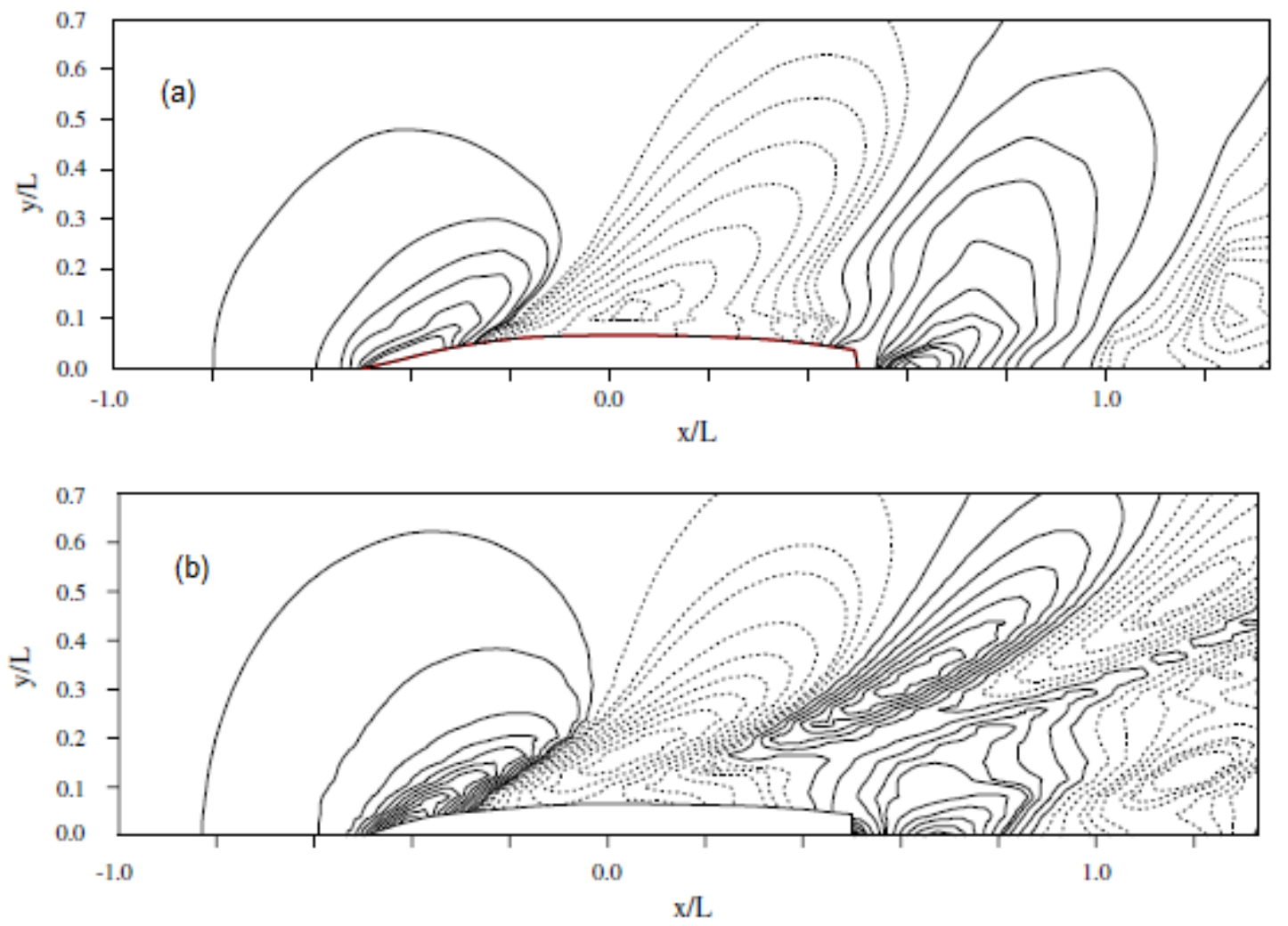

Figura 54 - Contornos das ondas para Froude 0,41, obtidos através do método: a) viscoso; b) potencial. Fonte: Ahmed (2011) - Adaptado.

Sabe-se que tradicionalmente os métodos potenciais têm a capacidade de fornecer melhores resultados de contornos de ondas do que os viscosos, isto é, os métodos potenciais representam a física do problema de forma mais realista. Notase na Figura 53 que o padrão de ondas obtido por Ahmed (2011) para método viscoso é muito distinto daquele fornecido pelo método potencial. Entretanto, para o Froude 0,41 os resultados obtidos foram mais próximos, Figura 54. 
Ao confrontar os padrões de onda obtidos no presente trabalho, considerando o afundamento e trim, com aqueles apresentados por Ahmed (2011), verifica-se para ambos os números de Froude que os contornos via StarCCM+ se aproximaram do método potencial, mesmo constatando-se pequenas diferenças na região de proa da embarcação para o caso de menor Froude, Figura 55.

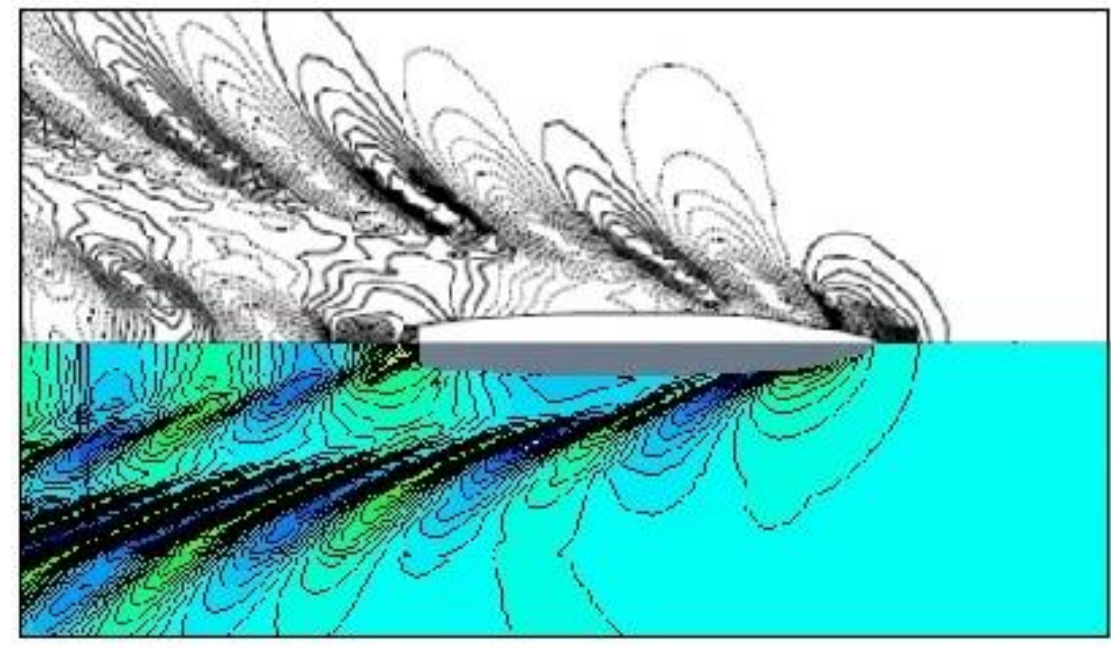

a) Froude 0,28.

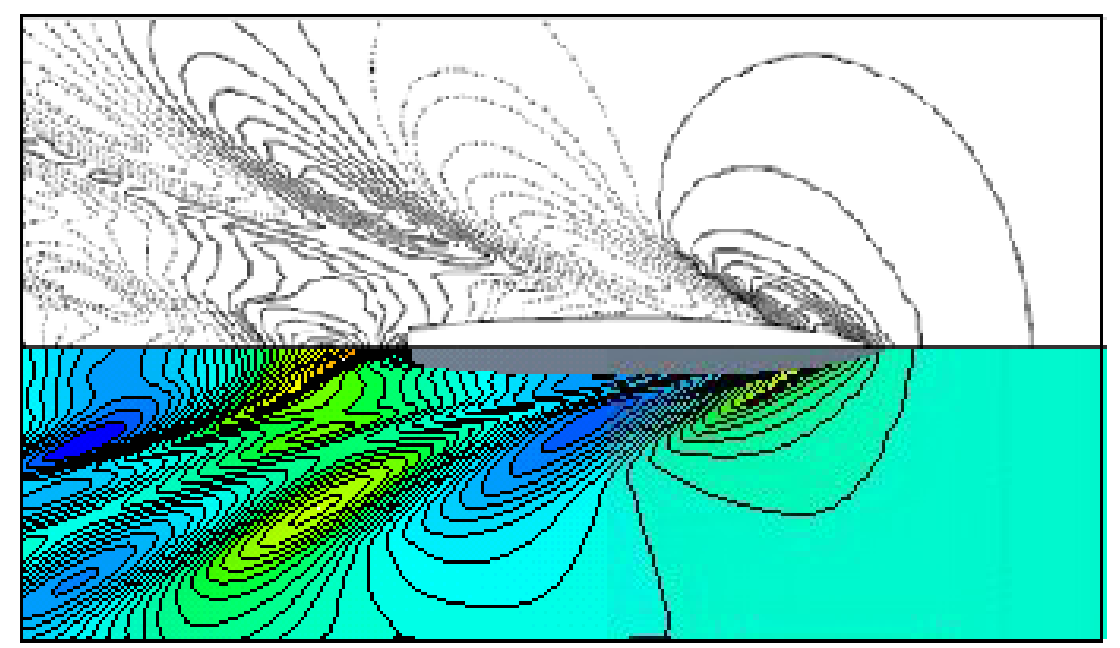

b) Froude 0,48 .

Figura 55 - Comparação entre os padrões de ondas obtidos pela solução potencial e viscosa.

As imagens da Figura 56 e da Figura 57 apresentam os perfis de onda na superfície do casco para os três valores de Froude simulados. Nota-se que para Froude 0,1 praticamente não há alterações na elevação da superfície livre, ratificando a dificuldade encontrada na representação dos contornos de onda para essa condição, enquanto que nos demais Froude os perfis de onda são nítidos. 


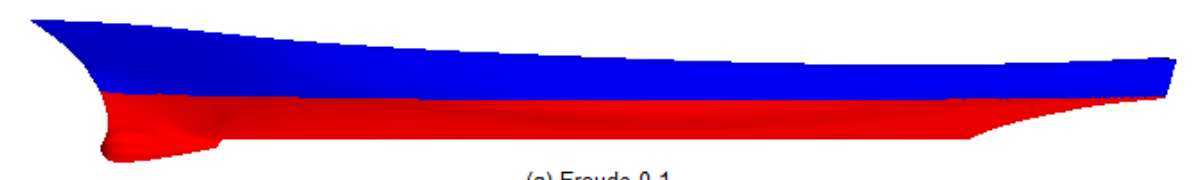

(a) Froude 0,1

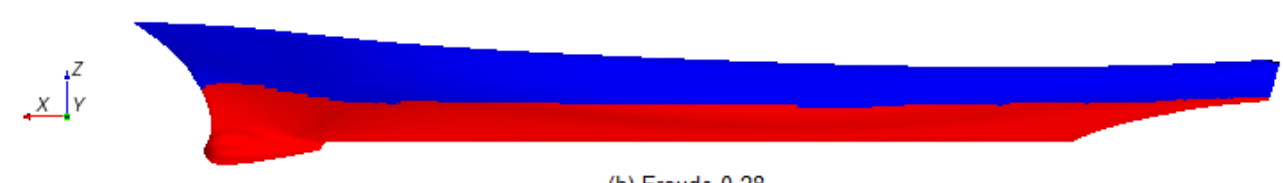

(b) Froude 0,28

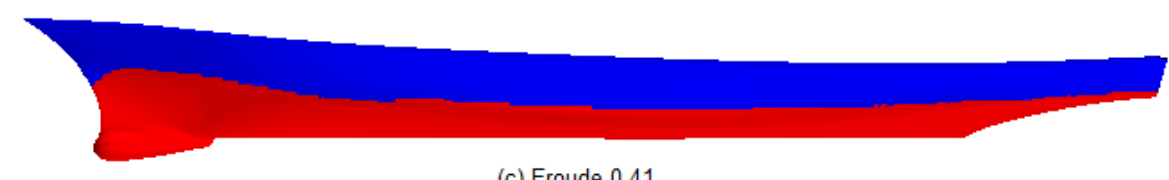

(c) Froude 0,41

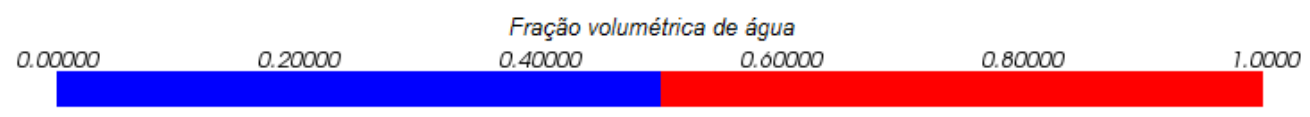

Figura 56 - Perfis de ondas obtidos na superfície do casco, sem considerar o afundamento e trim.

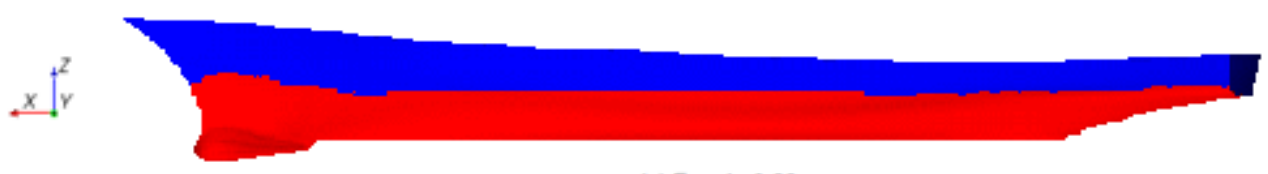

(a) Froude 0.28

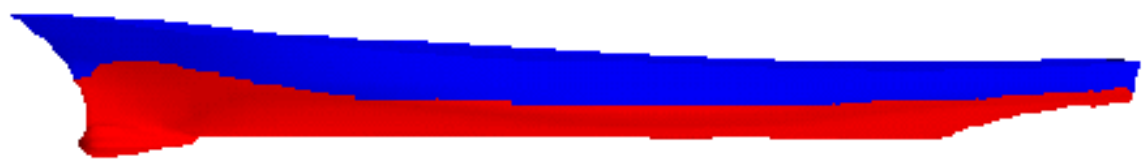

(b) Froude 0.41

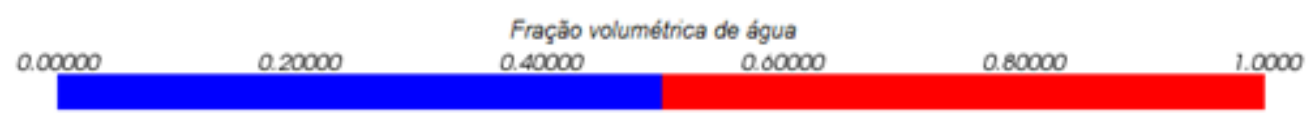

Figura 57 - Perfis de ondas obtidos na superfície do casco, considerando o afundamento e trim.

Dado o exposto, é evidente que caso se deseje obter o valor de resistência ao avanço do modelo com melhor grau de precisão, as características do ensaio experimental deverão ser reproduzidas da melhor forma possível. 


\section{CONCLUSÃO}

Foi discutida uma questão de fundamental importância em ensaios de resistência ao avanço de embarcações, que é a obtenção do fator de forma de cascos. Caso o fator de forma não seja estimado adequadamente, a resistência poderá ser subestimada, causando o dimensionamento incorreto do sistema propulsivo do navio. Dessa forma, a embarcação não apresentará a velocidade de serviço de projeto quando a respectiva potência fornecida pelo motor for aplicada, ou seja, o sistema propulsivo não estará otimizado, gerando prejuízos ao armador.

Segundo a ITTC (2011b), atualmente, a maioria dos laboratórios que realizam ensaios de resistência ao avanço utilizam a hipótese da ITTC (1978), em que é assumido que o fator de forma não sofre variações com alterações na velocidade de avanço e que o fator de forma do casco na escala real é o mesmo que os dos modelos ensaiados em tanques de provas.

$O$ presente trabalho avaliou através de simulações com o software de volumes finitos StarCCM+ da CD-Adapco, se as hipóteses propostas pela ITTC são procedentes. Foram realizadas simulações do casco DTMB5415 em diferentes escalas, mantendo-se Froude constante, utilizando a metodologia double-model, em que a superfície livre não foi considerada e, dessa forma, a resistência total obtida pôde ser tratada como resistência viscosa. Para a parcela friccional foram realizadas simulações com placas planas, de mesma área molhada, Lpp e Froude das escalas utilizadas com o DTMB5415. Nesse caso, a resistência total era equivalente à resistência friccional, uma vez que a geometria esbelta interfere minimamente no escoamento. Além disso, os coeficientes friccionais numéricos foram comparados com aqueles obtidos pelas linhas de correlação da ITTC'57, Grigson e Schoenherr, verificando-se que para as escalas frequentemente encontradas em ensaios de reboque os valores numéricos coincidiram com os da ITTC, porém, para escalas maiores os valores do software foram superiores aos demais, sendo mais próximos aos de Grigson. Assim, propõe-se como alternativa que a linha da correlação de Grigson seja aplicada para a escala real.

Da relação dos coeficientes viscosos e friccionais obteve-se os valores do fator de forma para cada caso e, consequentemente, foi possível obter a sua tendência em função de Reynolds, considerando Froude constante. Verificou-se que o fator de forma cresce com aumento de Reynolds, constatando-se que a hipótese 
da ITTC não se confirma. A própria ITTC, em seu $23^{\circ}$ comitê de propulsão, já acusou que o efeito da escala no fator de forma existe e que provavelmente é causado pela estimativa do coeficiente friccional da resistência de placa plana. Assim, sugere-se que os laboratórios realizem pesquisas extensivas com o objetivo de se corrigir a linha de correlação da ITTC ou ainda utilizar outras linhas de correlação que julgarem adequadas, para que a resistência não seja subestimada. Para o caso da segunda hipótese da ITTC, realizou-se uma pequena análise que mostrou que o fator de forma não é independente da velocidade.

Também foi avaliada a capacidade do software de CFD em estimar o valor da resistência ao avanço e o padrão de ondas irradiado pelo casco. Os resultados obtidos através do StarCCM+ foram confrontados com as médias dos ensaios realizados no tanque de provas do IPT, para três números de Froude. A maior e a menor diferença encontrada foi de aproximadamente $8,51 \%$ e 3,31\%, inferiores aos valores experimentais, para o caso de velocidade de avanço de 0,55 m/s e 2,24 m/s, respectivamente. Foram realizadas comparações entre os resultados obtidos pelas simulações que não consideraram o afundamento e trim com aquelas que os levaram em consideração e constatou-se que a restrição desses graus de liberdade causa diferenças significativas no valor da resistência ao avanço. Uma vez que o modelo numérico estava restrito em todos os graus de liberdade, os dados de afundamento e trim obtidos nos ensaios experimentais foram utilizados como condições iniciais nas simulações, ou seja, realizaram-se modificações na posição do casco em relação à superfície livre, de acordo com os valores fornecidos pelo IPT, Tabela 10. Caso os dados de trim não fossem disponibilizados, essa análise não seria possível a não ser que outras informações como, por exemplo, a inércia do modelo, lastro e etc fossem fornecidas para realizar as simulações com modelo livre em heave e pitch. Considerando-se as diferenças entre resultados experimentais e obtidos via CFD verificadas na literatura, é possível afirmar que os resultados encontrados foram satisfatórios.

A maioria dos laboratórios que possuem tanque de reboque demonstrou certa dificuldade para obter os padrões de onda de ensaios de resistência ao avanço, conforme apresentado pela ITTC (2011b). Por este motivo não havia dados disponíveis para se comparar os resultados numéricos com os experimentais. Dessa forma, optou-se pela comparação com resultados obtidos através de métodos potenciais, que geralmente se aproximam consideravelmente da solução real. 
Verificou-se que o padrão de ondas via StarCCM+ é muito semelhante aos gerados pelos métodos potenciais. A análise não foi realizada para o Froude 0,1 , pois a geração de ondas é mínima e a discretização utilizada não foi suficiente para descrever a superfície livre. Nesse caso, para que fosse possível visualizar o padrão de ondas, seria necessário um refino acentuado na região, que inviabilizaria a simulação. Para os demais casos a superfície livre foi obtida de forma satisfatória, corroborando a capacidade que os softwares de CFD possuem para auxiliar os laboratórios em suas dificuldades.

Embora se deva buscar nas simulações a melhor representação possível da física do problema, vale ressaltar que as diferenças entre resultados numéricos e experimentais sempre existirão, pois os programas de CFD são representações da realidade, que assumem certas aproximações e hipóteses para que seja possível obter a solução do problema estudado. Os softwares de CFD são potencialmente úteis em projetos e atualmente podem ser vistos como uma ferramenta indispensável, porém, devem ser utilizados paralelamente aos ensaios experimentais.

Vale ressaltar que as análises executadas consideraram apenas uma geometria específica de casco, portanto, as conclusões geradas através dos resultados obtidos são válidas para o modelo DTMB5415, embora sirvam de tendência e referência para outros tipos/formatos de cascos. Para que seja possível realizar conclusões globais serão necessários estudos extensivos com modelos de geometrias variadas, os quais demandarão uma grande quantidade de tempo e dinheiro.

Propõe-se que o presente trabalho seja utilizado como ponto de partida para estudos futuros como, por exemplo, a avaliação da influência de apêndices nos valores de fator de forma, isto é, pés de galinha e o eixo do propulsor, que possivelmente causarão diferenças em relação aos valores obtidos com o casco nu. 


\section{REFERÊNCIAS BIBLIOGRÁFICAS}

AHMED, Y.M. Numerical simulation for the free surface flow around a complex ship hull form at different Froude numbers. Alexandria Engineering Journal, Alexandria University, v.50, p. 229-235, 2011.

AIGUO, S., et al. Resistance Calculation and Motions Simulation for Free Surface Ship Based on CFD. Procedia Engineering, v.31, p. 68-74, 2012.

ALHO, A.; COSTA, R. Simulação Numérica de um Ensaio de autopropulsão de um Casco de Deslocamento. 23th Sobena, Brasil, Rio de Janeiro, 2010

ALHO, A.; PAIVA, M. Estudo Comparativo de Métodos Numéricos e Ensaios Experimentais dos Modelos 2517 e 2557 do Canal de Ensaios Hidrodinâmicos de El Pardo, 23th Sobena, Brasil, Rio de Janeiro, 2010.

ARIFF, M.; SALIM, M.S.; CHEAH, S.C., Wall y+ approach for dealing with turbulent flow over a surface mounted cube: part 2 - high Reynolds number, CSIRO, Australia, Melbourne, 2009.

BAOS, R. et al., Diseño de interceptores en pesqueros mediante cfd, 22th Copinaval, Buenos Aires, Argentina, 2011.

BERTRAM, V. Pratical Ship Hydrodynamics, Butterworth-Heinemann, Great Britain, 2000.

CHORIN, A. J., A Numerical Method for Solving Incompressible Viscous Flow Problems, Journal of Computational Physics, v. 2, p. 12-26, 1967

CHORIN, A. J., Numerical Solution of the Navier-Stokes Equations. Math. of Computation, v. 22, p. 745-762, 1971.

DÁVILA, M.; MENDONZ,A J.A.; VILLAGÓMEZ, R.J.C. Calculo de resistencia al avance de embarcaciones utilizando herrmamientas de dinamica de fluido computacional (cfd) en el cehiduni. 22th Copinaval, Buenos Aires, Argentina, 2011.

EÇA, L. ; HOEKSTRA M. On the accuracy of the numerical prediction of scale effects on ship viscous resistance, International Conference on Computational Methods in Marine Engineering, Barcelona, 2005.

FENG, B. et al. Application of CFD in Naval Ship Resistance Performance Optimization. Energy Procedia, v. 13, p 6704-6710, 2011. 
FERZIGER, J. ; PERIC, M. Computational Methods for Fluid Dynamics. s.I. : Springer, 2002.

FORTUNA, A.O., Técnicas Computacionais para Dinâmica dos Fluidos: Conceitos Básicos e Aplicações. São Paulo: Editora da Universidade de São Paulo, 2000.

GOMEZ, A.G. On the form factor scale effect. Ocean Engineering, v. 26, p 97-109, 2000.

ITTC, 8., 1957, Madrid, Spain, published by Canal de Experiencias Hidrodinamicas, El Pardo, Madrid, 1957

ITTC, 14., 1975, Form factor according to Prohaska, 1975.

ITTC, 15., 1978, The Hague, The Netherlands, published by the Netherlands Ship Model Basin, Wageningen, 1978.

ITTC 2002, Testing and Extrapolation Methods Resistance - Resistance Test, Recommended Procedure 7.5-02-02-01, Revision 01.

ITTC, 26., 2011a, The Specialist Committee on Computational Fluid Dynamics, Rio de Janeiro, Brasil, 2011.

ITTC, 26., 2011b, The Resistence committee, Rio de Janeiro, Brasil, 2011.

JEN-SHIANG, K.; YEN-JEN, C.; SHIU-WU, C., Numerical study on scale effect of form factor, Ocean Engineering, v 36, p. 403-413, 2009.

KEH-SIK, M.; SEON-HYUNG, K., Study on the form factor and full-scale ship resistance prediction method, Journal Mar Sci Technol, v. 15, p. 108-118, 2010.

LAMAS, F. et al., Estudo Comparativo de Métodos Numéricos e Ensaios Experimentais dos Modelos 2517 e 2557 do Canal de Ensaios Hidrodinâmicos de El Pardo, 23th Sobena, Brasil, Rio de Janeiro, 2010

MALISKA, C. R., Transferência de Calor e Mecânica dos Fluidos Computacional. s.I., LTC, 2004.

NI C.S., et al., Hull gesture and resistance prediction of high-speed vessels, Journal of Hydrodynamics, v. 23, p. 234-240, 2011.

PATANKAR, S. V., SPALDING, D. B., A Calculation Procedure for Heat, Mass and Momentum Transfer in Three-Dimensional Parabolic Flows. Int. Journal of Heat and 
Mass Transfer, v. 15, p. 1787-1806, 1972.

PERIC, M., Flow simulation using control volumes of arbitrary polyhedral shape, ERCOFTAC Bulletin, No. 62, September 2004.

PÉRIC, M., 2010a, Procedure of Gothenburg Workshop, 2010.

PÉRIC, M., 2010b, Procedure of Gothenburg Workshop, 2010.

PIMENTA, M. Dinâmica dos Fluídos e Fenômenos de Transporte Computacionais I.

São Paulo, Escola Politécnica da USP, 2011. Notas de Aula PME5229.

REPETTO R. A., Computation of Turbulent Free-Surface Flows Around Ships and Floating Bodies. 2001.105 p. Tese (doutorado) - Universidade de Hamburg, Alemanha, 2001.

RHIE, C. M.; CHOW, W. L., Numerical Study of the Turbulent Past an Airfoil with Trailing Edge Separation, AIAA Journal, v. 21, p. 1525-1532, 1983

SALAS, M. et al., Optimización de la resistencia de un casco esbelto mediante apéndice de popa, 22th Copinaval, Buenos Aires, Argentina, 2011.

SALIM, M.S.; CHEAH, S.C., Wall y+ Strategy for Dealing with Wall-bounded Turbulent Flows, IMECS, China, Hong Kong, 2009.

SALTARA, F. Dinâmica dos fluidos computacional. São Paulo, Escola Politécnica da USP, 2011. Notas de Aula PME2556. 